San Jose State University

SJSU ScholarWorks

Master's Theses

Master's Theses and Graduate Research

Summer 2013

\title{
Le Déchirement et le Châtiment de Soi dans Épaves de Julien Green et la Chute d'Albert Camus
}

Imene Aggoun

San Jose State University

Follow this and additional works at: https://scholarworks.sjsu.edu/etd_theses

\section{Recommended Citation}

Aggoun, Imene, "Le Déchirement et le Châtiment de Soi dans Épaves de Julien Green et la Chute d'Albert Camus" (2013). Master's Theses. 4326.

DOI: https://doi.org/10.31979/etd.zxmk-ry64

https://scholarworks.sjsu.edu/etd_theses/4326

This Thesis is brought to you for free and open access by the Master's Theses and Graduate Research at SJSU ScholarWorks. It has been accepted for inclusion in Master's Theses by an authorized administrator of SJSU ScholarWorks. For more information, please contact scholarworks@sjsu.edu. 


\title{
LE DÉCHIREMENT ET LE CHÂTIMENT DE SOI DANS ÉPAVES DE JULIEN GREEN ET LA CHUTE D'ALBERT CAMUS
}

\author{
A Thesis \\ Presented to \\ The Faculty of the Department of World Languages and Literatures
}

San José State University

In Partial Fulfillment

of the requirements for the Degree

Master of Arts

by

Imène Aggoun

August 2013 
(C) 2013

Imène Aggoun

ALL RIGHTS RESERVED 


\title{
LE DÉCHIREMENT ET LE CHÂTIMENT DE SOI DANS ÉPAVES DE JULIEN GREEN ET LA CHUTE D’ALBERT CAMUS
}

\author{
by \\ Imène Aggoun \\ APPROVED FOR THE DEPARTMENT OF WORLD LANGUAGES AND \\ LITERATURES
}

SAN JOSÉ STATE UNIVERSITY

August 2013

Dr. Dominique van Hooff

Department of World Languages and Literatures

Dr. Danielle Trudeau

Department of World Languages and Literatures

Dr. Jean-Luc Desalvo

Department of World Languages and Literatures 


\title{
ABSTRACT \\ DÉCHIREMENT ET CHÂTIMENT DE SOI DANS ÉPAVES DE JULIEN GREEN ET LA CHUTE D'ALBERT CAMUS
}

\author{
by Imène Aggoun
}

This thesis explores how the paths of Julien Green and Albert Camus cross through Épaves and La Chute, when their characters question who they are and what they have become. This study analyzes not only existentialist philosophy, but various other factors such as the authors' biography, literary criticism, and psychoanalysis to understand how Philippe in Épaves and Clamence in La Chute suffer the consequences of an absurd world. Based on the authors' biographies highlighting the common link with other nineteenth century writers, one can confirm Green's saying that the work arises from a "domestic crisis." The study exposes an absurd situation where the feeling of being indispensable is erased from the human heart and leads to self-torturing and selfpunishment. Green and Camus reveal the "absence" of a sense of responsibility, compassion, and solidarity in their protagonists and how the guilt crushes and tears apart man. Philippe and Clamence have suffered from their lack of morals and have reacted differently in terms of expressing remorse and seeking repentance. They are transformed into "Sisyphus" figures damned for eternity. 


\section{REMERCIEMENTS}

Cette thèse est le produit final d'années d'étude, de recherche et d'immersion dans un monde fascinant de la littérature française en général et celui de Julien Green et d'Albert Camus en particulier. Un monde d'exaltation qui m'a permis de voyager à travers le temps, de découvrir des endroits que je n'avais jamais imaginés, d'en revisiter d'autres mais cette fois-ci avec un œil nouveau.

Pour ce, nous tenons tout d'abord à remercier professeur Dominique van Hooff d'avoir accepté de diriger ce travail. Nous lui devons un grand respect et une profonde gratitude pour son immense générosité, son engagement, son expertise, ses conseils et ses encouragements.

Nos remerciements s'adressent également aux professeurs Danielle Trudeau et Jean-Luc Desalvo pour leurs cours enrichissants, leurs soutiens et leurs conseils précieux. Nous avons passé d'agréables moments dans leurs classes respectives où la stimulation intellectuelle et l'esprit d'analyse étaient toujours à l'ordre du jour.

Nous tenons enfin à remercier notre époux, Dr. Ahmed Chenna et nos trois enfants, Maryam, Yanis et Hanna, qui ont su faire preuve de beaucoup de patience. Leur aide nous a été précieuse. Nous leur dédions ce mémoire. 


\section{TABLE DES MATIÈRES}

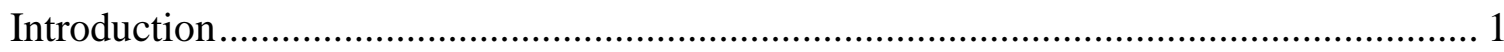

Partie I : Green et Camus, deux chemins qui se croisent ......................................... 11

Chapitre 1: L'univers absurde de Green et Camus ..................................................... 11

Chapitre 2: Contexte socio-historique d'Épaves et de La Chute ................................... 21

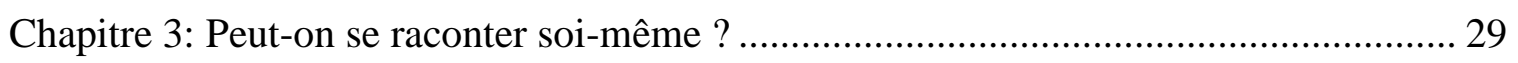

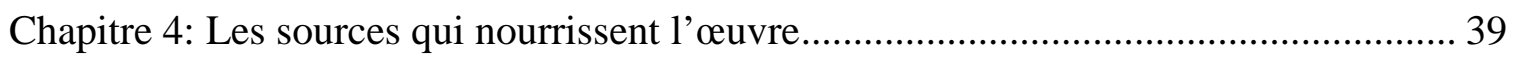

Partie II : Les multiples facettes de la faute ........................................................ 55

Chapitre 1: Narcissisme, indifférence, impuissance : les caractères à risque .................. 55

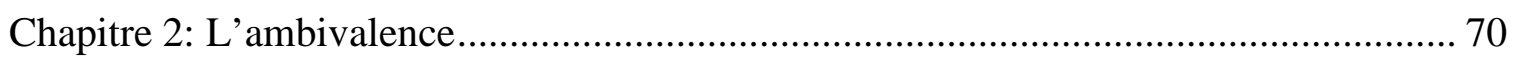

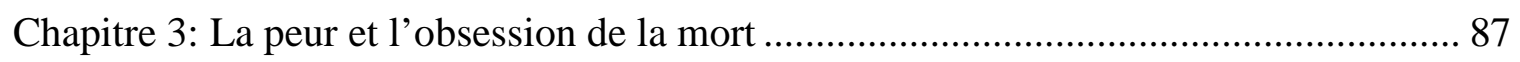

Partie III : Déchirement et châtiment....................................................................... 100

Chapitre 1: L'eau, le cri et le rire : Les symboles du déchirement .............................. 100

Chapitre 2: Le miroir, reflet de la culpabilité ........................................................ 118

Chapitre 3: Le salut dans l'abîme ....................................................................... 135

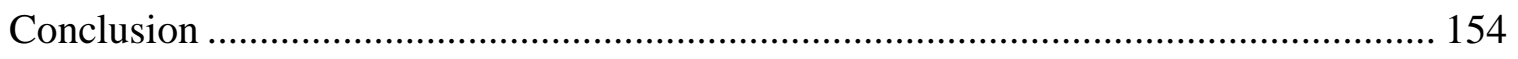

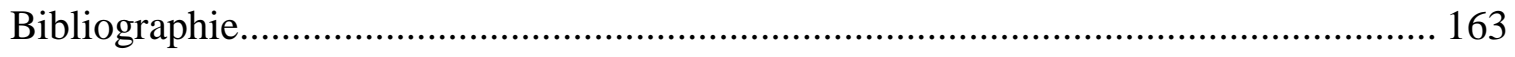




\section{Introduction}

Réunir Julien Green et Albert Camus dans une même étude comparative peut paraître surprenant à bien des égards. Leur vie personnelle ainsi que leurs œuvres sont les plus dissemblables qui soient. Comment peut-on rapprocher l'auteur de La Peste de celui de Pamphlet contre les catholiques de France, ou un existentialiste athée de quelqu'un qui toute sa vie a souhaité être un moine, voire un saint? Dans son autobiographie, Mille chemins ouverts, Green a écrit : «Je voulais être tout à la fois un dieu grec et un saint catholique. ${ }^{1}$ Et pourtant, ils appartiennent à la même époque, celle des écrivains-dramaturges du milieu du $\mathrm{XX}^{\mathrm{e}}$ siècle qui se sont imprégnés de lectures similaires et ont vécu dans le même contexte historique. Green a commencé sa carrière littéraire avant Camus, puisque douze ans séparent la date de publication de leur premier ouvrage. Pamphlet contre les catholiques de France de Green voit le jour en 1924, bien qu'il soit écrit sous le pseudonyme de Théophile Delaporte, tandis que Révolte dans les Asturies de Camus ne paraît qu'en 1936.

Écrivain américain, né et éduqué à Paris, Green a adopté le français comme langue d'écriture. Il a eu une carrière brillante avec dix-sept romans, cinq nouvelles, cinq pièces de théâtre, plus d'une dizaine de romans autobiographiques et pas moins de dixhuit volumes de journaux qui ont fait de lui un des grands écrivains et diaristes du siècle.

\footnotetext{
${ }^{1}$ Julien Green, CEuvres complètes V. Éd. Jacques Petit. Bibliothèque de la Péliade. (Paris: Gallimard, 1977) 924.
} 
D'autre part, Julien Green a contribué à la traduction de quelques-unes de ses œuvres en anglais. Parmi cette pléthore de productions, il a remporté le Grand Prix de Littérature de l'Académie française en 1970 qui est venu couronner une carrière littéraire originale. En effet, il fut le premier «non français » élu à l'Académie française, le 3 juin 1971. Malgré ses qualités littéraires en anglais, l'écrivain reste peu connu dans le monde anglo-saxon où son œuvre est parfois contestée.

Contrairement à son aîné, l'œuvre de l'écrivain, moraliste et philosophe Camus a traversé toutes les frontières en dépit d'une mort prématurée. Camus a eu une carrière extraordinaire, ses travaux font l'objet d'études littéraires et philosophiques dans les plus grandes universités du monde. Aujourd'hui plus qu'hier son œuvre a passé l'épreuve du temps. Cette dernière compte un nombre important d'essais, de nouvelles, de volumes, de Carnets et de pièces de théâtre sans compter les quelques adaptations théâtrales d'autres écrivains et les quelques textes inédits qui ont lancé sa carrière. Son roman $L a$ Peste, publié en 1947, ainsi que ses essais sur l'absurdité de la condition humaine, la résignation, l'indifférence, la révolte voire l'acceptation de cette absurdité inhérente aux conflits, guerres et déchéance des valeurs au $\mathrm{XX}^{\mathrm{e}}$, lui ont valu le prix Nobel de littérature le 17 octobre 1957, à l'âge de quarante-quatre ans.

Cependant, Green et Camus appartiennent à des milieux distincts et parfois ont fait des choix qui n'ont rien en commun. Green a grandi au sein d'une famille bourgeoise et contrairement à Camus, Green a été baptisé et élevé dans la religion anglicane. Il fut orphelin de mère en 1914, la même année où Camus a perdu son père. À la différence de 
Camus, Green a eu la chance de vivre quatorze ans avec sa mère qui a laissé une empreinte très vive sur la personnalité de son fils. Dans son autobiographie, Green nous confie : «Je me mets à penser à ma mère et il me sembla que d'une façon inexplicable elle était présente. $»^{2}$

Il publie son premier roman Mont-Cinère à l'âge de vingt-six ans. L'œuvre de Green tourne autour du combat entre le monde charnel et le monde spirituel, où souvent la religion est le thème sous-jacent et récurrent. Ainsi, il note dans son journal en 1946 : «Troublé par le problème que j'ai pris l'habitude d'appeler le problème des deux réalités : la réalité métaphysique et la réalité charnelle. Vais-je leur servir de champ de bataille jusqu'à la fin de mes jours ? » ${ }^{3}$ Ces quelques lignes révèlent le combat qui a traversé la vie de l'auteur qui rêvait d'une vie de saint mais qui n'a vécu qu'une vie d'homme. Son homosexualité et le désir sexuel de manière générale ne pouvaient se concilier avec ses aspirations religieuses. Ces thèmes principaux tournent autour d'un monde chaotique où les personnages en mal de spiritualité ne trouvent pas d'issue, ce qui les conduit le plus souvent à la violence, au mal et à l'autodestruction. Dans ses romans, Green dépeint des personnages frénétiques, tourmentés par la passion et les péchés, déchirés par le désir sensuel et la crainte du châtiment divin. Dans ses œuvres, il met davantage l'accent sur l'analyse psychologique de ses personnages pessimistes et conscients de l'absurdité de leur monde. Dans ce contexte de la condition humaine, on

\footnotetext{
2 Jacques Petit, Green (Paris : Desclée de Brouwer, 1972) 18.

${ }^{3}$ Petit 59.
} 
peut affirmer que Green vient de préparer le chemin pour les existentialistes. Ses thèmes sont si proches de ceux de Georges Bernanos et de François Mauriac qu'on l'a classé parmi les écrivains chrétiens du $\mathrm{XX}^{\mathrm{e}}$ siècle.

Le combat de Camus est d'un tout autre genre. Écrivain, moraliste, journaliste et philosophe français, Camus a grandi dans une famille pauvre, à Bab-el-oued un quartier populaire d'Alger, où il y avait peu de différence entre sa vie et celle des enfants arabes. C'est peut-être ce point commun qui a fait naître en lui le sens de la justice. Il a écrit: «C'est dans cette vie de pauvreté, parmi ces gens humbles ou vaniteux, que j'ai le plus sûrement touché ce qui me paraît le sens vrai de la vie. » ${ }^{4}$ Dans la première page de Carnets, on lit : «On peut voir - sans romantisme - la nostalgie d'une pauvreté perdue. Une certaine somme d'années vécues misérablement suffisent à construire une sensibilité. » ${ }^{5}$ Camus lui-même a proclamé « qu'il a découvert la liberté non pas dans les travaux de Karl Marx, mais dans la pauvreté. » ${ }^{6}$

Camus s'interrogeait sur le sens de la vie, une dimension qui a conféré à son écriture un caractère existentialiste. Dans ses œuvres, il dépeint des personnages qui sont à la recherche d'un monde presque parfait et qui basent leur vie sur des valeurs morales et humanitaires propres à tous les hommes plutôt que sur une volonté divine qui n'existe pas à ses yeux. Le mal qui frappe les hommes n'est qu'une absurdité. Comme les personnages de Green, ceux de Camus vivent une vie tourmentée par le malheur qui

\footnotetext{
${ }_{5}^{4}$ Albert Camus, Carnets I mai 1935 - février 1942 (Paris: Gallimard, 1964) 16.

5 Camus, Carnets I 15.

${ }^{6}$ Philip Thody, Albert Camus (New York: St. Martin Press, 1989) 3.
} 
s'abat sur les hommes, ils sont déchirés par le désir d'un monde gouverné par la justice, la raison et le bonheur d'un côté, et par la réalité des choses qui débouche sur un monde chaotique et irrationnel de l'autre. Dans Le Mythe de Sisyphe paru en 1942, Camus écrit : «L'absurde naît de la confrontation de l'appel humain avec le silence déraisonnable du monde. $»^{7}$

Son travail de journaliste lui a permis de mener à bien son combat de militant. En 1938, il a publié onze articles qui défendent la cause de Michel Hodent $;^{8}$ il a condamné les nazis et les Européens qui ne se sont pas engagés promptement devant leur menace, ce qui a abouti à une nouvelle guerre mondiale. Sa plume de journaliste a également permis de dénoncer l'injustice et la misère que subissent les Algériens pendant la colonisation de l’Algérie.

Ce que l'on vient de noter suggère une incompatibilité apparente entre Green et Camus, pourtant ceci ne doit en aucun cas amener à un jugement catégorique sur leur différence. S'il est indéniable que leur personnalité, leurs idéologies et leurs choix littéraires (retenus par chacun) sont éloignés, cependant des points communs les rapprochent.

Tout d'abord il est très important de rappeler leur intérêt commun pour le théâtre. Bien que l'œuvre dramatique de Green ne soit pas aussi abondante que celle de Camus, il

\footnotetext{
${ }^{7}$ Albert Camus, Le Mythe de Sisyphe (Paris: Gallimard, 1942) 46.

${ }^{8}$ Michel Hodent est conseiller spécialiste employé par une compagnie d'assurance arabe. Il a été emprisonné injustement le 23 août 1938 parce qu'il a essayé d'appliquer la loi correctement, ce qui dérangeait les grands propriétaires fonciers français installés en Algérie.
} 
a néanmoins écrit cinq pièces. Et si les thèmes de ses romans portent plus sur le problème de la méconnaissance de soi, source d'angoisse chez tous les personnages greeniens, la problématique de ses pièces se rapproche plus des thèmes de Camus qui traitent tout ce qui touche à la condition humaine. Chez Green, ce thème est représenté sous forme de métaphore « de la catastrophe annoncée. » ${ }^{9}$ Ainsi, Green avoue qu'il ne voit plus le thème de la mort comme motif romantique, mais plutôt comme une obsession. Selon Michael O’Dweyer et Michèle Raclot, «La dernière trilogie dénonce l'imposture qui consiste à vivre comme si la mort n'existait pas avec une soutenable frivolité. ${ }^{10}$

Camus a commencé à rédiger son premier roman en 1936, La Mort heureuse, qui ne sera publié qu'en 1971. Il s'est intéressé au théâtre, il fonde, la même année, avec un groupe d'amis le « Théâtre du Travail » à Alger. Plus tard, il changera le nom du groupe en «Théâtre de l'Équipe. » Il a adapté des œuvres au théâtre telles que Les Possédés et Les Frères Karamazov de Dostoïevski, Le Temps du mépris d'André Malraux, et bien d'autres. Il a également écrit ses propres pièces, telles que Les Justes, Caligula, L'État de siège. Le théâtre fut d'une grande importance pour Camus comme pour d'autres auteurs existentialistes, car il lui permettait de véhiculer des idées philosophiques d'actualité où le divertissement n'avait plus la priorité. Par exemple, dans Les Justes, on retrouve le thème de la révolte et de l'anarchie ainsi que des idées de justice, de politique

\footnotetext{
${ }^{9}$ Michael O’Dwyer et Michèle Raclot, Le journal de Julien Green: miroir d'une âme, miroir d'un siècle. (Bern : Peter Lang, 2005) 67.

${ }^{10}$ O’Dwyer 67.
} 
socialiste non démunies de violence qui expliquent la frustration de l'auteur. Il ajoute aussi des idées qui transmettent la notion du bien et du mal et comment peut-on sauver l'homme de ses actes ou l'homme de l'homme? Son succès au théâtre cependant reste plus modeste que ses romans et essais. Camus pense que si «l'essai expliquait, le roman décrivait, ou imposait un mythe, le théâtre était action, conflit vécu dans le geste et dans le mouvement. » ${ }^{11}$ Camus était persuadé que le théâtre lui permettait «d'étendre son action», sachant que le spectateur d'entre les deux guerres et surtout après la Deuxième Guerre mondiale a vécu des moments de crises qui sont représentés par le théâtre « existentialiste. »

L'attention particulière que chacun des deux auteurs prête à son pays abonde également en ce sens. Green rêve d'un Sud confédéré des États-Unis qui n'a jamais existé ailleurs que dans un monde révolu, alors que Camus se fait une idée d'un Sud qu'il voudrait recréer, un Sud qui satisfasse à la fois ses exigences d'humaniste et de militant pour la cause humaine et adapté à ses besoins personnels, ceux d'un fils protecteur de sa mère.

L'importance de la mère est également un sentiment qui rapproche les deux auteurs. Green reste très proche de sa mère qui a joué un grand rôle dans la formation de sa personnalité. Il a passé beaucoup de temps avec elle. C'est elle qui s'est occupée de son éducation religieuse. La surdité de la mère de Camus n'a pas empêché l'enfant de développer une relation forte avec celle-ci. Ils avaient développé un autre moyen de

${ }^{11}$ Albert Camus, Euvres complètes : Théâtre, récits, nouvelles (Paris : Gallimard, 1962) 1689. 
communication. Tout ce qu'ils faisaient était s'observer. Dans L'Étranger, il a écrit : «Qu'importait si, accusé de meurtre, il était exécuté pour n'avoir pas pleuré à l'enterrement de sa mère? » En effet, Meursault ${ }^{12}$ n'a pas pleuré sa mère.

Le fait que Camus soit souvent répertorié sous l'étiquette « écrivain militant» force la distinction avec Julien Green souvent catalogué comme écrivain catholique. Cependant le texte de La Chute permet un rapprochement avec le roman Épaves de Julien Green.

Pour ce qui est de leurs thèmes respectifs, nos auteurs se rejoignent dans le grand thème « de la condition humaine » et de l'angoisse existentielle qui l'accompagne, ainsi que dans «Le Sud rêvé » de Green et « le Sud idéalisé » de Camus. Le personnage de La Chute, Clamence, ressemble à Philippe, personnage greenien dans Épaves. À travers ces personnages les auteurs dévoilent leur morale qui se manifeste dans la conscience de soi. Notons que le premier nom que Green avait choisi pour son héros était Clémence $^{13}$ : quelle ressemblance avec Clamence !

Camus, qui ne se montre pas partisan de la religion puisqu'il se proclame athée a choisi un nom religieux pour son personnage «Jean-Baptiste » Clamence, dit «jugepénitent ». Ce dernier est déchiré tout comme Philippe ou Joseph Day de Mö̈ra ${ }^{14}$. La conscience pousse ces personnages soit à accomplir l'acte absurde dans le cas de Green soit à sombrer dans le délire chez Camus.

\footnotetext{
${ }^{12}$ Le personnage principal du roman de Camus L'Étranger.

${ }^{13}$ Julien Green, Euvres complètes II (Paris : Gallimard, 1973) 1304.

${ }^{14}$ Mö̈ra est un roman écrit par Green dont le personnage principal est Joseph Day.
} 
Dans La Chute, la prise de conscience coïncide avec l'émergence du double qui envahit la scène. On retrouve le même scénario chez les auteurs du XIX ${ }^{\mathrm{e}}$ siècle tels que Balzac et Dostoïevski où les personnages du Sous-sol et de Crime et châtiment ressemblent aux personnages greeniens et camusiens. L'eau trouble de la Seine, le cri et l'autoscopie à travers le miroir révèlent le double latent. «Ainsi l'eau, par ses reflets, double le monde les choses. ${ }^{15}$ À travers leurs œuvres, Camus et Green convergent dans leurs idées hégéliennes, bien qu'ils aient des personnalités tout à fait différentes. Mais Épaves et La Chute parlent le même langage, celui de la prise de conscience de l'absurde, de l'injustice et de l'indifférence du monde. Camus lui-même confirme cela dans son discours : « Le temps des artistes irresponsables est passé. » ${ }^{16}$

Dans cette étude, nous choisissons de comparer Green et Camus non à partir du prisme de la philosophie existentialiste, mais en montrant comment leurs personnages vivent les conséquences d'un monde absurde. Pour ce faire, nous nous attacherons à deux récits de maturité : Épaves de Green et La Chute de Camus. Nous nous interrogerons sur le rapport entre ces deux autofictions en mettant en exergue le lien commun avec certains écrivains du $\mathrm{XIX}^{\mathrm{e}}$ siècle, les caractéristiques de l'écriture autobiographique et le propos de Green lui-même, selon lequel l'œuvre naît d'une « crise intérieure. ${ }^{17}$ Il est évident que ni Épaves ni La Chute ne sont des autobiographies mais

\footnotetext{
${ }^{15}$ Gaston Bachelard, L'eau et les rêves : Essai sur l'imagination de la matière (Paris : Librairie José Corti, 1942) 61.

${ }^{16}$ Pierre-Henri Simon. Présence de Camus (Bruxelles: Renaissance du Livre, 1961) 18.

${ }^{17}$ Julien Green, Journal I (Paris: Plon, 1969) 1301.
} 
elles présentent des traits du roman autobiographique que nous développerons. Ensuite, nous allons montrer que ces œuvres ont en commun de dénoncer une situation absurde où le sentiment d'être indispensable les uns aux autres effacé du cœur de l'homme mène au déchirement et au châtiment de soi. Nous allons également montrer que Philippe et Clamence ne font qu'un car ils ont suivi le même parcours de morts-vivants, ils se sont transformés en Sisyphe, ils sont damnés pour l'éternité, mais par qui ? D’où vient leur châtiment? De quel crime sont-ils accusés ? 


\section{Partie I : Green et Camus, deux chemins qui se croisent}

\section{Chapitre 1 : L'univers absurde de Green et Camus}

Il nous semble nécessaire, avant même de commencer l'étude des deux œuvres, de présenter une étude biographique sommaire des auteurs. En pénétrant ainsi dans le monde de Green et de Camus, nous serons mieux à même de comprendre les tenants de la recherche existentielle et l'aboutissement tragique du destin des personnages d'Épaves et de La Chute. Pour Green, écrire est une question de survie. En effet «C'est le moyen le plus efficace mis à sa disposition afin d'exorciser les démons de son être divisé.» ${ }^{18} \mathrm{De}$ même chez Camus l'écriture est un moyen de se purger des sentiments de culpabilité.

Pourquoi un être divisé ? D’où vient le sentiment de culpabilité ? Pour répondre à ces questions, attardons-nous sur une tranche de vie de nos deux écrivains.

L'attachement de Green à la religion et la place qu'elle tient dans sa vie le poussent d'une manière intrinsèque à en parler ou à y faire allusion dans presque toutes ses œuvres. Il a lui-même affirmé en 1945 que « Ce serait même un grand péché que de ne pas écrire. ${ }^{19}$ Quelques années plus tard il ajoute que « de bien des manières, je suis tant soit peu un homme du XVII ${ }^{\mathrm{e}}$ siècle. Les idées religieuses de cette époque lointaine

\footnotetext{
18 John, M. Dunaway, “The Motive of Self-Discovery in Julien Green,” South Atlantic Bulletin 42. 2 (1977) : 87.

${ }^{19}$ Kathlyn E. Wildgen, Julien Green: The Great Themes (Birmingham : Summa Publication, 1993) 81.
} 
me paraissent justes pour tous les temps : ce sont celles des tout premiers siècles. ${ }^{20}$ Cependant, il serait incorrect de déclarer que Green n'a écrit que sur la religion. La nostalgie perpétuelle de son enfance se lit dans presque tous ses romans. Il a écrit «Pourquoi ne pas dire les choses très simplement? Je regrette beaucoup d'être aussi sensuel. Je veux me donner tout entier à mon travail, mais je ne puis me passer de l'amour physique. » ${ }^{21}$ L'univers absurde de Green se compose d'un monde spirituel et d'un monde de la chair qu'il a du mal à concilier. La religion a fait partie de l'univers de Green depuis sa naissance. Elle lui a été transmise par sa mère ainsi que la répugnance de l'impureté. Mais elle ne lui a enseigné rien d'autre. Il a grandi dans un univers familial qui le couve et le couvre d'amour, augmentant sa tendresse et sa sensibilité. Il avoue qu'il manquait beaucoup à cette éducation. Il écrit dans son journal Partir avant le jour :

Autour de moi, sans peut-être le savoir, elle [sa mère] dressait des interdits terribles [...] Le corps était l'ennemi, mais il était aussi la forteresse visible de l'âme et principalement le temple du Saint-Esprit. Tout devenait à la fois dangereux et sacré de ce qui touchait à la chair. ${ }^{22}$

Après la mort de sa mère, il s'est converti au catholicisme à l'âge de quinze ans mais il est resté fidèle à ce que sa mère lui a enseigné même lorsque celle-ci parlait en

\footnotetext{
${ }^{20}$ Wildgen 81.

${ }^{21}$ Wildgen 198.

${ }^{22}$ Green, Euvres V 733 .
} 
anglais et lui en français. L'Église est le second refuge de Green : «Je la sentais s'édifier autour de moi comme une forteresse invisible qui me mettait à l'abri du monde. ${ }^{23}$

Dans la première œuvre qu'il a écrite en 1924, Pamphlet contre les catholiques de France, le ton était bien différent. Il s'y est montré fanatique, employant un ton sombre qui laisse entendre sa révolte et sa fureur contre les catholiques. Un ton qu'il a bien regretté, car disait-il, « Ce dont je ne me rendais pas compte et qui ne m’apparut clairement que beaucoup plus tard, c'est que je m'en prenais secrètement à moi [...] j'étais furieux de découvrir que je n'étais pas un saint. » ${ }^{24}$ Malgré le succès de ce livre, Green avait du mal à avouer à sa famille qu'il en était l'auteur, car cela aurait choqué son entourage. Cette œuvre annonce la tempête de violence et de révolte qui déferle dans presque tous ses romans. Dans ce passage, il montre sa grande déception à l'égard des religieux que les Pères de l'Église renieraient aussi bien que le font les athées:

J'aime mieux l'attitude des incrédules qui trouvent que le catholicisme est absurde, que celle des catholiques qui trouvent qu'il est naturel. Je dirais même que l'attitude des incrédules est la seule qui soit dans l'esprit du catholicisme [...] Les incrédules parlent bien de la religion. Ils disent qu'elle est puérile et que leur raison ne l'accepte pas ; c'est bien. Les Pères n'auraient pas dit autre chose. ${ }^{25}$

À cette époque-là, l'auteur était attiré par l'invisible et c'est tout ce qui était vrai et tout ce qui comptait. Enivré par la religion, Green pense à entrer au monastère, mais cette idée s'est vite dissipée et le seul vrai monde qui existait pour lui jusque-là, a un

\footnotetext{
${ }^{23}$ Petit 18.

${ }^{24}$ Green, Euvres I 1229.

${ }^{25}$ Green, Euvres I 887.
} 
concurrent. En plus du monde lointain de la Bible, Green découvre un monde visible et accessible qui lui fait faire fausse route. Un royaume s'ouvre à lui auquel il ne peut résister. Le désir est trop fort, il se débat alors entre ces deux royaumes qui tous deux lui procurent un grand plaisir. Il écrit en 1949 :

[...] Deux forces en présence, également redoutables : l'énergie spirituelle et l'émotion passionnelle. Dans tout ce que nous voyons, il y a de l'émotion passionnelle, et dans tout ce que nous ne voyons pas, il y a de l'énergie spirituelle, mais dans tout ce que nous voyons l'énergie spirituelle entre comme les eaux d'un fleuve qui crève ses barrages, et dans tout ce que nous ne voyons pas, l'émotion passionnelle monte comme une grande marée irrésistible. Il y a de l'émotion passionnelle dans une prière si pure qu'un enfant ne la dira pas mieux, et dans l'emportement de la chair, il y a quelque chose qui ressemble à l'aveugle désir du Paradis perdu. ${ }^{26}$

Green découvre alors l'absurdité de l'univers, où le bien et le mal cohabitent et dont l'être est alors saint et tyran à la fois: «Ce fut par le péché que je retrouvai l'humanité $»^{27}$ confessa Green dans son journal.

À l'âge de dix-sept ans, Camus quitte l'appartement de Belcourt, quartier populaire d'Alger, pour aller vivre avec son oncle boucher qui avait espéré transmettre l'amour de sa profession à son jeune neveu, mais ce dernier l'a déçu en préférant faire des « petits boulots ». Grâce à son professeur Louis Germain, Camus a pu obtenir une bourse et entrer au Grand Lycée d'Alger en 1924. Camus est toujours resté reconnaissant envers son professeur à qui plus tard, il dédiera le discours du prix Nobel. Camus est

\footnotetext{
${ }^{26}$ Petit 59.

${ }^{27}$ Green, CEuvres V 733.
} 
entré à l'université d'Alger où il a préparé une thèse sur les études de saint Augustin ${ }^{28}$ dont il s'est imprégné. Saint Augustin prêche pour l'amour d'autrui, et Camus milite pour le bien de la société. Ses travaux ont été couronnés par un Diplôme d'études supérieures qui lui a été décerné en 1936. Le déchirement intérieur de Jean-Baptiste Clamence, personnage principal de La Chute, Camus l'a hérité de saint Augustin. Ce dernier, à cause de la lutte intérieure qui le déchire, abandonne alors le monde et se retire dans un monastère. Similaire à Green, saint Augustin a dû se battre contre la concupiscence de la chair et d'autres passions. Se rappelant ces moments, il confesse :

J'étais retenu par les frivoles plaisirs et les folles vanités, mes anciennes amies, qui secouaient en quelque sorte les vêtements de ma chair et murmuraient : Nous abandonnes-tu? Et, à partir de ce moment, ne seronsnous plus avec toi de toute l'éternité? Encore un instant, et tu ne pourras plus faire ceci ou cela, et pour l'éternité! Et que me suggéraient-elles, ô mon Dieu, en me disant: ceci ou cela? Que votre miséricorde éloigne cette pensée de l'âme de votre serviteur! Quelles turpitudes! Quelles ignominies! Et déjà je n'entendais plus leur voix qu'à demi : elles n'osaient plus venir en face me combattre ouvertement, mais elles grondaient par derrière, me mordant furtivement, à mesure que je m'éloignais, pour me forcer à me retourner. Elles me retardaient cependant : j'hésitais à m'arracher à elles, à secouer leur joug, pour aller où j'étais appelé, et une impérieuse habitude me disait encore : Penses-tu pouvoir vivre sans elles? ${ }^{29}$

\footnotetext{
${ }^{28}$ Saint Augustin comme Camus est né en Algérie au IV ${ }^{\mathrm{e}}$ siècle. Il est considéré comme le plus important Père de l'Église et le plus grand esprit des premiers siècles du Christianisme. Évêque d'Hippone (aujourd'hui appelée Annaba, ville située à l'est de l'Algérie), il a écrit de nombreux documents sur la philosophie et la métaphysique. Son œuvre la plus connue est Les Confessions. Saint Augustin a eu une immense influence sur les grands penseurs français, du XVII ${ }^{\mathrm{e}}$ au XX $\mathrm{XX}^{\mathrm{e}}$ siècle, tels que Descartes, Pascal, Rousseau, etc.

${ }^{29}$ Jean Félix Nourrisson, La Philosophie de saint Augustin II (Paris: Librairie Académique, 1866) 3.1 Internet Archive 2011.
} 
Durant toute sa vie, saint Augustin a prêché la paix, la concorde et la tolérance, termes qui constituent les idées maitresses de Camus. Dans une de ses notes de Carnets, on lit: «Le seul grand esprit chrétien qui ait regardé le problème du mal, c'est saint Augustin. ${ }^{30}$

Camus en tant qu'écrivain engagé exhibe peu ses sentiments et sa vie personnelle dans ses œuvres, exception faite pour son premier recueil d'essais L'Envers et l'endroit, qu'il publie en 1937 et dans lequel sont mêlés des récits d'expériences personnelles, des descriptions de scènes de la vie quotidienne et des réflexions métaphysiques et morales. Dans Actuelles I, parlant de lui, il dit : «Je suis né pauvre et sans religion sous un ciel heureux, dans une nature avec laquelle on sent un accord, non une hostilité. Je n'ai donc pas commencé par le déchirement mais par la plénitude.» ${ }^{31}$ Ses thèmes sont souvent récurrents. Ainsi, pendant l'occupation, il publie en 1942 et dans la clandestinité son roman L'Étranger qui sera suivi la même année de l'essai philosophique Le Mythe de Sisyphe. Ces deux œuvres appartiennent à l'ensemble qu'il baptisa plus tard le « cycle de l'absurde. » Dans ce contexte il écrit: «L'absurde, c'est la raison lucide qui constate ses limites. $»^{32}$ La révolte et la solidarité, exprimées de manière convaincante dans La Peste, sont des thèmes qui distinguent Camus parmi ses contemporains, car « Ce n'est pas la révolte en elle-même qui est noble, mais ce qu'elle exige. » ${ }^{33}$

\footnotetext{
${ }^{30}$ Camus Albert, Carnets II janvier 1942-mars 1951 (Gallimard : Paris, 1962) 179.

${ }^{31}$ Albert Camus, Actuelles I : Écrits politiques (Chroniques 1944-1948) (Paris: Gallimard, 1950) 145.

${ }^{32}$ Camus, Le Mythe 72.

${ }^{33}$ Albert Camus, Euvres complètes III 1949-1956 (Paris: Gallimard, 2008) 147.
} 
L'œuvre de Green et celle de Camus développent toutes deux une conception pessimiste de l'existence. Cette même conception pessimiste existentielle que l'on retrouve chez les écrivains du XIX ${ }^{\mathrm{e}}$ siècle comme Baudelaire et autres, Green y adhère et l'accepte avec fatalisme, alors que Camus refuse cette situation et se résigne. Il cherche des réponses et des solutions aux problèmes de l'humanité et choisit de se révolter. Cette différence des deux écrivains se reflète dans leurs personnages. En effet les personnages greeniens ne se révoltent pas. Ils n'ont pas la capacité de le faire. Ils subissent leur destinée. Philippe, plutôt fataliste, montre sa lâcheté en voulant se suicider. Ceci n'est pas unique à Philippe; c'est le même parcours de tout personnage greenien qui est souvent voué au malheur et dont le chemin aboutit à la mort. Mais parfois lorsqu'ils se réveillent de leur léthargie et qu'ils essaient d'agir, tant bien que mal, leurs efforts sont stériles, pitoyables ou tragiques. Dans Épaves, Éliane quitte le domicile familial pour fuir son obsession mais revient aussitôt Philippe tente de se rapprocher de son fils et Henriette, sans grande conviction, prend un amant pour remplacer son mari impuissant. Devant cette force mystérieuse qui entrave leurs actions, leur déchirement intérieur augmente et le châtiment s'installe dans leur cœur et leur conscience.

Les personnages camusiens, quant à eux, sont souvent des lutteurs. Ainsi, Rieux, personnage principal de La Peste, a mené un combat acharné contre la peste qui a ravagé la population de la ville d'Oran. Au départ ils sont passifs comme les personnages greeniens, mais au cours de leur vie ils deviennent comme leur créateur. Ils décident de vivre intensément par l'action. Citons à titre d'exemple le plus connu, Meursault, 
protagoniste de L'Étranger, qui, accablé par son quotidien, ne fait rien pour changer son destin. Clamence, un peu différent, décide d'agir, disant tardivement, même si son action semble absurde, qu'il tient à « rouler sa pierre » comme Sisyphe. L'action ne manque pas chez Camus. En plus de son travail de directeur de théâtre, il se joint à Pascal Pia pour fonder le journal quotidien, Le Soir Républicain, dont le but est de dénoncer la misère des peuples opprimés et de témoigner de leur pacifisme foncier.

De plus, le jeune auteur, pendant l'occupation, fut séduit par le travail du groupe de résistants «Combat » mené par Pia et qui possède son propre journal. Camus se joint alors à eux avec grand enthousiasme. Il décide de mener un combat moral au moyen de sa plume. Il écrit : « Nous portons tous en nous nos bagnes, nos crimes et nos ravages. Mais notre tâche n'est pas de les déchaîner à travers le monde elle est de les combattre en nous-mêmes et dans les autres. » ${ }^{34}$ Dans tous les écrits de Camus, il existe toujours un criminel, un meurtrier, un traitre, un méchant qui nous rappellent le choix des personnages tels qu'ils sont présentés dans les contes de fées. Il y a aussi l'homme bon. L'existence de l'homme bon a été proclamée par les premiers penseurs et «la corruption de l'homme non régénéré ne l'empêche point d'avoir des vertus morales véritables, et de faire quelques fois de bonnes actions dans la vie civile, qui viennent d'un bon principe, sans aucune mauvaise intention. ${ }^{35}$

\footnotetext{
${ }^{34}$ Albert Camus, Euvres complètes III 320.

${ }^{35}$ Nourrisson, 269.
} 
L'Envers et l'endroit dans lequel l'auteur exprime l'intensité de son désir de vivre face à la mort absurde et inéluctable nous apprend beaucoup de choses sur son créateur. Dans sa préface, il note :

Il n'y a pas d'amour de vivre sans désespoir de vivre, ai-je écrit, non sans emphase, dans ces pages. Je ne savais pas à l'époque à quel point je disais vrai ; je n'avais pas encore traversé les temps du vrai désespoir. Ces temps sont venus et ont pu détruire tout en moi, sauf justement l'appétit désordonné de vivre. ${ }^{36}$

Green et Camus réclament tous deux la justice mais ne la vivent pas de la même manière. Ceci est bien compréhensible sachant qu'ils viennent de deux mondes différents. Le premier était né dans l'aisance, s'est converti au catholicisme et vit en bourgeois, sous le ciel gris de Paris ; l'autre était né pauvre, agnostique et prolétaire, sous le soleil d'Alger.

Bien qu'ils soient différents sur bien des points, Green et Camus partagent une certaine vision humaniste. On peut dire que l'humanisme de Green est un humanisme chrétien ou «passif » alors que celui de Camus est un humanisme militant ou « actif. » De ce fait, on découvre mieux le rapport qu'entretient l'œuvre avec chacun des auteurs. Ainsi, la relation entre l'identité et l'écriture devient évidente.

Comme les auteurs de la seconde moitié du $\mathrm{XX}^{\mathrm{e}}$ siècle, Green et Camus ont été marqués par les deux guerres mondiales qui ont bouleversé l'humanité à jamais. Face à cette période de désarroi, de bouleversements sociaux et politiques, l'auteur ne peut

\footnotetext{
${ }^{36}$ Albert Camus, Euvres complètes: Essais (Paris : Gallimard, 1965) 11.
} 
qu'être influencé par ces drames qui touchent sa vie de près ou de loin. Nos deux auteurs se coulent dans leur fiction et ressuscitent la réalité. Green a évoqué à plusieurs reprises qu'il se sentait très proche de ses livres : «Je voudrais pouvoir dire la vérité sur moimême [...] Je ne vois guère d'autre moyen de m'en tirer que d'écrire un roman. ${ }^{37}$ À propos de Camus, Jean-Paul Sartre note «l'admirable conjonction d'une personne, d'une action et d'une œuvre. ${ }^{38}$

${ }^{37}$ Green, CEuvres IV. Éd. Jacques Petit. Bibliothèque de la Pléiade (Paris: Éditions Gallimard, 1975) 670.

${ }^{38}$ Albert Camus, Euvres complètes I (Paris: Éditions Gallimard, 2006) XL. 


\section{Chapitre 2 : Contexte socio-historique d'Épaves et de La Chute}

Green a écrit Épaves, lorsqu'il avait exactement 30 ans, dans une période caractérisée par sa rupture avec la religion. Il rompt avec l'Église en 1928 pour ne reprendre qu'en 1939. En 1930, il commence à travailler sur Épaves qu'il termine un an plus tard. Avec ce roman, Green voulait dépeindre «le récit d'un chercheur d'aventures nocturnes dans le Paris de notre époque. ${ }^{39}$ Green se tourne vers le bouddhisme espérant trouver des réponses aux questions qui le tourmentent.

Si l'on compare ce roman avec d'autres comme Mö̈ra ou Le Visionnaire où ressortent la violence et la passion religieuse, Épaves apparaît plus calme et plus conservateur. Bien que le roman ne manque pas de scènes qui font allusion à la religion, à travers le comportement des personnages comme Éliane et Henriette. Le roman dénote un certain calme qui est même proche de l'indifférence, cette indifférence que Green reproche justement à l'homme pendant cette période. Le calme de Philippe malgré les quelques scènes violentes temporise l'ambiance du roman. Il y a très peu de mouvements ; tout est intérieur, caché, pensé, senti et surtout rêvé: Un calme noir comme l'eau de la Seine, un calme qui précède l'orage qui va perturber le bien-être de son protagoniste. Le calme même qui pousse Éliane à penser au crime.

\footnotetext{
${ }^{39}$ Green, Journal I 18.
} 
Les conditions qui ont poussé l'auteur à écrire un tel roman est la crainte de la guerre, l'inquiétude de l'époque et surtout l'amour du rêve. Cet amour a été transmis à ses personnages. Éliane rêve d'acquérir le cœur de Philippe, «Elle désire un bonheur qu'elle n'ose conquérir, veut un crime qu'elle ne tentera même pas de commettre. ${ }^{40}$ Philippe, quant à lui, rêve de retrouver le couple et de sauver la femme qui l'a appelé à son secours, mais son impuissance l'en a empêché. Plus tard « Il imagine un suicide qui se transforme en une comédie dérisoire. ${ }^{41}$ Un suicide qu'il n'a même pas eu le courage d'accomplir.

Dans Épaves, tout se déroule dans Paris, un Paris presque inconnu à nous lecteurs, un Paris nocturne dans lequel Philippe déambule. Cette «ville-lumière » que l'on qualifie comme la capitale du monde ou la plus belle ville du monde s'est montrée sous un charme, une beauté et une attraction particulière aux yeux de l'écrivain et son protagoniste. Les adjectifs utilisés pour décrire la capitale sont très nostalgiques, énigmatiques et mystérieux et dressent un arrière-plan qui dégage une austérité semblable à celle de Philippe. On parle de gouffre, de façades lugubres, de ciel sinistre, et de misère insolente qu'étalaient les bâtiments de la ville. Il semble que Philippe ne voie que «les immeubles noirs élevaient leurs façades lugubres dans le ciel aveugle, ${ }^{42} \ll$ la caserne de la Manutention délabrée par plusieurs incendies » ou des «murs couverts de saleté

\footnotetext{
${ }^{40}$ Green, Euvres II 1308.

${ }^{41}$ Green, Euvres II 1308.

${ }^{42}$ Green, Euvres II 4.
} 
comme d'une guenille revêtaient ce soir une louche et criminelle beauté. » ${ }^{43}$ Green, comme Baudelaire dans les Fleurs du mal, fait ressortir la beauté de la ville dans tout ce qui est laid et, comme Balzac, nous décrit « la ville aux mille visages. »

Ce soir-là tout a changé pour Philippe, même « les paysages familiers changent sans raison apparente, aux yeux même qui les connaissent le mieux. ${ }^{44}$ Connaissant la place que tient Paris chez Green, il n'est pas surprenant de le voir la décrire ainsi. Doté d'une vision romantique, il a écrit plusieurs louanges sur « la ville lumière »: « Nous savons bien que Paris est beau, mais les peintres nous le redisent avec toute l'autorité de leur génie et l'on demeure muet devant une ville que Manet, Degas, Monet et tant d'autres nous donnent, si différente de ce que nous voyons et pourtant si réelle. » ${ }^{45}$

Même la lumière qui, d'habitude représente quelque chose de positif, vient de perdre son mystère, et « rien de cela ne paraissait beau, ni précieux. Au contraire, tout devenait futile et médiocre, et subitement s'enlaidissait. » ${ }^{46}$ Elle devient violente, agressive, crue et dure envers Philippe, Éliane et les autres personnages du roman. Des descriptions qui nous font penser aux textes de Baudelaire lorsqu'il décrit sa quête d'un ailleurs et où la tristesse de l'existence a pris dans l'époque moderne des formes déprimantes : réverbères blafards, ruisseaux nauséabonds, prostituées, mendiants etc. tout ce décor pittoresque de la ville décourage l'âme et la plonge dans le «spleen. »

\footnotetext{
${ }^{43}$ Green, Euvres II 16.

${ }^{44}$ Green, Euvres II 16.

45 Julien Green, Paris (New York: Marion Boyars, 1991) 136.

${ }^{46}$ Green, Euvres II 4.
} 
Cette morosité qui entoure l'auteur est étroitement liée à ce qui se passait dans sa vie sur le plan personnel et social. Un conflit intérieur s'installait alors chez Green. Le 16 octobre 1929, il note dans son journal: «Il m’est impossible de travailler avec application pour plusieurs raisons dont la principale est que je n'arrive pas à trouver le début de mon livre.» ${ }^{47}$ Un an plus tard, il ajoute : «Les nouvelles d'Allemagne m'ont assombri. Troubles en Rhénanie. Comment travailler à un roman alors que la paix est menacée ? ${ }^{48}$ Green est très inquiet et il ne le cache pas. Selon lui une guerre n'est pas à exclure. Le 19 octobre 1930, il écrit dans son journal : « Les menaces de guerre semblent plus sérieuses qu'il y a une année. J'ai fini par accepter cette possibilité effrayante, je me résigne de vivre dans l'attente d'une catastrophe. ${ }^{49}$ Alors volontairement ou involontairement cette peur a été transmise à son protagoniste Philippe.

Green avoue tout au long de son journal que pendant cette période il lui a été très difficile d'écrire. En 1928 il écrit que pour surmonter cette difficulté, «Il faut essayer d'obtenir de soi une espèce de dédoublement. ${ }^{50}$ Cette notion de dédoublement est souvent l'une des caractéristiques des personnages greeniens, de Joseph ${ }^{51}$ à Philippe. En juillet 1931, lors d'un séjour à Heidelberg, Green écrit : « Les nouvelles politiques nous inquiètent et l'incertitude du lendemain m'empêchent de jouir pleinement de ces

\footnotetext{
${ }^{47}$ Green, Journal I 19.

${ }^{48}$ Green, Journal I 34.

${ }^{49}$ Green, Journal I 34.

${ }^{50}$ Green, Journal I 19.

${ }^{51}$ Joseph est le protagoniste du roman Mö̈ra qui accomplit son crime comme si un autre l'avait fait à sa place.
} 
vacances. Dans ces conditions il est difficile d'écrire un roman.» ${ }^{52}$ Green tenait des discussions politiques avec son entourage où il est souvent question de parler de l'Allemagne ou d'un certain « aventurier » nommé Hitler.

Malgré toute cette agitation autour de lui, Green essaie de créer un environnement calme afin d'achever son œuvre. Le 31 décembre, qui coïncide avec l'achèvement de son livre, il écrit: « Ainsi finit une année pleine d'inquiétude et de menaces. ${ }^{53}$

Camus a écrit La Chute en 1956. Les années cinquante représentent pour l'auteur de La Peste une décennie de révoltes, de déceptions et de conflits mal vécus. En 1951 il a écrit L'Homme révolté dans lequel il exprime ses idées comme des confessions. Cet essai a été critiqué par la revue des Temps Modernes dirigée par Sartre et Beauvoir. À travers ses écrits, il remet en cause toutes les « doctrines » ou mouvements, notamment le marxisme, le communisme et le surréalisme ; ceci augmente la liste de ses ennemis, entre autres André Breton.

Camus a très mal reçu les critiques de la revue et une querelle entre lui et Sartre, un ami qui lui était cher, s'est déclenchée. Certains pensent que cette dispute est une des causes qui a poussé Camus à écrire La Chute. De quelle chute s'agit-il ? Celle de Sartre, de ses ex-compagnons ou de lui-même ? C'est peut-être la chute de l'homme tout simplement. Cette œuvre a été publiée deux ans après le début de la guerre d'indépendance de l'Algérie, son pays natal, et de 1955 à 1956 Camus écrit dans

\footnotetext{
${ }^{52}$ Green, Journal I 60.

${ }^{53}$ Green, Journal I 86.
} 
Actuelles une série d'articles sur le déchirement de l'Algérie qui le tourmente. «Qui pense au drame des rappelés, à la solitude des Français d'Algérie, à l'angoisse du peuple arabe ? $»^{54}$ Écrit Camus, comme une mère qui essaie de sauver tous ses petits sans vouloir en sacrifier aucun. Et pourtant il y avait aussi une vive hostilité de la part des Français d'Algérie envers lui lorsqu'il plaida pour l'instauration d'une «trêve civile » en 1956. De plus, il se sentait exilé en France et en Algérie. Tous ses éléments poussent l'auteur à écrire une œuvre dans laquelle il s'interroge et dénonce l'incapacité des intellectuels à agir et à faire changer le monde.

Cette dualité omniprésente chez l'auteur résulte du croisement des cultures originelles chez lui: africaine et européenne, française et algérienne. C'est aussi une situation ambiguë pour lui : il est né parmi les colonisateurs mais il partage le sort des colonisés. Ce sentiment d'ambiguïté, de déchirement et de balancement, Camus le résume de la sorte : «Je n'ai jamais vu très clair en moi pour finir. Mais j'ai toujours suivi, d'instinct, une étoile invisible [...] Il y a en moi une anarchie, un désordre affreux. » ${ }^{55}$

En 1956, il lance un appel de trêve à Alger, mais ceci a provoqué le mécontentement du FLN et de la France et l'a forcé à vivre dans une solitude et un silence intérieur. Ce balancement crée en lui une impuissance à se ranger dans une catégorie et à définir sa position clairement.

\footnotetext{
${ }_{54}$ Albert Camus, Actuelles III. Chroniques algériennes 1939-1958 (Paris : Gallimard, 1958) 134.

${ }^{55}$ Camus, Carnets II 303.
} 
Clamence, impuissant lui aussi, est incapable de sauver une jeune femme qui s'est noyée dans la Seine. Sa fin est aussi dérisoire que celle de Philippe dans Épaves. Il finit par s'exiler et par passer ses journées à rouler sa pierre comme le personnage du Mythe de Sisyphe.

Sur le plan personnel, la vie de Camus à l'époque où il a écrit La Chute passait par des moments difficiles. À son propre état de santé qui n'était pas à envier, il voit la santé de sa femme se dégrader de jour en jour sous ses yeux, ce qui provoque chez lui un sentiment de culpabilité. Dans une lettre du 26 décembre 1953 à Jean Grenier, il écrit :

Je suis désolé de vous avoir demandé d'annuler le billet de voyage de Francine, mais j'ai pensé que c'est la meilleure chose à faire, je suis dans une situation très difficile. La condition de Francine est alarmante. J'ai pensé que le retour à la maison d'enfance va l'aider à retrouver son équilibre. Au contraire, j'ai trouvé que sa dépression s'est empirée et a sombré dans une dépression clinique et s'est compliquée par des signes d'angoisse et d'obsession. Je suis très inquiet et je me blâme pour ne pas avoir pris le premier signe au sérieux. ${ }^{56}$

Le 29 décembre il lui écrit une autre lettre dans laquelle il lui parle de son état moral et émotionnel. En 1954, Camus comme Green, est passé par des moments de stérilité, il avait du mal à écrire; il confie alors à son ami socialiste Roger Quilliot qu'il est resté six mois sans pouvoir écrire.

\footnotetext{
${ }^{56}$ Albert Camus et Jean Grenier, Les Correspondances, 1932-1960 (Paris: Gallimard, 1981) 160. «I am sorry for having called upon you to have Francine's trip canceled, but I thought that would be the most practical way. I am, in fact, in a very difficult situation. I found Francine here in an alarming condition. I had hoped that returning to her childhood home would help her regain her balance. On the contrary I found that her depression had deepened into clinical depression and was complicated by signs of anxiety and obsession. I am quite worried and I blame myself for not having taken the first symptoms more seriously.
} 
Ces deux romans respectivement atypiques représentent une dimension tragique du monde qui finit par mener les hommes à la dérive. Ils apparaissent comme une expression de la faute qui provoque un déchirement interne. Le déchirement de Clamence comme celui de Philippe montre la souffrance qui régit notre monde. Ni le personnage de Green ni celui de Camus n'ont eu le courage de Zola lorsque sans aucune hésitation, celui-ci a haussé la voix pour refuser la culpabilité du capitaine Dreyfus en prononçant les mots qui résonnent jusqu'à aujourd'hui: «J'accuse! » Green transmet sa douleur à ses personnages, cette douleur qu'il a découverte très jeune. Dans son journal Partir avant le jour, il écrit : «[II] me vient à l'esprit que mon premier souvenir est un souvenir de douleur physique. On me soigne et j'ai mal. » ${ }^{57}$

${ }^{57}$ Julien Green, Partir avant le jour (Paris: Grasset, 1963) 9. 


\section{Chapitre 3 : Peut-on se raconter soi- même?}

« Détestable, l'écrivain qui parle, exploite ce qu'il n'a jamais vécu. ${ }^{58}$

Dans cette partie, nous allons essayer de répondre aux questions suivantes afin de comprendre les motivations qui ont poussé nos deux auteurs à rédiger ces œuvres qui sont si différentes de leurs travaux habituels et si ambiguës: comment est-il possible d'écrire sur soi ? Pourquoi le faire? Dans quel but?

Si on se réfère à la définition de l'autobiographie, Épaves et La Chute ne font pas partie de cette catégorie. Ce sont des récits en prose certes, ils traitent une ou des vies individuelles mais ne répondent pas aux critères de l'autobiographie tels qu'ils sont définis par Philippe Lejeune dans Le Pacte autobiographique ${ }^{59}$. Philippe n'est pas Green et Clamence n'est pas Camus. Cependant on peut aisément affirmer que ces œuvres représentent un amalgame de fiction et de réel. De temps en temps, dans La Chute, on voit resurgir Camus au premier plan. Par exemple, Clamence mentionne que le sport est l'une des rares activités qui lui apportent du bien-être et de l'épanouissement: «Les matchs du dimanche, dans un stade plein à craquer, et le théâtre, que j’ai aimé, sont les seuls endroits du monde où je me sente innocent. » ${ }^{60}$ Cette période remonte bien sûr aux moments heureux de sa jeunesse, sa vie à Alger et son paradis perdu.

\footnotetext{
${ }^{58}$ Camus, Carnets II 20.

59 Philippe Lejeune, Le Pacte autobiographique (Paris : Le Seuil, 1975).

${ }^{60}$ Camus, Euvres complètes: Théâtre 1520.
} 
Green révèle dans son journal qu'il aurait voulu « écrire un livre à la première personne, pour l'accent de vérité que donne cette forme. ${ }^{61}$ Ainsi, il se rapproche de Rousseau alors que Camus n'a pas hésité à le faire dans La Chute. Non seulement Clamence utilise le « je » lorsqu'il s'adresse à son interlocuteur mais, selon l'image dressée par son créateur, ils ont l'air de se ressembler: «Vous avez à peu près mon âge, l'œil renseigné des quadragénaires qui ont à peu près fait le tour des choses. » ${ }^{62}$ D'ailleurs ce n'est pas la première fois que Camus peint des personnages qui lui ressemblent. Dans l'adaptation de Requiem pour une nonne de Faulkner, il a même fait subir au personnage des changements pour le rapprocher davantage de lui. Par exemple, dans la version originale le protagoniste est âgé de cinquante ans alors que dans la version de Camus il en a quarante.

Selon la genèse d'Épaves, «Le livre plonge dans l'autobiographie et l'on y voit resurgir, au hasard des images et des lieux, le souvenir des promenades de l'enfant et du jeune homme, les rêveries de l'adolescent devant les paysages parisiens. » ${ }^{63}$ Ces promenades permettent à Philippe de se retrouver tête-à-tête avec lui-même. Clamence explique à son interlocuteur ses errances nocturnes : «J'aime marcher à travers la ville, le soir, dans la chaleur du genièvre. Je marche des nuits durant, je rêve ou je me parle interminablement. ${ }^{64}$

\footnotetext{
${ }^{61}$ Green, Euvres II 1306.

${ }^{62}$ Camus, Euvres complètes: Théâtre 1480.

${ }^{63}$ Green, Euvres II 1306.

${ }^{64}$ Camus, Euvres complètes: Théâtre 1482.
} 
Les auteurs transfèrent inconsciemment quelques expériences de leur vie et font remonter des souvenirs enfouis qui constituent malgré eux un contexte, un décor et une fin tragique. En réponse à la critique qui trouve que Green est un romancier objectif, François Mauriac écrit : «M. Julien Green se présente dans les moindres détours les lieux que fréquentent ses personnages. Il connaît les escaliers, les corridors, il sait combien il y a de marches au perron ... » ${ }^{65} \mathrm{Si}$ pour Green l'écriture permet la confession à travers ses héros, pour Camus elle assume généralement un rôle dénonciateur et de parti pris. Cette communication entre l'auteur et son protagoniste a un pouvoir thérapeutique et cathartique puisqu'elle permet à Green d'extérioriser sa souffrance et ses tourments par le dévoilement. D’ailleurs Épaves est presque démuni de dénouement « ou plutôt le seul dénouement est l'aveu arraché à Philippe. » ${ }^{66}$ Un aveu de faiblesse, d'impuissance et d'indifférence comme tous les autres personnages du roman se renferment dans leur rêve personnel. Un aveu semblable fut arraché à Clamence quelques années plus tard.

L'écrivain se fonde sur ce qu'il a vu, vécu, pensé, senti, désiré, imaginé ; tout écrivain écrit à partir de ses expériences personnelles. Ainsi, pour Camus « $L a$ Chute ressemble à un diamant noir, avec des facettes lisibles, souvent limpides quant à sa vie, mais au cœur inaccessible. Camus n'est pas saint Augustin, néanmoins il livre un

\footnotetext{
${ }^{65}$ Dominique van Hooff, « Le Naturalisme de Julien Green dans ses premiers romans. » Julien Green nondit et ambiguïté. Éds. Société Internationale d’Études Greeniennes (Paris: L'Harmattan, 2007) 185.

${ }^{66}$ Green, Euvres II 1307.
} 
superbe fragment d'une confession de saint Camus. » ${ }^{67}$ C'est dans cette œuvre que l'auteur prend du recul et résume sa vie telle qu'il la voit.

«L’œuvre est un aveu » ${ }^{68}$ pour la plupart des romanciers. Camus a révélé une partie de sa vie dans ses œuvres où il a présenté ses idées, ses sentiments et ses expériences de la vie ou, comme le définit Philip Thody, son « autobiographie intellectuelle. » ${ }^{69}$ Et pourtant il a tout fait pour « décourager les critiques de considérer ses livres comme le reflet de sa propre expérience. ${ }^{70}$

Par contre dans Carnets on retrouve un style plus spontané « le je est un $i l$ et un $i l$ direct, sarcastique, comme s'il était plus facile de prendre du recul sur soi-même en s'adressant à d'autres. ${ }^{71}$ Il n'a pas été aussi loin que Gide ou Proust qui ont transposé une partie de leur vie privée dans leurs écrits, alors que lui, écrivain militant et engagé s'est intéressé aux questions de son temps, celles de la condition humaine. Dans Carnets, il précise que ce qu'il écrit est un témoignage de la société, et qu'il se voit dans l'obligation de le faire : «D'autres écrivent par tentation différées. Et chaque déception de leur vie leur fait une œuvre d'art, mensonge tissé des mensonges de leur vie. Mais moi, c'est de mes bonheurs que sortiront mes écrits. Même dans ce qu'ils auront de plus

\footnotetext{
${ }^{67}$ Olivier Todd, Albert Camus: Une vie (Paris: Gallimard, 1996) 638.

${ }^{68}$ Camus, Carnets I 16.

69 Thody 4.

70 Thody 4.

71 Todd 80 .
} 
cruels.» ${ }^{72}$ Camus nous révèle les raisons qui l'ont poussé à écrire. Dans Carnets, il anticipe et répond à plusieurs de nos questions.

Contrairement à Camus, Green ne cache pas son désir de se refléter de temps en temps dans ses écrits et surtout pendant la période de son enfance. En 1926, il écrit dans son journal : « Il ne se passe pas de jour sans que je songe à mon enfance ${ }^{73}$ et en 1931 il confirme qu'il s'inspire de son enfance, qu'il qualifie de « Paradis perdu » pour écrire. Il note : «Tout ce que j'écris procède en droite ligne de mon enfance. ${ }^{74} \mathrm{Il}$ ajoute plus tard : «Cette merveilleuse époque de ma vie trouve quelquefois un écho dans mes livres, dans L'Autre sommeil surtout. ${ }^{75}$ L'amour, la famille est également un thème présent chez ce romantique attardé. Il regrette que chez certains ce sentiment noble soit absent ou enfoui. Plus conscient de sa tendance, il ajoute : «La conscience c'est la mémoire, je souffrirai d'une petite diminution de la conscience de n'avoir pas noté au passage les mille détails de ma vie quotidienne, car ce qu'on oublie est prodigieux. ${ }^{76}$

La création de Green est un mélange de réalité et de fiction. Analysant Manuel, protagoniste du Visionnaire, il lui donne la vie et la liberté. Green lui passe la plume et c'est donc à Manuel de décider de la suite du récit : «Mais Manuel est comme ensorcelé par sa propre tristesse. Sans le savoir, il est romancier. Il ressent comme tant d'entre nous l'angoisse de vivre dans un monde qu'il ne comprend pas, et pour échapper à cette

\footnotetext{
${ }^{72}$ Camus, Carnets I 25.

${ }^{73}$ Wildgen 198.

${ }^{74}$ Wildgen 198.

${ }^{75}$ Green, Journal II 28.

${ }^{76}$ Green, Journal II 39.
} 
angoisse, il écrit : «Créons des mythes pour remplacer une réalité ingrate, mais ne nous étonnons pas de retrouver dans ces fables l'effroi que nous portons en nous. » ${ }^{77}$

Cependant on ne peut pas tout raconter de soi soit par discrétion, soit par incapacité du langage qui parfois ne peut traduire toutes les idées, moins encore les émotions de l'auteur. Souvent ce que l'on lit n'est qu'une tentative de ce que l'on veut dire, car il y a certaines descriptions qui échappent au langage. Mais en faisant appel aux héros des romans, l'auteur se laisse aller et s'ouvre plus sur la réalité des faits et sur les sentiments vécus, puisqu'il ne s'agit plus de lui mais d'un autre ; c'est alors un vol d'identité permis. Alors, hypnotisé, il se peint librement et ses expériences deviennent révélatrices. Ainsi, on découvre clairement un double chez ces auteurs, voire un je multiple. Le discret et l'exhibitionniste, ce qui mène toujours à la naissance de paradoxes.

Green à propos de ses écrits qui correspondent le plus souvent aux rêves, selon lui, dit : «Qu'ai-je fait d'autres depuis que j'écris des romans que de raconter mes rêves les rêves que sont mes livres - et la critique me les montre comme des tableaux et me les explique ! Ainsi se fait ma cure et ma catharsis ! ${ }^{78}$

Dans Pamphlet contre les catholiques de France, Green met beaucoup de luimême, ses expériences et surtout ses tourments. Il reproche aux catholiques ce que Clamence, le héros ou l'anti-héros de La Chute, reproche aux bourgeois de Paris. Tous

\footnotetext{
${ }^{77}$ Green, Euvres II 1392.

${ }^{78}$ Flavia Vernescu, Clivage et intégration du moi chez Julien Green (Birmingham: Summa Publications, 1994) 66.
} 
deux s'autocritiquent et se condamnent à la place de leurs pairs. Ce conflit intérieur chez Green et Camus a causé une révolte et une violence interne qui finit par rejaillir à travers les mots, car on ne peut parler de la douleur que si on l'a vécue et on ne peut parler d'injustice que si on l'a subie. L'écrivain est plus crédible lorsqu'il s'inspire de ses propres expériences.

Green, en parlant du personnage de Mö̈ra, disait que « le drame de Joseph est aussi le mien.» ${ }^{79}$ Dans Épaves, Green revient sur les lieux de son enfance, rue Passy, rue Beethoven, il décrit les promenades qu'il a l'habitude de faire avec son compagnon Robert de Saint-Jean ainsi que ses rêveries de jeunes adultes devant un Paris sublime.

Toutefois la différence entre Camus et Green réside dans le fait que le dernier ne cache pas la réalité des choses. Il avoue en effet que dans ses écrits il y a toujours une ombre de lui-même qui apparaît comme toile de fond de ses romans : «C'est que je m'en prenais secrètement à moi, ${ }^{80}$ alors que Camus, lui, a toujours nié la présence de portions autobiographiques.

À propos du personnage de La Chute, Camus nie toute ressemblance avec Clamence bien que souvent ses lecteurs et son entourage reconnaissent une de ses facettes dans son personnage car «Après tout il n'est pas chrétien. » ${ }^{81}$ Todd dans La

\footnotetext{
${ }^{79}$ Petit, Green 61.

${ }^{80}$ Petit, Green 38.

${ }^{81}$ Todd 642.
} 
biographie de Camus dresse une liste de ressemblances entre Camus et Clamence. ${ }^{82}$ La vérité est que Camus n'apparaît pas uniquement chez le héros de son roman mais plutôt dans plusieurs personnages. Il est probablement très difficile de choisir quel est parmi ses personnages fictifs celui qui le représente le mieux.

Même si le roman ne coïncide pas exactement avec l'autobiographie, il présente des caractéristiques du roman autobiographique et s'en rapproche fortement. À travers Épaves et La Chute, Green et Camus examinent quelques thèmes de l'existence qui leur sont très chers et qui leur sont communs. Ceci leur permet de nous parler de nous et de notre existence.

Il arrive souvent que l'auteur décrive inconsciemment ses expériences. Par exemple, Green disait « Je travaille bien avec la rage d'oublier, de me plonger dans un monde imaginaire. Et qu'est-ce que j'y trouve dans ce monde ? Mes problèmes démesurément grandis. ${ }^{83}$ Comme le remarque John Dunaway, Green «n'invente pas, il raconte ce dont il est témoin. Pour cette raison, écrire des fictions pour Green est d'autant plus un processus de découverte, de création. Ses personnages le mènent à une compréhension totale de son véritable soi... Le romancier doit alors devenir ce qu'il écrit. ${ }^{84}$ C'est ce que Green définit comme « une réalité de vision. »

\footnotetext{
${ }^{82}$ Olivier Todd écrit dans la biographie de Camus un article intitulé « Le cri du prisonnier» dans lequel il explique la ressemblance entre Camus et son héros: «Une des lectrices averties, Francine, comprend que son mari - son frère - veut se délivrer d'une part de lui-même, comme du milieu parisien où il se sent mal à l'aise. » Sartre quant à lui écrit à propos de La Chute : «Un chef-d'œuvre sinon le meilleur livre de Camus parce qu'il s'y montre et s'y cache tout entier. »

${ }^{83}$ Petit, Green 42.

${ }^{84}$ Dunaway 86.
} 
Philippe a trente et un ans, le même âge que Green lorsqu'il a écrit Épaves. Comme son créateur il fait très attention à son apparence physique et apprécie ses promenades dans les rues de Paris que Green lui-même faisait alors qu'il écrivait Épaves. C'est un homme assez réservé et solitaire. Il rêve d'être écrivain! Clamence a également le même âge que Camus lorsqu'il a écrit La Chute. Comme son créateur, il vit dans une société où il côtoie beaucoup de gens et aime défendre la cause des faibles, de par sa profession. Il parle comme un philosophe.

Les personnages de Clamence et de Philippe correspondent à la description des personnages réalistes, voire balzaciens. Les auteurs nous révèlent beaucoup d'information à leur sujet : leur physique, leur statut social, leur comportement par moment, avec leur portrait psychologique. Leur passé est raconté, par des flash-back, par le personnage lui-même, la source de motivation du présent du personnage est soit explicite soit implicite. Ces personnages donnent l'impression qu'ils agissent par euxmêmes puisque le narrateur et l'auteur s'effacent, ce qui favorise l'illusion de réalité. Mais la technique que Camus utilise dans La Chute est l'une des plus modernes dans le domaine des styles d'écriture : «le style Camus » ou l'écriture devient quasiment transparente pour ne céder la place qu'à la réalité. Le personnage de Clamence va plus loin que les personnages balzaciens, car il se confond avec le narrateur et devient à la fois un regard sur le monde et une conscience réflexive sur lui-même. Il s'accuse puis passe le miroir aux autres pour qu'ils en fassent autant : «Dans La Chute, l'illusion est poussée plus loin : nous avons le sentiment que Clamence est personnellement l'auteur du récit, 
qu'il l'a découpé en séquences selon son gré, lui donnant même le thêâtre qu'il lui convient et en prévoyant jusqu'au dénouement. ${ }^{85}$

${ }^{85}$ Pierre-Louis Rey, La Chute Camus (Paris: Hatier, 1997) 42. 


\section{Chapitre 4 : Les sources qui nourrissent l'œuvre}

Le but de ce chapitre est de montrer qui a influencé les œuvres de Green et de Camus et où dans ces deux textes on peut voir cette influence. Il est vrai que la plus grande inspiration de Green puise ses sources dans le Journal qu'il a commencé depuis l'âge de vingt ans et dans lequel il relate ses mémoires. À ce propos, Marilyn Gaddis Rose note que «parfois le journal révèle le travail à venir des années avant même que Green ne l'ait consciemment imaginé. ${ }^{86}$ Ainsi, le premier volume édité et publié date de 1928. Depuis, le journal est devenu son œuvre la plus importante et la meilleure, selon l'auteur lui-même.

Dans ses premiers romans comme L'autre sommeil, Moïra et Chaque homme dans sa nuit, Green fait vivre à ses protagonistes sa violence interne, sa révolte et ses propres tourments et il ne le cache pas : «Je trompe la violence qui fait le fond de ma nature en écrivant mes livres. ${ }^{87}$ En 1928, il note dans la première page de son journal : «Je suis tous les personnages ... $»^{88}$. Dans Épaves qui apparaît un peu plus tard, Philippe est décrit comme un personnage passif mais à la fois impuissant, déchiré, tiraillé. Green déverse toute son anxiété dans ce personnage.

\footnotetext{
${ }^{86}$ Marilyn Gaddis Rose, “The Journal of Julian Green.” The French Review. $39: 5$ (1966): 696. «Sometimes the journal reveals the work to come, years before Green has it even in his conscious imagination. » ${ }^{87}$ Green, Journal I 10.

${ }^{88}$ Green, Journal I 1.
} 
Mais en plus de son journal, Green montrait un grand appétit pour la lecture, car ses livres étaient ses meilleurs compagnons, ses guides dans sa solitude et ils ont aussi influencé ses œuvres. Dans Épaves et La Chute, Green et Camus ont adopté l'ambivalence que l'on retrouve chez leurs précurseurs, en particulier les auteurs du $\mathrm{XIX}^{\mathrm{e}}$ siècle. Green parle souvent dans son journal de Pascal, Dickens, Shakespeare, Racine et bien d'autres. Pascal, de même, a bien habité Green et Camus et tous deux se sont nourris de ses thèmes et de ses «pensées. »

Green a aussi traduit des œuvres d'Edgar Poe qui a eu une grande influence sur lui. Sa première rencontre avec l'œuvre de ce dernier fut à l'âge de 19 ans et sa réaction se résume dans la réplique suivante : «Les yeux m'en sortiront de la tête. » ${ }^{89}$ Cependant sa relation avec Gide était plus amicale que professionnelle. Selon son journal, Green et Gide étaient très proches. Ils s'échangeaient même des textes à lire et à critiquer. Mais la place que tient Gide pour Camus est singulière d'abord parce qu'ils ont partagé la même tragédie de la maladie. Gide comme Camus fut atteint de la tuberculose alors qu'il était en Algérie, expérience qu'il qualifie de « rendez-vous de sensations. » ${ }^{90}$ Ils sont devenus tous deux «poreux » aux sensations à travers la maladie.

Dans l'article que Camus a écrit sur l'auteur des Nourritures terrestres, il affirme qu'il avait à peine seize ans lorsqu'il a lu cette œuvre qui est pour lui le « rendez-vous

\footnotetext{
${ }^{89}$ Myriam Kissel, Le Cheminement de l'écriture: l'espace dans l'œuvre de J. Green (Berne: Peter Lang Édition, 2005) 35.

${ }^{90}$ Todd 47.
} 
[...] manqué. $\gg^{91}$ Mais la lecture de La Douleur d'André de Richaud lui a permis de rentrer dans le monde de la littérature : «La Douleur me fit entrevoir le monde de la création où Gide devait me faire pénétrer. ${ }^{92}$ Gide dont il avoue avoir lu toute l'œuvre et avoir adapté au théâtre Le Retour de l'enfant prodigue. En 1932, dans tout son premier texte, Intuitions, Camus note en épigraphe une phrase de Gide : «J'ai souhaité d'être heureux comme si je n'avais rien d'autre à être. ${ }^{93}$ On a même rapproché La Chute de Camus de L'immoraliste de Gide dont le point de comparaison est basé sur la réaction de l'homme par rapport à la nature et comment celle-ci l'influence.

Dans ce qui suit, nous allons examiner brièvement les recoupements multiples des conceptions entre nos deux auteurs et ceux qui les ont influencés.

En lisant cette phrase de Charles Baudelaire : «Il y a dans tout homme, à toute heure, deux postulations simultanées, l'une vers Dieu, l'autre vers Satan» ${ }^{94}$ on croirait lire Green. Ni Baudelaire ni Green n'arrivent à faire un choix et ils ont tous deux du mal à concilier les deux mondes : celui du bien et celui du mal. Ces mondes qui représentent respectivement pour Green le monde de la spiritualité et celui de la chair, comme il le dit si bien:

Je m'efforçais, dans ces pages, de relater tout ce que j'avais retenu de ma vie charnelle et de ma vie spirituelle non sans essayer de faire voir le

\footnotetext{
${ }^{91}$ Camus, Euvres complètes : Essais 1117.

${ }^{92}$ Camus, Euvres complètes : Essais 1169.

${ }^{93}$ Camus, CEuvres complètes : Essais 1170.

${ }^{94}$ Charles Baudelaire, Mon cour mis à nu (Paris: Livre de Poche, 1972) 111.
} 
conflit qui en résultait, parce que ce conflit qui me déchirait me paraissait aussi ce qu'il y avait de plus important dans ma destinée. ${ }^{95}$

La position de Camus à ce sujet ne fait pas exception, ce qui explique son état d'âme, le malaise qui l'a déchiré toute sa vie depuis le jour où il a pris conscience de l'absurde qui régit le monde et crée le malheur des hommes. Camus se sent algérien tout en essayant de rester français. Le dilemme pour lui est de pouvoir se classer de manière civique, situation insoutenable car il se trouve tiraillé entre deux groupes qui se séparent.

Selon Gaddis Rose, les écrivains qui ont le plus inspiré Julien Green sont Baudelaire, Mallarmé, Valéry et Hawthorne. Baudelaire écrivain et poète français du $\mathrm{XIX}^{\mathrm{e}}$ siècle, période où le romantisme a atteint son apogée, a su à travers ses œuvres, entre autres Les Fleurs du mal, nous exposer toute sa réflexion sur l'être humain en général et sa réflexion spirituelle en particulier. Baudelaire et Camus, par manque de foi, reprochent à Dieu de ne pas sauver l'homme : « Mais je poursuis en vain le Dieu qui se retire. ${ }^{96}$

En 1861 Baudelaire écrit à sa mère : «Et Dieu! diras-tu ? Je désire de tout mon cœur (avec quelle sincérité, personne ne peut le savoir que moi) croire qu'un être extérieur et invisible s'intéresse à ma destinée, mais comment faire pour le croire ?» ${ }^{97}$

\footnotetext{
${ }^{95}$ Jacques Petit, Julien Green : l'homme qui venait d'ailleurs (Paris: Institut National de l'Audiovisuel, 1969) 30.

${ }^{96}$ Charles Baudelaire, Les Fleurs du mal (Paris: Le livre de Poche, 1999) 207.

${ }^{97}$ Jacques Darriulat, « Baudelaire la beauté des modernes : de la damnation du Spleen à la rédemption des Correspondances, » 12 mars $2011<$ http://www.jdarriulat.net/Auteurs/Baudelaire/Baudbeautemod/SpleenCorresp.html>.
} 
Le poète et le philosophe n'ont pas la foi mais leur relation avec Dieu et le Christ n'est pas complètement inexistante.

Camus et Baudelaire sont deux révoltés qui souffrent des abus de la vie. Mais si Baudelaire et Green définissent cette même dualité qui inévitablement semble les tourmenter, ils s'opposent dans leur foi. Green, conscient de son dilemme, a néanmoins confiance en Dieu alors que le dandy n'a pas confiance en Dieu et en plus il est plus favorable à Satan, idée bien romantique. Cette opposition n'a en rien affecté l'admiration qu'éprouve Green pour le poète. À propos de la poésie de Baudelaire, Green dit :

Les mots font un mal terrible. Ils ont une forme, un parfum, un galbe, une chaleur, une douceur, ils prennent la place de ce qu'ils décrivent et créent chez le lecteur une sorte d'hallucination, parce qu'ils sont produits par une hallucination chez le poète, s'il a du génie. ${ }^{98}$

Baudelaire a retenu l'attention des auteurs d'Épaves et de La Chute par ses œuvres qui présentent une conception d'un monde déchiré tel qu'il est présenté par les deux protagonistes Philippe et Clamence. Ce monde déchiré par deux pôles opposés, ceux du bien et du mal, ceux de la chair et de l'esprit, ceux de Satan et de Dieu et ceux de l'exil et du royaume. Et même si Baudelaire et Green partagent peu de choses en ce qui concerne leur vie familiale et sociale, l'amour et même la vénération de la mère est commun aux deux. En outre, la perte du père de l'un et celle de la mère de l'autre a laissé des séquelles et un traumatisme chez les deux écrivains.

${ }^{98}$ Gaddis Rose 698. 
Les Épaves est le titre qu'avait choisi Baudelaire pour les morceaux de poésie « condamnés, » des Fleurs du mal. C'est aussi le titre que Julien Green a adopté pour représenter les âmes faibles et condamnées qui sont ses protagonistes. Mais avant de décider pour Épaves, Green a pensé choisir Crépuscule, encore un titre emprunté à un poème de Baudelaire «Crépuscule du soir » dont la source d'inspiration est « une phrase de Joseph de Maistre, dans Les Soirées de Saint-Pétersbourg : la nuit est une complice naturelle constamment à l'ordre de tous les vices. ${ }^{99}$ Ce poème traite le thème de la nuit et ses effets pernicieux. Les situations malencontreuses qu'ont vécues Philippe et Clamence ont eu lieu dans les ténèbres de la nuit. La nuit est la source d'inspiration de Green :

Voici le soir charmant, ami du criminel

II vient comme un complice, à pas de loup; le ciel

Se ferme lentement comme une grande alcôve, Et l'homme impatient se change en bête fauve. ${ }^{100}$

La thématique de l'exil et de l'errance dans un Paris à double teinte qui caractérise Épaves et La Chute se retrouvent également dans la section Tableaux parisiens de l'œuvre Les Fleurs du mal de Baudelaire. Ces auteurs ont décrit un Paris entre le rêve et la réalité. L'errance de Philippe semble bien réelle mais celle d'Éliane n'est qu'un rêve. Si pour Baudelaire la ville est un moyen d'échapper au « Spleen », pour Green à travers Philippe, elle est décrite comme moyen d'échapper à l'angoisse qui le torture chaque jour qui passe. Une angoisse déclenchée par un péché, une impuissance

\footnotetext{
${ }^{99}$ Charles Baudelaire, Les Fleurs du mal (Paris: Librairie Larousse, 1973) 65.

${ }^{100}$ Baudelaire, Fleurs 65.
} 
ou un sentiment de culpabilité, en somme par une faute ou un crime. Mais la quête de l'idéal et la révolte sont les dénominateurs communs de Baudelaire et de Camus et sont vraisemblablement la cause de ce déchirement immuable.

Tous deux accusent Dieu d'injustice et de cruauté face au malheur des êtres et de la condition humaine. Baudelaire ouvre Les Épaves par des lamentations, des regrets et déceptions comme il l'avoue dans «Le Coucher du soleil romantique »: « Mais je poursuis en vain le Dieu qui se retire. ${ }^{101}$ C'est cette absence de Dieu qui frappe Camus lors de la mort du fils du juge Othon dans La Peste. Le docteur Rieux qui sert de porteparole à l'auteur en s'adressant au père Paneloux qui représente la religion chrétienne, lui fait savoir qu'il ne croit pas à un Dieu qui laisse mourir un enfant. Du point de vue du style littéraire, selon David Halker, «Camus se range évidemment du côté de ces grands romanciers (parmi lesquels Halker cite Balzac, Sade, Melville, Stendhal, Dostoïevski, Proust, Malraux et Kafka).» ${ }^{102}$

En 1848, Baudelaire surprit son monde en s'intéressant à la politique. En portant la cape du militant, il se transforme de dandy en ami du peuple dont il s'engage à défendre la cause. Comme Camus journaliste, Baudelaire fonde un journal, Le Salut public, à travers lequel il révèle ses idées sociales et modernistes. Il ressemble à Jean-

\footnotetext{
${ }^{101}$ Baudelaire, Les Fleurs du mal (Paris: Le livre de poche, 1999) 207.

${ }^{102}$ David H. Walker, éd. Actes du colloque de Keele, 25-27 mars 1993: Albert Camus, les extrêmes et l'équilibre (Amsterdam: Rodopi, 1994) 184.
} 
Baptiste Clamence dans « sa colère, ses haines et ses rancœurs contre l'ordre bourgeois sclérosé et injuste. ${ }^{103}$

Contrairement à ce qu'on aurait pensé, Green se range dans la même catégorie que Baudelaire en laissant «éclater »sa « haine du bourgeois, » ${ }^{104}$ il va même critiquer le comportement de Flaubert, qu'il admirait tant sur le plan littéraire, car ce dernier « crie toujours contre les bourgeois, mais il finit par leur ressembler. ${ }^{105}$ N'oublions pas que lorsque Green voulait appeler son roman Crépuscule, il s’est posé la question : « Mais Crépuscule de quoi ? De la bourgeoisie sans aucun doute. » ${ }^{106}$

La lecture des œuvres Épaves et La Chute nous donne l'impression du déjà-vu. La Seine et le décor du lieu de la tragédie, Balzac l'a déjà imaginé dans La Peau de chagrin. De plus Raphaël de Valentin ${ }^{107}$ comme Clamence décide de vivre en reclus, une sorte d'exil, afin d'éviter les tentations et les risques de la vie qui peuvent avoir des conséquences fatales. Comme Philippe, Raphaël a voulu écrire « une grande œuvre » qui pour les deux avorte. Ils considèrent sérieusement l'idée du suicide qui n'aboutit pas. Dans les trois romans, la Seine représente un autre personnage aussi important que le héros ou l'anti-héros, et Paris joue un rôle de premier plan. La ville est considérée le lieu propice pour montrer la tragédie de l'homme contemporain qui sera confronté à des situations qui provoquent inquiétude et angoisse.

\footnotetext{
${ }^{103}$ Fanny Berat et Marie-Aude de Langenhagen, Baudelaire (Levallois-Perret: Studyrama, 2006) 36.

${ }^{104}$ Green, Journal I 70.

105 Green, Journal I 68.

106 Green, Journal I 84.

${ }^{107}$ Raphaël est le nom du protagoniste de l'œuvre de Honoré de Balzac La Peau de chagrin, publié en 1831.
} 
Paris pour Balzac et Green, qui tous deux ont écrit un livre sur la ville lumière, est une multitude de choses : c'est la description minutieuse d'une rue, d'un quartier, de ses habitants, l'accumulation massive de détails physiques, techniques et historiques ; la physiologie de la ville et son influence sur les êtres humains. C'est la démonstration de cette relation presque mécanique de cause à effet, de ce déterminisme [...]. ${ }^{108}$

En somme, le milieu social des personnages, le caractère physique de leur drame et la nature des conflits font que les trois œuvres La Peau de chagrin, Épaves et La Chute présentent des affinités.

Enfin tous ces protagonistes bien que doués d'un pouvoir, ne font rien de leur vie. Ils finissent tous les trois rongés par le remords et l'amertume.

Si on peut affirmer que Baudelaire a influencé Green et Camus, on en dira autant si ce n'est pas plus de Dostoïevski. Tous deux évoquent la mort horrible du père de l'auteur assassiné par ses propres employés, « les moujiks. » De manière générale, les écrivains russes comme Gogol, Lesskov et Tolstoï étaient peut-être les plus admirés par Green et Camus. Tolstoï fait partie des premières lectures de Green. En 1965, il participe à l'adaptation de La Dame de pique de Pouchkine et La Mort d'Ivan Ilitch, alors que Camus a adapté Les Frères Karamazov de Dostoïevski pour le théâtre. Camus s’identifie à Tolstoï dans l'amour de la mère. Dans ses Carnets, il reprend une citation de Tolstoï : «S’il m’était donné encore dans les heures douloureuses de la vie, de revoir ce sourire (de sa mère) ne fût-ce qu'un instant, je ne connaîtrais pas la douleur. » ${ }^{109}$ D'après

\footnotetext{
${ }^{108}$ Marthe Blinoff, « Dostoïevski et Balzac. » Comparative Literature, 3.4 Autunm (1951) : 347.

${ }^{109}$ Albert Camus, Carnets II 238.
} 
ses Carnets, Camus était un grand admirateur de Tolstoï et Dostoïevski, car il a lu leurs œuvres et leur autobiographie avec vénération : «Lui, tête baissée, se jette dans le brouillard, vole et tombe en épilepsie, il porte en son âme une anxiété perpétuelle, une déchirure, aborde au plus près le songe et y recherche la chair et le sang. ${ }^{110} \mathrm{Ce}$ sont les mots d'Alexandre Blok décrivant son ami qu'il surnomme «l'aveugle, » Dostoïevski. Ces caractéristiques sont semblables à celles de Green qui dans sa fin de jeunesse, a écrit : «L’âme de Dostoïevski est universelle, il est le père Karamasov, mais aussi, courant d'un pôle de l'enfance à l'autre, il est Aliocha, il est tous les luxurieux, tous les assassins, tous les startsi, toutes les victimes et tous les saints de la création. ${ }^{111}$

Green n'a jamais voulu avouer l'influence qu'avaient eue les auteurs russes sur ses écrits, mais il a confessé qu'il était subjugué par l'art de Dostoïevski : « [Il] a le sentiment de pénétrer dans un univers qui fait écho au sien et de s'en nourrir. » ${ }^{112} \mathrm{Si}$ Dostoïevski et Green se ressemblent dans leur création littéraire, l'auteur russe et Camus se rapprochent dans leur détermination pour l'engagement politique et social par la plume. En effet par leur profession de journaliste, ils ont su lever la voix et dénoncer l'injustice.

Dans son journal Green manifeste sa révolte et son inquiétude à l'égard de l'injustice, des guerres et des massacres, en somme toute la souffrance de l'humanité.

\footnotetext{
${ }^{110}$ Myriam Kissel, « Julien Green et Dostoïevski : une écriture mystique. » Julien Green et alii : rencontres, parentés, influences (Dijon: Édition Universitaires de Dijon, 2011) 107.

${ }^{111}$ Kissel, Julien Green 100.

${ }^{112}$ Kissel, Julien Green 106.
} 
Avec Épaves, on peut dire que Julien Green s'est joint aux deux militants Dostoïevski et Camus en exposant le problème de la condition humaine et le destin des hommes avec un grand désespoir puisque «celui qui désespère des événements est un lâche, mais celui qui espère en la condition humaine est un fou. ${ }^{113}$

Les personnages de Green ressemblent à ceux de Dostoïevski. Ils sont en général sombres, violents, victimes de passions extrêmes et hantés par des obsessions qui les mènent souvent au gouffre comme Joseph Day, le protagoniste de Moïra, au délire comme Éliane d'Épaves et à la folie comme Adrienne Meusurat, le personnage du roman éponyme.

Seulement, la question qui a intrigué plusieurs critiques est pourquoi Green a du «mal à reconnaître sa dette envers Dostoïevski ? » Il a toujours justifié son manque d'enthousiasme à lire Dostoïevski par l'absence de bonne traduction ; néanmoins il a avoué à la même époque que son ami Robert de Saint-Jean lui a raconté l'histoire de $L a$ Confession de Stavroguine, chapitre censuré dans les premières éditions du roman Les Démons, et qu'il l'a lu presque à la même période où il a rédigé Épaves. Ce roman est en quelque sorte la suite des Possédés, le roman que Camus a adapté pour le théâtre.

En 1923, André Gide avait écrit un essai critique sur l'auteur russe intitulé Dostö̈evski ${ }^{114}$ publié chez Plon. Alors il nous paraît improbable que Green ne l'ait pas lu. Enfin, plus tard, dans son journal, Green fait la critique de L'Idiot de Dostoïevski qu'il

\footnotetext{
113 Camus, Carnets II 106.

${ }^{114}$ André Gide, Dostö̈evski (Paris: Librairie Plon, 1923).
} 
semble ne pas apprécier car il note : «D’une façon générale, je ne crois à ce livre qu’à demi. Je n'y retrouve pas cette magnifique invasion de la vérité de Crime et châtiment où le lecteur n'est pas en état de refuser l'histoire qu'on lui raconte. ${ }^{115}$ Puis il continue : «Et ces longues conversations ne me paraissent pas devoir être rapportées avec tant de minutie. On n'a jamais cette impression de bavardage dans Crime et châtiment. » ${ }^{116} \mathrm{Ce}$ roman de l'auteur russe est l'un de ses favoris avec Les Frères Karamazov.

Dans une interview avec Sophie Lannes, Green déclare : «Il [Dostoïevski] demeure pour moi le grand romancier universel. Je n'en vois pas de plus grand. ${ }^{117}$ L'admiration de Camus pour Dostoïevski est tout aussi profonde que celle de Green. Mis à part le fait qu'il avait accroché le portrait de Dostoïevski et Tolstoï dans son bureau, Camus laisse voir son admiration chaque fois que l'occasion lui est présentée : «J'ai admiré Dostoïevski à cause de ce qu'il me révélait de la nature humaine. Mais très vite, à mesure que je vivais plus cruellement le drame de mon époque, j’ai aimé dans Dostoïevski celui qui a vécu et exprimé notre destin historique. ${ }^{118}$ Dans La Chute Clamence fait référence au roman Crime et châtiment : «Pour être connu il suffit en somme de tuer sa concierge. ${ }^{119}$ Dans son roman La Folie sur scène, Martine Agathe Coste raconte que « lorsqu'il lui vint l'idée de Caligula,

\footnotetext{
${ }^{115}$ Green, Euvres IV 1217.

116 Green, Euvres IV 1218.

${ }^{117}$ Sophie Lannes, « Julien Green, mon voisin. » 16 février 2008. 28 juillet 2011. <http://www.arllfb.be/ebibliotheque/seancespubliques/16022008/7lannes.pdf>

118 Camus, Euvres complètes: Théâtre 1883.

${ }^{119}$ Camus, CEuvres complètes: Théâtre 1489. Dans ce roman, le protagoniste a tué la concierge de l'immeuble où il habite.
} 
Camus venait d'interpréter le personnage d'Ivan Karamazov. ${ }^{120}$ Mais ce qui est plus patent c'est l'assimilation des Possédés aux deux auteurs puisque Camus en a fait l'adaptation théâtrale. Tous deux savent exploiter les grands thèmes de la tragédie moderne. Par exemple, plusieurs écrivains se sont posé la question si L'Étranger de Camus est un palimpseste de Crime et châtiment de Dostoïevski. D'ailleurs, cette ressemblance ne se limite pas à ces deux œuvres. Une grande partie de l'œuvre camusienne trouve son inspiration dans celle de Dostoïevski. Toute l'idéologie $d u$ Mythe de Sisyphe et de L'Homme révolté trouve source dans Les Possédés, où Kirilov ${ }^{121}$ tient les mêmes discours que Camus : «Les Possédés sont une des quatre ou cinq œuvres que je mets au-dessus de toutes les autres. À plus d'un titre, je peux dire que je m'en suis nourri et que je m'y suis formé. » ${ }^{122}$ Il va plus loin en «affirmant que sans Dostoïevski la littérature française du $X^{\mathrm{e}}$ siècle ne serait pas ce qu'elle est. » ${ }^{123}$

Déjà, dans les premières pages de La Chute, où Clamence décrivait son attitude de dominateur, il faisait référence au père de l'auteur russe car il disait qu'il aurait souhaité pouvoir agir « comme un propriétaire russe » et qu'il « [admirait] le caractère : il faisait fouetter en même temps ceux de ces paysans qui le saluaient et ceux qui ne le saluaient pas pour punir une audace qu'il jugeait dans les deux cas également

\footnotetext{
${ }^{120}$ Martine Agathe Coste, La Folie sur scène: Paris 1900/1968 (Paris: Éditions Publibook, 2004) 282.

${ }^{121}$ Protagoniste des Possédés.

122 Camus, Euvres complètes: Théâtre 1886.

${ }^{123}$ Camus, CEuvres complètes: Théâtre 1887.
} 
effrontée. ${ }^{124}$ Dans ce passage Camus faisait référence au père de Dostoïevski qui a été tué plus tard par les mains de ces mêmes paysans. Mais l'œuvre de l'auteur russe qui se rapproche le plus de La Chute est Le Sous-sol qui a fait l'objet de nombreux travaux d'exégèse, dont certains ont souligné les ressemblances entre ces deux œuvres.

Ernest Sturm souligne dans son texte que «Camus s’est directement servi de L'Homme du souterrain ${ }^{125}$ pour créer Clamence, habillant le premier de vêtements modernes, afin d'obtenir un personnage psychologiquement semblable à son prédécesseur, et partageant la même philosophie. ${ }^{126}$ Plus encore, cet homme que Dostoïevski classe dans la catégorie des hommes esclaves de leur destin, n'est qu'un autre Philippe, personnage greenien, qui confronté à l'absurde, se tourmente, se déchire et se châtie sans pour autant essayer de changer son destin. Il est aussi Clamence qui n'est pas plus différent du reste des protagonistes que Camus qualifie d' «âmes mortes ou déchirées, incapables d'aimer et souffrant d'impuissance, désireuses de croire et ne le pouvant, tout comme ceux qui peuplent notre société et notre monde spirituel. » ${ }^{127}$

L'homme du Sous-sol ressemble à Clamence. Il a le même âge que ce dernier et comme lui, il est imbu de sa personne. Il se révolte contre l'homme normal à défaut du bourgeois. Mais comme Philippe, le doute et la peur l'empêchent d'agir. Certains

\footnotetext{
${ }^{124}$ Camus, Euvres complètes: Théâtre 1522.

125 Le vrai titre en anglais est Notes from the Underground ou bien Letters from the Underworld, mais les critiques y font référence sous le nom : The Underground Man. Strurm a préféré utiliser la traduction du titre donné par la critique. En français, on le retrouve sous le titre Les Carnets du sous-sol.

${ }^{126}$ Ernest Sturm, Conscience et impuissance chez Dostö̈evski et Camus (Paris: Librairie A.G. Nizet, 1967) 21.

${ }^{127}$ Sturm 20.
} 
critiques, décrivent la ressemblance entre ces deux œuvres comme « un dialogue intime, à un siècle de distance, entre les deux écrivains. ${ }^{128}$ De par leur forme qui est la confession, les deux auteurs ont voulu donné une vision subjective de leur monde. Par contre, dans Épaves, la confession de Philippe n'est pas directe, mais très subtile. Tantôt il confesse, tantôt il revient sur sa confession.

Kissel en comparant Les Confessions de Stavroguine de Dostoïevski avec Le Visionnaire de Julien Green soulève beaucoup de ressemblances. D’abord, les protagonistes, Matriocha et Marie-Thérèse, sont toutes deux victimes de viol et de mauvais traitements qu'elles subissent de la part de leur entourage et également dans les « instants de violence paroxystique » qui se «produisent au sein d'un réel hyper présent.» ${ }^{129}$ Green a lu le roman de Dostoïevski alors qu'il écrivait Le Visionnaire. Mais il faut noter aussi que Manuel et Joseph Day se ressemblent dans leur comportement, surtout après l'acte sexuel où chacun d'eux s'est humilié et souillé. Une humiliation qui est semblable à celle de Philippe dans sa confrontation avec le gamin qui a essayé de l'attaquer sur les quais de la Seine et qui l'amène à prendre conscience de sa lâcheté. Le personnage greenien et le personnage dostoïevskien sont constamment confrontés à l'absurde. Ni l'un ni l'autre ne comprend pourquoi Dieu les a créés dans un tel chaos. Dans ce tumulte on retrouve les personnages camusiens qui, de plus, trouvent cela d'autant plus absurde qu'ils doivent rendre compte de leurs fautes.

\footnotetext{
${ }^{128}$ Sturm 22.

${ }^{129}$ Kissel, « Julien Green » 110.
} 
Dostoïevski, Green et Camus nous poussent, à travers leurs œuvres, à sonder notre âme pour découvrir nos bons et mauvais côtés. Les drames de Balzac à Green et Camus en passant par Dostoïevski sont des drames bourgeois. 


\section{Partie II : Les multiples facettes de la faute}

\section{Chapitre 1: Narcissisme, indifférence, impuissance : les caractères à risque}

Quand on est, par rapport à la faute, l'élève de l'angoisse, on ne trouve de repos final que dans la rédemption. ${ }^{130}$

S. Kierkegaard

Que reproche-t-on à Philippe et à Clamence? Quel est ce crime dont ils se sentent coupables ? Doit-on dire plutôt faute ou défaillance? Et quelle est la frontière entre la prudence et l'impuissance?

Ces protagonistes adhèrent tous aux mêmes injonctions, celles d'une société qui veut tout gagner quel que soit le prix, et qui fait tout pour sauver les apparences. Ainsi, Philippe guette le moindre gramme qui risque de déformer son corps ou la moindre ride qui puisse le défigurer à jamais. Éliane, de même, regrette un corps de jeunesse qui en la quittant a entraîné avec lui son unique chance de séduire son beau-frère. Clamence quant à lui, veut être au-dessus de tous : « Oui, je ne me suis jamais senti à l'aise que dans les

\footnotetext{
${ }^{130}$ Sören Kierkegaard - Le concept de l'angoisse - L'angoisse comme salut par la foi (chapitre V), 24 décembre 2012. 12 janvier 2013. < http://www.booston.fr/article-soren-kierkegaard---le-concept-de-1angoisse---l-angoisse-comme-salut-par-la-foi-chapitre-v-113765804.html>.
} 
situations élevées. » ${ }^{131}$ Mais quoi qu'ils fassent leur destin prend toujours de l'avance sur eux.

Dans cette étude, on définit le crime ou la faute comme une corruption de l'âme et l'on se demande comment on va les confronter ? Avec quelle force ? Ainsi, si on se met du côté des psychanalystes, le crime ou la faute peut se présenter sous différentes formes et les motivations qui poussent au crime moral sont également différentes. Le destin de l'homme et l'absurdité du monde ont suscité la curiosité intellectuelle de nombreux écrivains, moralistes et philosophes. Green et Camus ont essayé de montrer dans Épaves et La Chute comment Clamence, Philippe, Éliane et Henriette y font face. Comment des êtres déprimés et déséquilibrés arrivent à accomplir des actes importants dans une sorte d'état second. Ces actes vus d'une certaine logique n'ont rien de troublant mais ils obéissent plutôt, selon la psychanalyse, «à une logique qui n'était plus celle de la vie socialisée. Il s'agissait d'une 'autre' logique, plus affective, plus proche du monde mental des enfants, insensible en tout cas aux impératifs du bon sens ou de la stricte logique.» ${ }^{132}$ On peut qualifier leur comportement de narcissique, indifférent, vaniteux et égoïste : «Pendant des années il [Philippe] s’était cru supérieur à ceux qu'il appelait mentalement : les autres, avec la somme de dédain que cette expression comporte. » ${ }^{133}$

\footnotetext{
${ }^{131}$ Camus, Euvres complètes: Théâtre 1487.

132 Jean-Paul Charrier, L'Inconscient et la psychanalyse (Paris: Presse Universitaire de France, 1968) 3.

${ }^{133}$ Green, Euvres II 43.
} 
Clamence, sans aucun scrupule, étale devant cet inconnu qu'il a rencontré au bar Mexico-City, ses actions délétères envers les femmes surtout, mais envers les vieux aussi et les démunis en général. Clamence clairement donne une image négative, prétentieuse de sa personnalité et de sa conduite corruptive, non professionnelle et non conforme à l'éthique de l'avocat qu'il est. Il défend les criminels à condition qu'ils soient « de bons meurtriers $»^{134}$ en tout état de cause. Même les actions charitables qu'il accomplit envers un pauvre, un aveugle, un vieillard ou une femme, il ne les fait pas par altruisme mais pour satisfaire son amour-propre.

Comme si la liste de ses fautes n’était pas assez longue, il ajoute : «baiser la main d'une pauvre femme et briser là, croyez-moi cher monsieur, c'est atteindre plus haut que l'ambitieux vulgaire et se hisser à ce point culminant où la vertu ne se nourrit plus d'ellemême. ${ }^{135}$ Parfois ce genre d'action ne relève plus du narcissisme mais de la perversité surtout lorsqu'il admet ses fautes pour aussitôt après trouver un moyen de les tourner à son profit : «La face de toutes mes vertus avait ainsi un revers moins imposant. Il est vrai que dans un autre sens, mes défauts tournaient à mon avantage. » ${ }^{136}$ Clamence trouve même une bonne raison pour le vol du tableau des Juges intègres. Cependant la métaphore de ce vol bien que subtile, lui permet de montrer que les vrais juges sont remplacés par des faux juges, mais personne ne semble s'en apercevoir, même ceux qui leur sont très proches. Ainsi, il prouve que la justice est corrompue.

\footnotetext{
${ }^{134}$ Camus, Euvres complètes: Théâtre 1485.

135 Camus, Euvres complètes: Théâtre 1487.

${ }^{136}$ Camus, CEuvres complètes: Théâtre 1519.
} 
Le psychiatre Christophe André qui a étudié un certain nombre de patients, afin de comprendre comment les gens perdent l'estime de soi et comment rétablir l'estime de soi, déclare :

Si l'on croit les philosophes, les sociologues et autres politologues, nous étouffons peu à peu notre ego. L'individualisme toujours croissant de l'individu moderne nous conduirait à toujours plus de paresse, d'incivisme, de laxisme, de complaisance envers nous-même. L'estime de soi ne serait-elle finalement que de l'égoïsme et du nombrilisme ? Du narcissisme? Un sous-produit de l'irresponsabilité de sociétés qui, par leurs violences ou leurs mensonges, fabriquent à la chaîne des individus persuadés qu'ils ne survivront que si leur valeur est supérieure à celle des autres? La valorisation de l'estime de soi déboucherait alors sur le culte de moi, au détriment des valeurs altruistes nécessaires à toute vie en société. $^{137}$

Philippe et Clamence sont l'exemple type de ce genre d'individus. Ils ne partagent certainement pas l'avis de Pascal qui dit que « le moi est haïssable » ni celui de Kant : «l'amour de soi, sans être toujours coupable, est la source de tout mal. ${ }^{138}$ Bien sûr il faut faire la distinction entre l'amour de soi et l'obsession de soi qui devient toxique dans la plupart des cas, comme dans celui de nos protagonistes. Dans La Chute, Clamence confesse un de ses péchés : «Moi, moi, voici le refrain de ma chère vie » ${ }^{139}$ disait-il à son interlocuteur. Il reprend plus tard ce même discours pour affirmer : « Il y avait plus de trente ans que je m'aimais exclusivement. ${ }^{140}$ Clamence explique, avec

\footnotetext{
${ }^{137}$ André Christophe, Imparfait, libre et heureux : pratiques de l'estime de soi (Paris: Odile Jacob, 2006) 17.

${ }^{138}$ Alain Montoux. Le Dictionnaire des organisations (Paris: Éd. Publibook, 2012) 618.

${ }^{139}$ Camus, Euvres complètes: Théâtre 1500.

${ }^{140}$ Camus, Euvres complètes: Théâtre 1527.
} 
vantardise à son interlocuteur, que ce qui compte le plus à ses yeux est lui-même et comment la nature l'avait gâté en lui donnant un physique plus que satisfaisant. ${ }^{141}$ D'ailleurs il se nomme « le beau mannequin. ${ }^{142}$

Dès les premières pages de La Chute, Clamence insiste sur l'importance de l'estime de soi. Il explique comment ce concept lui procure une paix : « Le sentiment du droit, la satisfaction d'avoir raison, la joie de s'estimer soi-même, cher monsieur, sont des ressorts puissants pour nous tenir debout ou nous faire avancer. ${ }^{143}$ Il pousse l'ironie plus loin car c'est le seul moyen de justifier ses fautes : «Combien de crimes commis simplement parce que leur auteur ne pouvait supporter d'être en faute ! » ${ }^{144}$ Philippe est certainement du même avis que Clamence : ce qui compte pour lui c'est lui-même. D'ailleurs les jours qui suivent le drame de la Seine l'ont affecté jusqu'à ce qu'il se soit rendu compte qu'il avait pris du poids. Alors, sa première réaction fut alarmante pour quelqu'un qui n'accepte aucune déchéance physique : «Plutôt que de voir son corps se défigurer, il eût accepté d'être vingt fois plus lâche. » ${ }^{145}$

Tout au long de son récit, Clamence semble fier de raconter que toute action qu'il entame ne sert avant tout que ses intérêts personnels. Par exemple, dans ses conquêtes avec les femmes, il raconte :

\footnotetext{
141 «La nature m'a bien servi quant au physique, l'attitude noble me vient sans effort. » Camus $E$ Euvres complètes: Théâtre 1485.

${ }^{142}$ Camus, Euvres complètes: Théâtre 1523.

${ }^{143}$ Camus, Euvres complètes: Théâtre 1485.

${ }^{144}$ Camus, CEuvres complètes: Théâtre 1485.

${ }^{145}$ Green, Euvres II 74.
} 
Outre le désir que j'avais d'elles, je satisfaisais l'amour que je me portais, en vérifiant chaque fois mes beaux pouvoirs [...] Une sorte de prétention était en effet incarnée en moi que j'avais de la difficulté à imaginer, malgré l'évidence, qu'une femme qui avait été à moi pût jamais appartenir à un autre. ${ }^{146}$

La faute telle qu'elle se présente dans les œuvres que nous étudions est une conséquence d'un égoïsme rationnel où tout se joue sur l'intérêt personnel et où toute morale est inexistante. Par exemple, l'horreur de Camus face à la guerre qui se déclare le pousse à écrire : «Devant la menace constante de la destruction totale par la guerre - la privation donc d'avenir - quelle morale peut nous permettre de vivre seulement dans le présent ? Honneur et liberté. » ${ }^{147}$

Green, quant à lui, n'est pas sûr de sa réaction face à l'ennemi allemand et à l'atmosphère qui régnait pendant cette période alors qu'il écrivait Épaves. Son inquiétude est transférée sur son protagoniste : «En présence d'une révolution, se défendrait-il ? Il en vient à en douter. ${ }^{148}$ Une des images que dépeint Green dans Épaves est la descente dans la cave de Philippe avec son fils. Cette scène est déjà apparue dans Léviathan où Guéret descend dans une cave. Clairement dans cette scène Philippe a voulu tester son fils pour voir s'il était aussi lâche que lui, mais ce dernier n'a montré aucun signe de frayeur, bien au contraire, c'est un garçon très courageux qui vient de rendre son père très fier.

\footnotetext{
${ }^{146}$ Camus, Euvres complètes: Théâtre 1507.

${ }^{147}$ Camus, Carnets III mars1951- décembre 1959 (Paris: Gallimard, 1989) 165.

${ }^{148}$ Green, Euvres II 1306.
} 
La différence qu'il faut souligner entre nos protagonistes est que Clamence s'accuse de son crime et qu'il accuse les autres : «Je n'ai plus d'amis mais des complices. ${ }^{149}$ Alors que Philippe s'auto-accuse avec hésitation. Penser aux autres est une idée tout à fait nouvelle pour lui, parce que, qu'ils soient victimes ou criminels, il s'en moque. Contrairement à Clamence et son créateur, Philippe ne fait pas le bilan de sa vie et de ses fautes comme le fait, même de manière sarcastique, Clamence, depuis qu'il a entendu le rire sur le pont des Arts.

Le déséquilibre de tous ces personnages fictifs émane de leurs créateurs respectifs. Green confesse que son déséquilibre est né de la religion : «Elle a réussi à y mettre déjà un déséquilibre si inquiétant que je la crains encore, bien que j’ai retrouvé mon assiette. ${ }^{150}$ Green compense ce déséquilibre par l'absence de religion dans la vie où le cœur de Philippe qui, toujours préoccupé de soigner son image de marque, ne se soucie guère d'aucune spiritualité ni de son entourage. Le déséquilibre est né d'une existence pathétique, d'une sottise universelle et d'un monde absurde auquel l'homme essaie de donner un sens bien qu'il en soit incapable. Il conclut que, aussi longtemps que les hommes continuent à se haïr et que l'homme n'arrive pas à assumer sa condition d'homme, et tant que tous les êtres ne se prêtent pas la main pour combattre le mal, ce dernier subsistera. Dans Les Pensées, Pascal condamne l'amour de soi ou, comme il le nomme, l'amour-propre : «La nature de l'amour-propre et de ce moi humain est de

\footnotetext{
${ }^{149}$ Camus, Euvres complètes: Théâtre 1513.

${ }^{150}$ Green, Journal I 22.
} 
n'aimer que soi et ne considérer que soi, instinct qui porte [l'homme] à se faire

Dieu. » ${ }^{151}$ Camus critique l'homme égoïste de son siècle, lorsqu'il écrit :

De plus en plus, devant le monde des hommes, la seule réaction est l'individualisme. L'homme est à lui seul sa propre fin. Tout ce qu'on tente pour le bien de tous finit par l'échec. Même si l'on veut toutefois le tenter, il est convenable de le faire avec le mépris voulu. Se retirer tout entier et jouer son jeu. ${ }^{152}$

L'orgueil et la vanité ont détruit tout sentiment humanitaire chez les protagonistes et le monde se rétrécit à ne contenir qu'eux. Ce phénomène a germé dans leur âme depuis leur jeunesse. Philippe, par exemple, lorsqu'il était jeune «s'amusait à tenir mentalement une liste des personnes qui le complimentaient sur sa bonne mine. ${ }^{153}$ Il se trouvait beau et « ne trouvait d'énergie que pour éloigner de lui ce qui pouvait troubler son humeur. » ${ }^{154}$ Son narcissisme le pousse à se contempler fréquemment dans un miroir où il prend plaisir à se regarder.

En plus du narcissisme, l'indifférence est l'une des fautes morales des protagonistes chez Green et Camus, qui s'allient pour la condamner. L’indifférence est le contraire de l'amour. Dans la préface de L'Envers et l'endroit, Camus note : « Cette profonde indifférence qui est en moi comme une infirmité de nature. » ${ }^{155}$ Elle est souvent causée par un désespoir de la vie ou une acceptation d'un destin imminent ou un manque de volonté ou de force pour continuer le combat. Indirectement ceci nous fait

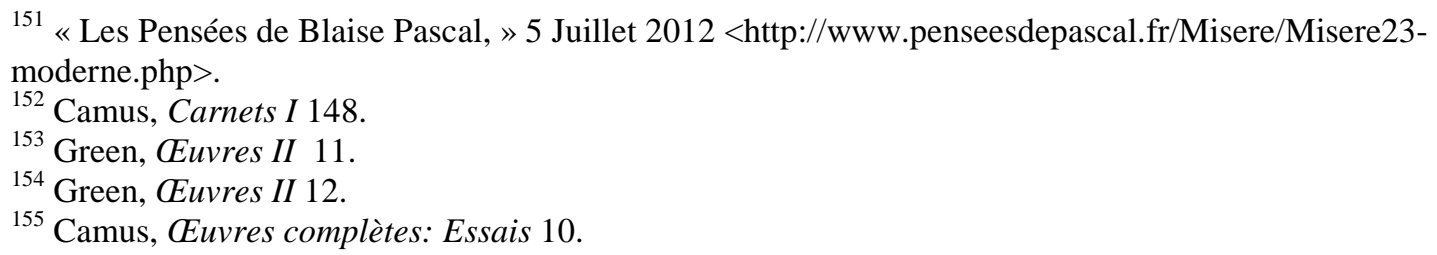


penser à l'indifférence de Meursault lors de la mort de sa mère. Dans L'Étranger, Meursault fut condamné parce qu'il ne s'était pas conformé aux règles de la société. Une société qui plus ou moins exige que l'homme pleure la mort de sa mère. Meursault s'est montré indifférent envers son décès. Ne pas avoir pleuré à l'enterrement de sa mère lui a coûté la vie. Mais l'indifférence de Clamence est sans limite et croît avec le mépris de l'autre. Il avoue : «l'indifférence qui occupait déjà tant de place en moi ne trouvait plus de résistance et étendait sa sclérose. » ${ }^{156}$

Après le rire que Clamence a entendu sur le pont, il décide de mettre en place un plan pour améliorer sa personne. De manière ironique, il confesse à son interlocuteur : «L'obligation où je me trouvais de cacher la partie vicieuse de ma vie me donnait par exemple un air froid que l'on confondait avec celui de la vertu, mon indifférence me valait d'être aimé, mon égoïsme culminait dans ma générosité. » ${ }^{157}$ L'indifférence de Clamence, ce personnage insaisissable, est dû au manque de volonté à vouloir aider autrui, mais surtout de la misère de sa condition. Même s'il porte en lui la loi morale, il décide intentionnellement de l'ignorer. Contrairement à Clamence, Philippe n'est pas un être de raison, il est plus guidé par ses instincts : un amour de soi. Les obligations morales, il n'en a pas connu. Il passe sa journée à tourner en rond et sa nuit à errer dans les rues de la ville. Sa vie est faite de néant, de solitude et d'ennui qui, selon Pascal, est la cause du drame humain :

\footnotetext{
${ }^{156}$ Camus, Cuvres complètes: Théâtre 1530.

${ }^{157}$ Camus, CEuvres complètes: Théâtre 1519.
} 
Rien n'est si insupportable à l'homme que d'être dans un plein repos, sans passion, sans affaire, sans divertissement, sans application. Il sent alors son néant, son abandon, son insuffisance, sa dépendance, son impuissance, son vide. Incontinent il sortira du fond de son âme l'ennui, la tristesse, la noirceur, le chagrin, le dépit, le désespoir. ${ }^{158}$

L’œuvre de Green dépeint entre autre comme il le dit lui-même des «personnages incapables d'achever leurs actes.» ${ }^{159}$ Philippe, très prudent à la vue du couple qui se dispute, fait tout pour passer inaperçu. Il s'est mis même à courir, « ce qu'il jugeait intérieurement un peu ridicule ${ }^{160}$ mais il finit toujours par trouver un moyen de justifier une de ses réactions qui suscitent un trouble intérieur. Pour lui, il est préférable de «s'attacher à son propre destin assez riche en énigmes, assez lourd de secrets pour satisfaire l'inquiétude la plus vaste. ${ }^{161}$ L'appel au secours de la victime le glace puis il décide de ne pas intervenir et de s'évader de la scène du crime.

L'indifférence et l'impuissance de Philippe vis-à-vis de sa famille a conduit sa femme Henriette à le tromper, sa belle-sœur Éliane à vouloir se suicider et la femme qui a sollicité son aide au bord de la Seine à périr. En somme, lâcheté ou indifférence, le résultat est le même. Jacques Decour, un des critiques d'Épaves, note : «Il ne faut pas dire que nous n'ayons rien de commun avec cet homme antihérö̈que : n’avons-nous pas nos abîmes de bassesses et de lâcheté. » ${ }^{162}$ Si la faute présume l'ignorance d'une loi que

\footnotetext{
${ }^{158}$ Stanley Appelbaum, Pensées et provinciales choisies (Mineola: Dover Publication, 2004) 192.

${ }^{159}$ Green, Euvres II 1308.

${ }^{160}$ Green, Euvres II 4.

${ }^{161}$ Green, Euvres II 4.

${ }^{162}$ Green, Euvres II 1316.
} 
l'on enfreint en toute conscience alors l'indifférence est de toute évidence une faute commise par les protagonistes dont la conséquence est le mal moral qui les déchire.

Dans Pamphlet contre les catholiques de France, Green a écrit : «De toutes les forces du monde, l'indifférence est la plus redoutable. Le ciel ne peut rien contre elle. Elle déjoue les ruses les plus puissantes de l'amour ; elle veut se damner et elle se damnera [...] Elle est la seule hérésie qui compte. ${ }^{163}$ Dans Épaves, il dénonce l'indifférence de Philippe à voir les autres souffrir sans se sentir concerné ou affecté par leur malheur. Son fils ne fait pas exception. Plus tard Philippe ne retrouve une paix intérieure que lorsqu'il se réconcilie avec son fils.

Camus n'a jamais cessé de condamner l'indifférence humaine. Dans Actuelles $I I I$, il a écrit un article intitulé «Bonne conscience », dans lequel il déplore le fossé qui se creuse de jour en jour entre les Français de l'Algérie et ceux de la métropole et leur manque de responsabilité à secourir les petites gens comme il les appelle ; les Français qui ne sont pas des colons et qui vivent dans des conditions médiocres:

Les gouvernements successifs de la métropole appuyés sur la confortable indifférence de la presse et l'opinion publique secondés par la complaisance des législateurs, sont les premiers responsables du massacre actuel [...] Reconnaissons donc une bonne fois pour toute que la faute est ici collective. Mais n'en tirons pas l'idée d'une expiation nécessaire. ${ }^{164}$

\footnotetext{
${ }^{163}$ Green, Euvres I 885.

${ }^{164}$ Camus, Actuelles III 142.
} 
Camus dénonce l'impuissance française face aux maux de l'Europe, l'impuissance des Français partisans de l'indépendance de l'Algérie, et de manière générale, l'impuissance de l'être humain face au monde absurde.

L'impuissance, cette incapacité humaine à changer l'ordre des choses face à une menace inéluctable qui laisse l'homme moderne fragile, a emprisonné Philippe dans son corps qui devient comme un sarcophage. Ce dernier n'arrive pas à se suicider bien qu'il ait tout planifié. L’idée du suicide a effleuré son esprit il y a bien quelques années. Il ne s'est jamais senti bien dans sa peau, car il étouffe dans son appartement parisien qui fait partie des biens de la famille. Lui, il ne possède rien qui lui soit propre, même ce physique et cette force qu'il « tenait d'un père robuste alors que lui, le fils, traînait une molle et vaine existence. » ${ }^{165}$ Green le décrit comme quelqu'un d'une « nature facile et indolente. ${ }^{166}$

La mauvaise conscience de Philippe n'est pas entièrement liée à la mort de la femme de la Seine mais en partie à cause de la situation d'échec qu'il vient de vivre. Il n'a pas été à la hauteur et ceci freine son épanouissement habituel. De surcroît cette lâcheté lui rappelle son impuissance envers sa femme car «beaucoup de sentiments servent de masque, d'écran à une culpabilité impénétrable. ${ }^{167}$ Philippe n'est qu'un homme dont le dégoût reflète une vie misérable et un destin fatal.

\footnotetext{
165 Green CEuvres II 11.

${ }^{166}$ Green Euvres II 12.

${ }^{167}$ Sarah Famery, Etre soi sans culpabiliser (Paris: Eyrolles Pratique, 2008) 16.
} 
Clamence, lui est d'un tout autre genre : beau parleur, effronté et rusé il ne cache pas sa lâcheté auprès de son interlocuteur. Il lui raconte avec ironie l'incident avec le petit homme en motocyclette qui l'avait battu sans qu'il puisse se défendre, mais, comme Philippe, il a perdu la lumière par sa faute. La découverte de sa lâcheté l'a bouleversée: «[Je] dévorai pendant quelques jours un vilain ressentiment. » ${ }^{168}$ Son impuissance vient de lui faire découvrir une nouvelle image qu'il ne connaissait pas : « [II] ne m’était plus possible de caresser cette belle image de moi-même» ${ }^{169}$ disait-il en poursuivant son soliloque. Un soliloque qui témoigne d'un salut inespéré. Depuis, il a compris que coupable même sans crime, il doit être jugé.

L’indifférence d'Éliane la pousse à prendre la place de sa sœur et à gagner le cœur de son beau-frère mais trouvant une sorte de résistance de la part de celui-ci, elle n’a plus le courage de continuer à jouer ce rôle qu'elle s'est attribué car « je n’ai su faire que du mal ${ }^{170}$ avoua-t-elle. Quant à Henriette, elle mène une double vie : une vie de luxe qu'elle partage avec sa famille et une autre avec son amant qui lui permet de plonger dans le monde de son enfance, les seules années de bonheur qu'elle a connues. Elle est indifférente envers son fils car il lui rappelle sa faute : son mariage avec Philippe. Cependant «[à] moitié pauvre et à moitié riche elle s'estimait à peu près heureuse. ${ }^{171}$

\footnotetext{
168 Camus, Euvres complètes: Théâtre 1503.

${ }^{169}$ Camus, Euvres complètes: Théâtre 1503.

${ }^{170}$ Green, Euvres II 124.

${ }^{171}$ Green, Euvres II 82.
} 
L'enfance pour Henriette et Philippe représente les années de joie et de bonheur. Pour elle, ses escapades chez son amant lui sont chères malgré ce que cela lui coûte. Cette image de misère et de pauvreté qui règne dans son appartement l'arrache du présent et l'emporte des années en arrière, chez elle lorsqu'elle était petite fille. Pour Philippe se rapprocher de son fils lui permet de se projeter à travers lui et de pouvoir goûter au bonheur, ne serait-ce qu'une fois. Encore une fois, à travers son personnage Green exprime sa nostalgie du passé et des moments de bonheur. Il écrit : «Si je pouvais revoir et bien observer l'enfant que j'étais à huit ans, je comprendrais mieux l'homme que je suis devenu. $»^{172}$

Dans la préface des Possédés, Camus qualifie les protagonistes d' «âmes mortes ou déchirées, incapables d'aimer et souffrant d'impuissance, désireuses de croire et ne le pouvant, tout comme ceux qui peuplent notre société et notre monde spirituel. » ${ }^{173}$ Clamence n'est pas une exception.

Dans Épaves, Green tourmente Philippe. Il le pousse presque au suicide en espérant réveiller le spirituel qui dort en lui. Or, Philippe sombre dans l'indifférence totale depuis sa jeunesse. Cela n’a rien de surprenant sachant qu'à cette époque Green s'est éloigné temporairement du céleste et de la spiritualité, égaré, il erre comme ce Parisien qu'il a créé dans les rues de Paris sans trouver de repères pour l'aider à sortir du gouffre. Avec cela Green entre dans une ère romantique qui se traduit par la solitude et

\footnotetext{
${ }^{172}$ Green, Euvres V 696.

${ }^{173}$ Sturm 20.
} 
l'angoisse de son protagoniste, plus évidente dans ce roman que dans le reste de l'œuvre greenienne. Le repère chrétien que Green a connu depuis son enfance s'est écarté petit à petit de lui. Il vit dans le péché mais sans lâcher la prise du divin. 


\section{Chapitre II : L'ambivalence}

Le doute est le commencement de la sagesse. ${ }^{174}$

Aristote

L'être humain est de nature ambivalente que ce soit dans ses sentiments, ses jugements, ses désirs, ses croyances, ou même ses comportements, souvent en rapport avec les problèmes de la condition humaine qui, selon Pascal, est « en effet singulièrement complexe, mélange de grandeur et de misère étroitement dépendantes l'une de l'autre. » ${ }^{175}$ Il est important cependant de noter que l'ambivalence n'a rien de mal, d'irrationnel ou de négatif mais au lieu de se ranger dans une catégorie ou opter pour une tendance ou motivation ou même un sentiment, on choisit d'appartenir à un monde plus hétérogène avec des valeurs qui peuvent être contradictoires.

Certains psychanalystes comme Freud, Mélanie Klein ou Karl Abraham classent les ambivalents dans une catégorie névrotique axée, entre autre, sur la notion de libido. D'après Klein, ${ }^{176}$ l'ambivalence apparaît chez l'être dès les premiers jours de sa vie. Le nourrisson passe d'un sentiment de crainte, d'angoisse et de frustration à celui d'apaisement, de gratification et de sécurité, et l'objet déclencheur est le sein maternel qui tantôt est le «le bon objet » et tantôt « le mauvais objet» selon sa disponibilité ; sa présence procure un apaisement et son absence, une frustration. Cette ambivalence n'est

\footnotetext{
${ }^{174}$ Catherine Cudicio, Les Bienfaits de la simplicité (Paris: Eyrolles, 2011 ) 97.

${ }^{175}$ Claude Genet, Pensées Pascal (Paris: Hatier, 1993) 30.

${ }^{176}$ Hanna Segal, Introduction to the Work of Melanie Klein (London: Karnac Books, 1988) 69.
} 
pas toujours anodine puisqu'elle mène au déchirement douloureux mais parfois libérateur. Pourquoi l'être se retrouve-t-il dans une situation d'ambivalence ?

Il est difficile de répondre à cette question sans préciser le domaine d'étude comme la philosophie, la psychanalyse, la sociologie ou la littérature. «Emprunté de l'allemand Ambivalenz, composé du latin ambo 'tous les deux' et valence du bas latin valentia 'puissance, valeur' caractère de ce qui est ambivalent. L'ambivalence d'un mot, d'une expression, d'une attitude. ${ }^{177}$ En psychanalyse, ce terme a été introduit en 1910 par le psychiatre suisse Eugen Bleuler, connu pour avoir ajouté dans le vocabulaire psychiatrique les termes de «schizophrénie » et «d'autisme. »

On reconnaît l'ambivalence dans trois secteurs de la vie psychique ; deux volontés qui s'opposent, affirmation d'une thèse et de son contraire et enfin aimer et haïr simultanément la même personne. Mais finalement on n’a gardé que la manifestation dans ce troisième cas, sphère affective de la vie psychique. ${ }^{178}$

Plus tard le terme « ambivalence » a été repris par Freud pour justifier l'existence de deux sentiments ou comportements opposés tels que l'amour et la haine en donnant plus d'importance dans son étude au conflit d'ambivalence, ce qui « contribuerait au développement de sentiment de culpabilité et du besoin de réparer l'objet que l'on a

\footnotetext{
177 «Ambivalence. » Centre national des ressources textuelles et lexicales. 18 octobre 2012. $<$ http://www.cnrtl.fr/definition/academie9/ambivalence>.

${ }^{178}$ Encyclopaedia Universalis. 18 octobre 2012. <http://www.universalis.fr/encyclopedie/ambivalencepsychanalyse/>.
} 
voulu endommager.» ${ }^{179}$ Freud conclut que si des sentiments opposés coexistent, alors l'un est dans le conscient et l'autre dans l'inconscient.

Ce phénomène reflète souvent l'incertitude, la mise en doute et les paradoxes de l'être qui, « incapable de savoir certainement et d'ignorer absolument, » ${ }^{180}$ cherche à acquérir deux objets opposés, ou à avoir deux idées ou pensées, deux valeurs, deux états de conscience avec des motivations contraires ou inconciliables. L'envie de réunir thèse et antithèse dans un même concept n'est pas toujours une tâche facile et peut paraître impossible. Or l'ambition de l'homme, l'évolution de l'existence et ses vicissitudes, les changements des événements fait que l'être peut avoir des désirs, des aspirations et des tendances qui s'opposent. L'ambivalence, cette « double valeur simultanée positive et négative, d'une même tendance qui se présente à la conscience ou se manifeste dans la conduite, sous l'aspect de deux composantes opposées, » ${ }^{181}$ semble être une caractéristique commune de Green et de Camus qu'ils infusent dans certains de leurs protagonistes tels que Philippe, Éliane et Clamence qui confirme : «Mon métier est double, voilà tout, comme la créature. $»^{182}$

En littérature, l'ambivalence apparaît dès l'époque des épopées et plus tard des romans précieux, lorsque le héros est déchiré entre l'amour et le devoir. Céline Mathew

\footnotetext{
${ }^{179}$ Bénédicte Vidaillet, Véronique d'Estaintot, Philipppe Abecassis, La Décision (Bruxelles: De Boeck Université, 2005) 95.

${ }^{180}$ Blaise Pascal, Pensées cité par Claude Genet, Pensées Pascal (Paris: Hatier, 1993) 32.

${ }^{181}$ Juliette Favez-Boutonier, La Notion d'ambivalence. Étude critique, valeur séméiologique (Paris: L'Harmattan, 2004) 64.

${ }^{182}$ Camus, Euvres complètes: Théâtre 1480.
} 
constate en 1984 que peu d'ouvrages ont été écrits sur l'ambivalence. ${ }^{183}$ D'ailleurs, «Chez Dostoïevski, devenu à la mode au lendemain de la guerre, c'était l'ambivalence des sentiments, la présentation de héros capables de tout le mal et de tout le bien, le divorce entre les actes commis et la nature de celui qui les avait commis qui accaparait l'attention. ${ }^{184}$

L'étude de l'ambivalence de Philippe, d'Éliane et de Clamence est fortement liée à celle de leurs créateurs respectifs. En commençant par le protagoniste et en remontant vers l'auteur, on aura ainsi cerné le problème de l'ambivalence grâce au journal et à la biographie de l'auteur y compris son espace de création afin de mieux comprendre son fantasme de créateur. À partir de ce moment-là il devient très difficile de dissocier le réel et l'imaginaire puisque le lecteur accède enfin au conscient et à l'inconscient de l'auteur, à la réalité physique et à la réalité «psychique » que l'auteur déverse dans son œuvre sans être toujours clairvoyant. Green, conscient de sa dualité, écrit dans son journal :

[...] il y a le croyant d'un côté et le romancier de l'autre. Le croyant parle dans son journal et se penche par-dessus l'épaule du romancier. À partir de Mö̈ra seulement, il y a eu les premiers éléments d'une rencontre. Dans l'Ennemi, l'union s'est faite. ${ }^{185}$

Green comme Camus avait emprunté à la littérature russe l'ambivalence que l'on reconnaît surtout chez Dostoïevski. Dans une lettre à une amie, ce dernier qui se

\footnotetext{
${ }^{183}$ Celine Mathew, Ambivalence and Irony in the Works of Joseph Roth (NewYork: Peter Lang, 1981).

184 «Ambivalence, » Centre national des ressources textuelles et lexicales. <http://www.cnrtl.fr/definition/ambivalence>.

${ }^{185}$ Green, Euvres IV 1412. On retrouve souvent des thèmes dans l'œuvre qui ne sont pas abordés dans le journal.
} 
proclame « enfant de l'incroyance et du doute » lui confesse qu' « il se reprochait d'avoir professé des idées auxquelles il n'adhérait pas profondément. » ${ }^{186}$ En fait, le cas de Green et de Camus est semblable, dans un sens, à celui de leur précurseur. Leurs actions et leurs convictions ne sont pas toujours en harmonie. Le problème d'ambivalence au centre de l'œuvre de Green et de Camus remonte à leur origine et à leur identité. Le premier est américain, adopte le français comme langue véhiculaire qui lui permet d'exprimer au mieux ses sentiments, refuse la nationalité française lorsqu'on la lui a offerte mais vit comme un Parisien dont l'âme est exilée quelque part dans son «paradis perdu. »

Le Sud des États-Unis est le seul vrai pays que Green reconnaisse comme patrie, la patrie-mère car l'attachement à sa mère est indissociable de celui qu'il éprouve envers son pays perdu : «Pour l'exilé qu'il est, sans toujours le savoir (exilé d'une patrie disparue, le Sud), le monde se dédouble. » ${ }^{187}$ Cet attachement est encore plus profond que l'amour de la patrie, car il s'enracine dans le conscient et le subconscient de Green et affecte son comportement, ses convictions et ses désirs : «La religion de ma mère était anglaise et par conséquent toute la religion devait l'être aussi. » ${ }^{188}$ Cependant après la disparition de sa mère, il abandonne la religion anglicane de sa mère et abjure le protestantisme. Obstiné et convaincu que tout ce qui se rattache à sa mère est vrai et le reste est trompeur, il déclare dans son journal à l'époque où il se trouvait aux États-Unis:

\footnotetext{
186 Sturm 25.

${ }^{187}$ Petit, Green 20.

${ }^{188}$ Green, Euvres V 666.
} 
«Si attaché que je fusse à la France, je me rendis compte qu'une partie de moi-même n'avait d'autre origine que la terre où je me trouvais maintenant. » ${ }^{189}$

Dans Partir avant le Jour, Green écrit en évoquant son enfance et les moments heureux qu'il passait :

[...] étendu sur les genoux de sa mère, nu et à plat ventre. Je me sens heureux de ce bonheur confus que j'ai éprouvé tant de fois par la suite, alors qu'à la douleur dont j' ai parlé (était-ce avant ce jour-là, ou le même jour et quelques minutes auparavant ?) se sont mêlés de l'effroi et une sorte d'horreur. ${ }^{190}$

Ces moments de bonheur sont teintés de tristesse et d'horreur. Une horreur qui l'a entouré pour ne plus jamais le quitter le jour où il atteint son conscient et réalise qu'il existe et «qu'on est soi-même et non ce qui nous entoure [...] Certes, je fus heureux par la suite, mais non comme je l'étais auparavant, dans l'Éden d'où nous sommes chassés par l'ange fulgurant qui s'appelle Moi. » ${ }^{191}$

Ce changement d'état d'esprit a brusquement poussé Green à se séparer du reste du monde. Avec la même spontanéité Philippe réagit lorsque sa belle-sœur quitte le domicile pour aller s'installer dans une pension. Il eut d'abord des instants d'ennui puis comme toujours il jette un regard sur l'un des miroirs qui orne sa maison, qui le rassure et le rend heureux, mais ce sentiment de confort se dissipe aussitôt avec les bruits des sabots

${ }^{189}$ Green, Euvres V 1047.

${ }^{190}$ Green, Euvres V 649.

${ }^{191}$ Green, Euvres V 658. 
de chevaux qu'il entend dans les rues de Paris : «Par un brusque retour de son esprit, il se jugeait vain, inutile. ${ }^{192}$

Philippe change d'état d'âme depuis qu'il a pris conscience de sa lâcheté et de son impuissance. Il est tantôt heureux et tantôt triste « tantôt farouche et batailleur, tantôt sensible et travaillé d'un grand souci. ${ }^{193}$ Contrairement au reste des protagonistes greeniens, Philippe ne prend aucune initiative, car il ne fait qu'exister dans la vacuité. Son ambivalence est différente de celle de Joseph Day, par exemple, qui est en permanence tiraillé entre la spiritualité et le plaisir inconscient de la chair. L'ambivalence de Philippe se résume dans le doute et l'incertitude de ses convictions par rapport à son image et l'ignorance de sa propre essence. Narcissique et vaniteux, sa vie se réduit à l'errance physique et émotionnelle.

Épaves ne présente pas la même violence qui caractérise le reste de l'œuvre greenienne et même le dialogue finit par s'effondrer dans le silence. Chacun des acteurs cache un secret et ne peut le divulguer à l'autre. L'ambivalence dans Épaves est nourrie par un enchevêtrement d'émotions et de relations personnelles complexes. L'amour, la jalousie, la haine, la pitié, la vanité et l'indifférence, font partie du quotidien dans cette famille bourgeoise. Même si la violence physique n'est pas présente dans Épaves, elle existe de manière subtile dans la lettre d'aveu d'Éliane, dans les intentions de Philippe

\footnotetext{
${ }^{192}$ Green, Euvres II 112.

${ }^{193}$ Green, CEuvres II 116.
} 
d'effrayer son fils (scène de la cave), dans la suggestion du suicide d'Henriette (scène du balcon) et dans le rire hystérique de cette dernière.

La relation de Camus avec sa mère n'est guère différente de celle de Green. Présente par son physique et absente par son silence, elle crée chez le petit Albert la même frustration que vit le nourrisson vis-à-vis du sein maternel. Mais il arrive que parfois « [le] silence les unit, comme un secret. ${ }^{194}$ Dénué de l'affection paternelle et confus quant à l'affection maternelle, il lui arrive parfois d'éprouver de la honte envers sa mère et aussi « la honte d'avoir honte. ${ }^{195}$ Sa présence à l'école lors de la distribution des prix le dérange à cause des habits qu'elle porte et qui laisse voir sa misère. En 1935, il écrit dans la première page de Carnets : «le sentiment bizarre que le fils porte à sa mère constitue toute sa sensibilité. Les manifestations de cette sensibilité dans les domaines les plus divers s'expliquent suffisamment par le souvenir latent, matériel de son enfance (une glu qui s'accroche à l'âme). » ${ }^{196}$

Dans la préface de l'un des premiers essais que le moraliste écrit à l'âge de vingtdeux ans, L'Envers et l'endroit, il note qu'il a mis « au centre de cette œuvre l'admirable silence d'une mère et l'effort d'un homme pour retrouver une justice ou un amour qui équilibre ce silence. » ${ }^{197}$ Ayant grandi dans un milieu où la « xénophobie affleure

\footnotetext{
194 Todd 46.

195 Todd 37.

${ }_{196}$ Camus Carnets I 15.

${ }^{197}$ Camus, CEuvres complètes: Essais 13.
} 
comme la solidarité, ${ }^{198}$ Camus se retrouve partagé entre un monde d'analphabètes constitué par sa famille, un monde d'instruits constitué par ses amis et ses professeurs et un monde de solitaires dont le moi est le seul acteur. L'œuvre de Camus s'est nourrie de discordances ou contradictions qui émanent de la vie même de l'auteur. Elle se complète dans «l'hésitation entre le bonheur simple et la grandeur, entre le désir de vivre au niveau sacré $[\ldots]$ et le refus d'abandonner l'homme ; obsession de la vérité et volonté d'indifférence devant l'impuissance à l'atteindre ; peur de la mort et amour passionné de la vie. »199

Pour démontrer l'ambivalence de l'attitude camusienne, citons cette définition de l'auteur lui-même : «Qu'est-ce que l'homme? Il est cette force qui finit toujours par balancer les tyrans et les Dieux. » ${ }^{200}$ Cette phrase explique l'état d'âme de Camus, le malaise qui l'a déchiré toute sa vie depuis le jour où il a pris conscience de l'absurde qui régit le monde et crée le malheur des hommes. Ses origines espagnoles viennent s'ajouter à son problème d'identité qui, selon certains spécialistes de l'ambivalence romanesque, est à l'origine de l'ambivalence elle-même.

Dans les premières années où Camus se confiait dans Carnets, que l'on peut considérer comme son journal intime, les descriptions de l'Algérie et de ses paysages ressemblent à des poèmes que l'on écrit à sa bien-aimée :

\footnotetext{
198 Todd 27.

${ }^{199}$ Camus, Euvres complètes: Essais 1171.

200 Albert Camus, Lettres à un ami allemand (Paris: Gallimard, 1972) 39.
} 
Le printemps à Paris : une promesse ou un bouton de marronnier et le cœur chavire. À Alger, le passage est le plus brusque. Ce n'est pas un bouton de rose. C'est mille roses qui, un matin, nous suffoquent. Et ce n'est pas la qualité subtile d'une émotion qui nous traverse, mais l'énorme et dénombrable afflux de mille parfums et mille couleurs éclatants. Ce n'est pas la sensibilité qui s'affirme mais le corps qui subit un assaut. ${ }^{201}$

Plus tard, les marronniers disparaissent et il ne reste qu' « un gourbi et une silhouette frileuse » et les boutons de rose se transforment en «corbeaux » le tout dans une « angoisse. » ${ }^{202}$

Camus est «ambivalent comme l'écrasante majorité de ceux qu'on appelle pieds noirs, » ${ }^{203}$ qui ressentent un malaise qui croît chaque jour. Certains refusent que les choses risquent de changer alors que d'autres plus lucides, comme Camus, se rendent à l'évidence qu'une fin prévisible est imminente. En 1958, Camus écrit : «Le matin l'Algérie m'obsède. Trop tard, trop tard [...] ma terre perdue, je ne vaudrais plus rien. ${ }^{204}$ Des mots de détresse dans une voix désespérée et une âme qui est déchirée.

Le problème d'identité de Camus est évidemment lié entre autre à l'ambivalence œdipienne. Il n'a pas connu son père et comme figure paternelle il a ses oncles, son maître Louis Germain et plus tard son professeur Jean Grenier, avec qui il a noué une grande amitié et qui a eu une profonde influence sur lui. Ces figures ont contribué à forger un «Moi » ambivalent, voire «polyvalent.» Ce moi fut complété par ses auteurs préférés, Dostoïevski, Kafka, Gide, Proust, Nietzsche, Kierkegaard et Malraux.

\footnotetext{
${ }^{201}$ Camus, Carnets I 176.

202 Camus, Carnets I 149.

203 Todd 44.

${ }^{204}$ Camus, Carnets III 235.
} 
Cependant ses lectures ne l'ont pas aidé à se placer de façon absolue ni du côté de saint Augustin ni du côté de Hegel, choix qui lui était impossible. La lecture de Crime et châtiment de Dostoïevski, figure du père par excellence, avait de surcroît remis en cause ses certitudes : «doute absolu sur ma vocation, » écrit-il dans Carnets, «j'examine sérieusement la possibilité de renoncer.» ${ }^{205}$

Camus aimait jouer de temps en temps ses personnages au théâtre. Le rôle d'Ivan Karamazov $^{206}$ fut une chance de vivre un réel tant espéré. Il l'a révélé lui-même dans une interview : «J'ai aimé par-dessus tout Ivan Karamazov. Je le jouais peut-être mal, mais il me semblait le comprendre parfaitement. Je m'exprimais directement en le jouant. » ${ }^{207}$

La critique a souvent reproché à Camus de ne pas inclure les Arabes dans ses œuvres. Comment peut-il défendre la cause des Arabes alors qu'ils sont presque absents dans ses œuvres ? Mis à part l'Arabe, personnage anonyme, qui se fait tuer dans L'Étranger et Saïd à qui l'auteur donne un rôle d'assassin dans L'Exil et le royaume, les Arabes ne font pas partie du monde fictif de Camus et par conséquent de sa réalité psychique. On peut imaginer que Camus vise un lecteur francophone lettré, alors qu'à son époque, la grande majorité des autochtones n'avaient pas accès à l'éducation. Dans la biographie de Camus, Olivier Todd confirme que dans « la classe du cours moyen deuxième année dirigée par Germain, il y a trois Arabes sur trente-trois élèves.» ${ }^{208}$

\footnotetext{
${ }^{205}$ Camus, Carnets III 194.

${ }^{206}$ Le héros de la pièce de Dostoïevski, Les Possédés, qu'il avait adapté pour le théâtre.

207 Alain Costes, Albert Camus et la parole manquante (Paris: Payot, 1973) 28.

208 Todd 31.
} 
Néanmoins dans sa littérature engagée, Camus consacre quelques articles ${ }^{209}$ dans Chroniques algériennes à la misère et la famine chez les Kabyles. Il décrit les faits « avec le minimum de mots pour qu'on ressente bien la détresse et l'absurdité d'une pareille situation. $»^{210}$ Le déchirement de l'Algérie est celui de Camus : «j’ai mal à l'Algérie, en ce moment, comme d'autres ont mal aux poumons, ${ }^{211}$ dit-il dans Lettre à un militant algérien et c'est aussi le déchirement de ses semblables, les Français d'Algérie, qui « sont les premières victimes ». De ce fait, être ambivalent devient une nature légitime car «qui pense au drame des rappelés, à la solitude des Français d'Algérie, à l'angoisse du peuple arabe ? ${ }^{212}$

Ambivalent aussi est ce refus de Camus de la guerre d'Algérie et du port des armes alors que lui-même a voulu s'engager dans l'armée. Cette tentative a échoué pour des raisons de santé. On peut cependant conclure que son antimilitarisme provient de son conscient alors que cette envie de s'engager peut être un désir de son psychisme ou son inconscient pour satisfaire ou venger un père absent à cause justement de la Première Guerre mondiale, et où il a succombé suite à des blessures. Une deuxième chance lui a été donnée pour assouvir ses désirs lorsqu'il s'est retrouvé à côté des résistants à combattre l'ennemi qui lui avait arraché son père.

\footnotetext{
${ }^{209}$ Plusieurs articles ont été publiés sur le sujet du 5 au 15 juin 1939 suite à un reportage initié par le quotidien Alger Républicain, qui regroupe des socialistes et des radicaux.

${ }^{210}$ Camus, Actuelles III 36.

${ }^{211}$ Camus, Actuelles III 125.

212 Camus, Actuelles III 134.
} 
La réaction de Camus vis-à-vis de la religion fait que le lecteur a du mal à comprendre de quel côté il se situe. Est-il vraiment athée comme il le prétendait ? Et pourtant, La Chute, de toutes ses œuvres, est celle qui transmet la parole salvatrice de Clamence. Du titre lui-même à la nouvelle fonction de Clamence, de prophète, de juge et de pénitent, en passant par son respect et son amour pour le Christ, Camus trompe le lecteur ou se moque de lui. La faute est son péché et le besoin de culpabilité est son salut. Il est aussi cet être égoïste et inhumain, un diable qui, en Afrique, a bu l'eau d'un agonisant et dont le but est de faire le plus de mal pour prouver qu'il domine.

À l'époque des troubles de l'Europe avec la popularité d'Hitler qui augmente chaque jour, Camus fut invité par son ami Fréminville à adhérer au communisme. À cette idée, il répond :

Si j'allais au communisme, et c'est possible, j'y mettrais dedans ma vitalité, mes moyens, mon intelligence, j'y mettrais tous mes talents, toute mon âme peut-être, pas tout mon cœur. Quelque chose de moi n'y serait pas [...] Ce n'est pas par respect de ce que je suis que je n'adhère pas. C'est par irrespect d'une œuvre noble, admirable. J'ai l'esprit de religion profondément ancré. Pour moi le communisme ne serait rien, s'il n'était pas une religion ... Adhérer, ce serait me forcer, me cacher ce qu'il y d'autre en moi. ${ }^{213}$

L'incertitude de Camus vis-à-vis de la religion, de la politique et même de son engagement ne fait que s'accentuer. Avec le temps, dans L'Envers et l'endroit, titre révélateur de l'ambivalence, Camus découvre ses cartes :

Pour moi, je sais que ma source est dans L'Envers et l'endroit, dans ce monde de pauvreté et de lumière où j'ai longtemps vécu et dont le

${ }^{213}$ Todd 68. 
souvenir me préserve encore des deux dangers contraires qui menacent tout artiste, le ressentiment et la satisfaction. ${ }^{214}$

Cette œuvre, que l'auteur écrit à l'âge de vingt-deux ans, définit déjà la philosophie et la devise de Camus. Il se veut rassembleur et non séparateur, évitant « la disjonction, la logique du $o u$ » et favorisant celle de «la conjonction du et, à jamais déchirée mais toujours recousue, entre les pôles extrêmes. » ${ }^{215}$

Tous deux, Green comme Camus, présentent une lucidité qui leur permet de trouver un juste milieu et d'échapper à la folie, à la révolte ou à la schizophrénie. Cette force de caractère, chacun la trouve dans ce qu'il lui donne une paix intérieure :

Pour corriger une indifférence naturelle, je fus placé à mi-distance de la misère et du soleil. La misère m'empêcha de croire que tout est bien sous le soleil et dans l'histoire; le soleil m'apprit que l'histoire n'est pas tout. Changer la vie, oui, mais non le monde dont je faisais ma divinité. C'est ainsi, sans doute que j'abordai cette carrière inconfortable où je suis, m'engageant avec innocence sur un fil d'équilibre où j'avance péniblement, sans être sûr d'atteindre le but. Autrement dit, je deviens un artiste, s'il est vrai qu'il n'est d'art sans refus ni consentement. ${ }^{216}$

Il faut reconnaître que la situation de Camus n'est pas enviable, du fait de son statut social et des problèmes que subit sa patrie. Colonisateur et colonisé, vivant parmi les chrétiens et les musulmans, il sent en lui un métissage non racial mais émotionnel, culturel et social qui lui colle à la peau jusqu'à la fin de ses jours, une dualité qu'il qualifie de condition humaine face ; à laquelle, il est étranger, révolté contre le

\footnotetext{
${ }^{214}$ Camus, Euvres complètes: Essais 6.

215 Jean François Mattéi, Albert Camus du refus au consentement (Paris: Presse Universitaire de France, 2011) 11.

${ }^{216}$ Camus, Euvres complètes: Essais 6.
} 
malentendu que provoque la justice ou l'injustice en lui. Être juste « c'était une peine et un malheur.» ${ }^{217}$

Dans Journal II Green fait allusion à cette ambivalence en affirmant : « Il faut que la lumière se rue dans l'ombre et que l'ombre se jette sur la lumière pour l'éteindre, mais c'est en nous que cela se passe. Extérieurement rien ne bouge, rien n'est changé. » ${ }^{218}$ Green est conscient de son ambivalence mais il n'y peut rien. Sa seule planche de salut est l'écriture qui lui permet de contrôler sa vie de rêve plus que sa vie réelle. Cette échappatoire lui est vitale pour atténuer le danger qui le menace : «J'ai essayé de retrouver un équilibre de plus en plus menacé par la dualité de ma nature $»^{219}$

Selon la seconde topique élaborée par le psychanalyste Sigmund Freud en 1924, le schéma explicatif du fonctionnement de l'esprit humain est représenté par trois éléments: «moi-ça (névroses de transfert), moi-surmoi (névroses narcissiques), moimonde extérieur (psychoses). » Selon ce modèle, Clamence est à la fois le Moi et le Surmoi, élément de la structure psychique qui selon Freud «joue, à l'égard du moi, le rôle de modèle idéal, de juge, de censeur en opposition aux désirs, aux pulsions. » ${ }^{220}$ Le moi, c'est ce jeune avocat des pauvres qui succombe à ses désirs et à ses pulsions alors que ce juge, exaspéré par l'égoïsme et la vanité des hommes, est dominé par « le surmoi

\footnotetext{
${ }^{217}$ Camus, Euvres complètes: Essais 11.

${ }^{218}$ Green, Euvres V 96.

${ }^{219}$ Green, Journal II 262.

220 «Surmoi, » Centre national de ressources lexicales et textuelles. <http://www.cnrtl.fr/definition/surmoi>.
} 
qui s'est tellement détaché du ça égoïste pour obéir à une obligation morale. » ${ }^{221}$

Philippe, quant à lui, est souvent représenté par le moi : vaniteux, orgueilleux et narcissique, il s'assure toujours que son image est impeccable. De temps en temps, tout au long de l'œuvre, il vit des moments de lucidité brefs qui lui permettent de voir son vrai visage et alors le surmoi entre en jeu pour le torturer. Par rapport à quoi Philippe et Clamence sont-ils ambivalents? Ils le sont en raison du problème de l'unité de l'homme, de la justice et de la condition humaine, face à la soumission aux normes et aux lois et le désir d'affirmer leur vraie nature, leur différence et leur individualité.

Philippe et Clamence sont tiraillés entre le désir d'affirmer la vie et celui de lui tourner le dos, mais le choix n'est pas toujours évident. Alors, ils continuent à vivre avec cette pathologie qu'est leur lâcheté et impuissance sans jamais pouvoir prendre de décision. Philippe et Clamence sont des « Narcisses » selon la formule de Joachim Gasquet: «Le monde est un immense Narcisse en train de se penser. » ${ }^{222}$

La force de l'œuvre de Green et de Camus, malgré les paradoxes qui les déchirent l'un et l'autre, réside dans leur motivation et acharnement pour trouver un équilibre en dépit de leurs contradictions.

\footnotetext{
221 «Surmoi, » Centre national de ressources lexicales et textuelles. <http://www.cnrtl.fr/définition/surmoi.>

${ }^{222}$ Cette citation qui apparaît à la page 45 du roman Narcisse de Joachim Gasquet, est citée par Bachelard dans L'Eau et les rêves. Bachelard 35.
} 


\section{Chapitre 3: La peur et l'obsession de la mort}

La mort a suscité maints discours aussi bien théologiques que philosophiques. Elle est récurrente dans tous les genres littéraires, tels que pièces de théâtre, essais, épopées, tragédies, récits légendaires, oraisons funèbres, romans, nouvelles, textes fictionnels ou poétiques. Bien que ses causes, ses manifestations, ses symboles diffèrent, le résultat est le même.

Dans la mythologie, elle a souvent été représentée comme un personnage fictif sous la forme squelettique d'une femme parfois vêtue d'un grand manteau à capuche. ${ }^{223}$ Dans le folklore occidental moderne on la surnomme «la grande faucheuse. » À une époque où la peste noire produisait des dégâts inestimables, la faucheuse était représentée sous sa forme la plus terrifiante, venue faucher les vivants d'un coup de lame.

«Ce que je hais, c'est la mort et le mal ${ }^{224}$ disait Camus. Quant à lui, Green écrit : «En y réfléchissant, j’ai constaté que la plus importune de mes phobies, et la plus persécutante est celle de la mort. Elle est dans tous mes livres [...] J'aborde enfin le sujet qui m'attire, me fascine et m'épouvante. C'est l'obsédé qui se jette dans l'abîme qu'il redoute.» ${ }^{25}$

Le refus de la mort, telle a été l'attitude de Green et de Camus. Ce dernier a été confronté à la mort dès son jeune âge puisqu'il a perdu son père à la bataille de la Marne

\footnotetext{
223 « La Mort. » 13 mars 2010. < http://fr.wikipedia.org/wiki/La_Mort_(mythologie)>.

${ }^{224}$ Camus, Peste 199.

${ }^{225}$ Green, Journal I 134.
} 
pendant la Première Guerre mondiale. La mort l'a privé de l'amour paternel dont la présence aurait pu combler le silence de sa mère et lui aurait permis d'échapper à l'autorité de sa grand-mère.

Confronté à la maladie très jeune, la mort n'a cessé de rôder autour de Camus. Il s'est rendu compte alors qu'il s'attachait à la vie avec acharnement. Le fantôme de la mort le suit partout où il va. En 1936, la guerre civile espagnole et les victimes qu'elle a engendrés a traumatisé Camus. En France, Camus retrouve ce même fantôme, en 1943, puisqu'il est encore une fois témoin des massacres commis par les Allemands ou plutôt les nazis. Camus déverse alors tout le sentiment d'injustice qu'il éprouvait face à ce conflit dans Lettres à un ami allemand. De 1945 à 1960, il est témoin des massacres des Arabes en Algérie, dont Clamence parle dans La Chute sous forme de confessions. Dans ses œuvres, il mentionne différentes causes de la mort. Il y a les fléaux tels que la peste, les guerres qui tuent, les sociétés, les meurtres, la peine de mort et le suicide ou la mort volontaire.

Camus aurait très bien pu choisir comme titre de l'œuvre qui lui a valu le prix Nobel «La Mort » puisqu'elle sert d'arrière-plan à l'œuvre ; de la mort de la jeune femme qui se jette dans la Seine jusqu'à la fin de l'œuvre où Clamence est en attente de la mort pour le soulager. De même Green n'a pas laissé cette occasion lui passer entre les doigts. L'image du chant du faucheur dans sa nouvelle Les Clefs de la mort représente la mort qui, comme son nom l'indique, est le thème principal de l'œuvre. 
Mais l'évocation la plus puissante et originale de la personnification de la mort se trouve dans le portrait de madame Pauque dans Le Malfaiteur. Il note :

On la voyait dans les couloirs, le visage tendu, la bouche pleine d'épingles et les bras chargés de papiers, allant vers sa mission avec une inébranlable foi dans les vertus du camphre et de la naphtaline. Tout cédait sur son passage. Elle entrait où elle voulait avec la liberté dont n'use que la mort. De sa main longue et sèche, elle plongeait au fond des armoires pour en tirer les vêtements sur lesquels son zèle allait s'exercer, et sur le tapis couvert de papier, étendait les robes, les manteaux et les pardessus, inertes victimes qu'elle s'apprêtait à ensevelir selon les rites fastueux. Avec une précision savante, elle laissait tomber dans les plis de la serge la mystique pincée de poudre qui sauve les tissus de la corruption. Cette cérémonie s'accomplit dans un profond silence, troublé seulement par le léger cliquetis des chaînes qui ornaient la poitrine de Mme Pauque et de temps en temps par un murmure de satisfaction annonçant que le salut d'un complet ou d'un manteau venait d'être assuré $[\ldots]{ }^{226}$

Précisons que ces deux auteurs n'ont jamais manqué de réserver une scène de mort ou plusieurs dans leurs œuvres. En fait le sujet tourne à l'obsession. Dans la pièce que Camus a écrite et qui porte le nom du protagoniste, Caligula, l'empereur de Rome a tellement été touché par la mort de sa sœur Drusila que cette rencontre avec la mort d'un être cher l'a foudroyé en lui faisant perdre la raison. «Les choses telles qu'elles sont, ne sont pas satisfaisantes. Ce monde tel qu'il est fait n'est pas supportable. J'ai besoin de l'immortalité, » ${ }^{227}$ disait-il dans son désarroi.

\footnotetext{
${ }^{226}$ Julien Green, Euvres complètes III. Éd. Jacques Petit. Bibliothèque de la Péliade. (Paris: Gallimard, 1973) 272.

227 Albert Camus, Caligula suivi de Le malentendu (Paris: Gallimard, 1958) 25.
} 
Caligula cherche à rendre l'impossible or il bouleverse tout son monde, il veut non seulement égaler les dieux mais les dépasser afin d'aboutir à un seul but : éliminer la mort et changer le destin. Il crie :

Ma volonté est de le changer. Je ferai à ce siècle le don de l'égalité. Et lorsque tout sera aplani, l'impossible enfin sur terre, la lune dans mes mains, alors, peut-être, moi-même je serai transformé et le monde avec moi, alors enfin les hommes ne mourront pas et ils seront heureux. ${ }^{228}$

Dans cette pièce publiée en 1944, Camus envisageait de l'intituler Caligula ou le sens de la mort. La mort est inévitable et invincible, Caligula a beau être empereur, car il n'a aucun pouvoir qui lui permette de vaincre la mort. Alors, il s'abandonne à celle-ci de manière inéluctable, puisque tout homme est amené à périr.

Pour Green, comme pour Caligula, la prise de conscience de la mort a changé sa vie. Depuis la mort de sa mère, il est devenu obsédé par le sujet qui fait partie de l'ensemble des thèmes les plus présents dans son œuvre. Dans son autobiographie Partir avant le jour, il note : «Au bonheur d'être en vie s'allie la détresse de se savoir mortel. ». ${ }^{229}$ Green était plus heureux lorsqu'il était jeune avant d'être « chassés par l'ange fulgurant qui s'appelle Moi. » ${ }^{230}$ Il a perdu l'être qui lui était le plus cher au monde, sa mère, alors qu'il avait à peine quatorze ans : «Dehors, tout était immobile, tout était mort $[\ldots]$ et moi-même comme un personnage dans un tableau. ${ }^{231} \mathrm{Ce}$ moment-là coïncide avec la fin de l'âge d'or pour l'auteur. Que ce soit dans son journal

\footnotetext{
${ }^{228}$ Camus, Caligula 40.

${ }^{229}$ Green, Euvres V 696.

${ }^{230}$ Green, Euvres V 658.

${ }^{231}$ Green, Euvres V 795.
} 
ou dans son autobiographie il lie toujours le sujet de la mort de sa mère à celui de l'amour. Emily, l'héroïne du roman Mont-Cinère, a eu la même réaction que son créateur. Lorsqu'elle apprit la nouvelle de la mort de sa grand-mère « elle demeura immobile. » ${ }^{232}$ La mort triomphe de Green ainsi que de ses protagonistes puisqu'ils sombrent tous « dans le désespoir. » ${ }^{233}$

À cette époque l'auteur prend conscience de sa propre existence mais aussi de l'existence de la mort qui vient perturber son calme intérieur et installer une mélancolie qui n’a jamais pu se dissiper. Dans son autobiographie, il note : « Alors qu'il est parfois si triste de voir les années s'enfuir, je ne sais pourquoi j'éprouve à me replonger dans mon enfance un bonheur sans trace de mélancolie. La mort n'existait pas encore. ${ }^{234}$ Après la mort de sa mère, Green découvre le péché et le plaisir. Alors la mort prend un sens complètement différent. Avant ce jour-là, elle représentait le passage au paradis. Il écrit dans son journal : « À quoi bon regretter les ombres de cette terre ? Il faut penser avec courage, avec espoir, à la mort, au grand pays lumineux qui s'étend au-delà de la porte noire. ${ }^{235}$ Cette idée nous permet précisément de comprendre la réaction de Philippe lorsqu'il a plongé sa main dans la Seine pour simuler le suicide. À ce momentlà, il pensait comme Green, l'eau et la mort vont l'arracher des méandres de l'existence et lui apporter peut-être un bonheur qu'il n'a jamais connu. Mais plus tard il se rend

\footnotetext{
${ }^{232}$ Green, Euvres I 208.

${ }^{233}$ Green, Euvres V 795.

${ }^{234}$ Green, CEuvres V 659.

${ }^{235}$ Green, Journal I 377.
} 
compte que ce paradis est perdu à jamais, il découvre qu'il est mortel : «J'étais furieux de découvrir que je n'étais pas un saint » et que « La mort est le salaire du péché.» ${ }^{236}$ C'est cette fureur qui déclenche la violence qui est présentée dans l'œuvre greenienne.

Toute la philosophie camusienne est bâtie sur deux concepts essentiels qui souvent sont étroitement liés à la notion de la mort : la révolte et l'absurde. Chez Camus, tout ce qui mène à l'absurde déclenche une révolte, un désespoir ou un espoir. La mort occupe une place importante dans la perspective de l'absurde et elle représente une thématique omniprésente dans ses œuvres. On se suicide pour échapper à l'absurde. On tue parce qu'on est révolté et aussi pour éviter de tomber dans l'absurde.

Camus disait qu'il avait trop de jeunesse en lui pour être capable de parler de la mort, et pourtant il en parle presque dans toutes ses œuvres. Il est même hanté par la mort, comme tout philosophe qui la craint et la redoute. La hantise des philosophes grecs de la Grèce antique est de tout autre genre et contraire à celle de Camus. Par exemple, Lucrèce s'arme d'une philosophie argumentative pour dénoncer cette menace alors que Montaigne, pour vaincre sa peur imagine les divers exercices permettant de l'apprivoiser tels que le refoulement. Platon et Hegel pensent qu'ils peuvent vaincre la mort en accédant à l'immortalité alors que Socrate l'envisageait comme solution à la vie.

Les images de la mort, Camus les décrit de différentes façons. Dans La Peste, on assiste à la mort douloureuse du fils du juge Othon et à la tentative de suicide de Cottard ; dans Lettres à un ami allemand : à la condamnation et à l'exécution des résistants ; dans

${ }^{236}$ Petit 65. 
Caligula; à la mort de la femme aimée Drusila et à l'assassinat de Caesonia ; dans Les Justes : au sacrifice de Kaliyev. Dans L'Étranger, le meurtre de l'Arabe par Meursault et sa propre exécution, ainsi que l'assassinat de Jan par sa mère et sa sœur dans $L e$ Malentendu sont encore les sujets principaux de ces œuvres. Ces événements douloureux invoquent les mille visages de la mort.

Si la mort tient une place importante dans les œuvres de Camus, c'est pour exprimer et clarifier sa pensée sur le sujet. Il condamne le meurtre individuel et collectif, le suicide ainsi que l'absurde et la violence. La mort est l'ennemi commun des hommes. Dans Les Justes, Camus décrit le dilemme du révolté qui est amené à tuer et qui ne peut retrouver l'honneur que dans le sacrifice du bonheur, de l'amour et de sa propre vie. On retrouve le même sacrifice chez les héros de Green qui expriment leurs idées sur le bonheur et le plaisir. En tuant le personnage Moïra, dans le roman éponyme, Joseph Day, le personnage principal, tue le désir sexuel qui est en lui et qui l'éloigne $\mathrm{du} \ll$ paradis. »

Dans La Chute et Épaves la mort hante les personnages. Depuis qu'il a été témoin du suicide de la jeune femme, Clamence vit dans le spectre de la mort qui l'a mené à ne plus se reconnaître. C'est cette mort qui a donné naissance à sa conscience. Déchiré et désorienté, Clamence prononce les mots suivants : «Je mesurais les années qui me séparaient de ma fin. Je cherchais des exemples d'hommes de mon âge qui 
fussent déjà morts. » ${ }^{237}$ Incapable d'accepter l'idée de la fin, Clamence s'impose dans la vie par la parole. La mort a le même effet sur Philippe qui a tenté de se suicider afin de se libérer. Le parcours de ces personnages semble voué au malheur et leur chemin aboutir à la mort.

Dans Le Mythe de Sisyphe Camus définit clairement le cycle de l'absurde, sa relation avec le suicide ainsi que l'homme absurde. Sisyphe est l'homme absurde par excellence tout comme Don Juan. Ces personnages vivent des situations absurdes et récurrentes dont on ne voit jamais ni la fin ni l'aboutissement. Ils ne sont pas si différents de Philippe et Clamence qui adhèrent aux mêmes caractéristiques définies par Camus : «L'absurde, c'est l'homme tragique devant un miroir. » ${ }^{238}$ Le moraliste met l'accent sur la propriété fondamentale de l'homme qui est son intelligence et comment elle peut l'aider à changer sa situation. Le héros de l'absurde doit faire face à l'absurdité du quotidien et lui trouver un sens ou un but alors que le suicidaire ne voit aucun sens à la vie. Camus arrive à la conclusion que l'absurde est en même temps « conscience et refus.» ${ }^{239}$ Même si Sisyphe n'atteint jamais son but et ne pourra jamais rouler la pierre jusqu'au sommet de la montagne, seule la lutte vers le sommet suffit à le rendre heureux.

L'absurde chez Green se trouve chez ses héros angoissés par le non-sens de leur existence et de leur destinée. Dans Épaves Green écrit : «Dans ce monde dont la raison d'être nous échappe, chacun suit obscurément une destinée secrète qu'il ne connaîtra

\footnotetext{
${ }^{237}$ Camus, Euvres complètes: Théâtre 1521.

${ }^{238}$ Camus, Carnets II 94.

${ }^{239}$ Camus, Étranger 138.
} 
peut-être jamais. ${ }^{240}$ Les protagonistes greeniens essaient de changer leur destinée mais ils se rendent compte que parfois la mort est la seule solution. L'absurde représente aussi pour Green l'existence de deux mondes incompatibles : le monde des désirs défendus qui est du à son homosexualité et le monde spirituel. Cette coexistence crée un déchirement chez lui qu'il transmet à ses personnages. Tel est le cas de Philippe. Déjà dans les premières pages d'Épaves, Green parle de la vie monotone et parfois douloureuse d'Éliane qui, pleine d'espoir, ne peut changer sa condition. Amoureuse de son beau-frère dans le secret et le silence, elle n'a aucune emprise sur sa vie. Elle ne peut même pas dormir à cause de la lumière clignotante qui entre dans sa chambre la nuit : « Je vais essayer de m'endormir pendant les dix secondes d'obscurité ${ }^{241}$ se disait-elle. Elle pense se plaindre au gérant de l'immeuble en face, mais «l'autre » Éliane lui répond : «Si tu te plains, on retirera l'enseigne. Tu feras du tort à ces gens. » Après une brève réflexion, elle ajoute «Tort à ces gens, [...] Tant pis. Je m'habituerai. » ${ }^{242}$ Mais le mal finit par prendre le dessus sur elle au point où elle a même voulu tuer sa sœur. Elle demeure comme les autres personnages dans un «no man's land.»

Malgré une attitude ambivalente envers la mort, Green a toujours été un opposant à la peine de mort. Les guerres l'effraient, mais la guerre qui l'a traumatisé durant toute son enfance était la guerre de sécession, entre le Nord et le Sud, qu'il évoque dans son Journal par des histoires sombres. Green lie la violence, voire le meurtre, ou le suicide à

\footnotetext{
${ }^{240}$ Green, Euvres II 30.

${ }^{241}$ Green, CEuvres II 13.

${ }^{242}$ Green, CEuvres II 13.
} 
la sensualité. Ainsi, la mort est le seul moyen de changer le destin des hommes. Durant la période où il a écrit Épaves, Green rêvait d'un monde où le spectre de la mort et les tourments de l'homosexualité sont inexistants. Un monde qu'il a tant cherché et qu'il a tant espéré trouver. Un monde idéal « où les préoccupations d'ordre sexuel n'existeraient pas, parce que les souffrances qu'elles ne cessent d'engendrer me paraissaient hors de toute mesure ${ }^{243}$ étant donné que l'absence du plaisir entraîne l'absence du péché.

Le suicide l'autre forme de la mort et est très présent dans Épaves et La Chute. Les héros de Camus adoptent différents types de suicide : le suicide physique, le suicide spirituel et le suicide philosophique. Dans Le Mythe de Sisyphe, Camus parle de deux types de causes ; les causes apparentes et les causes cachées. Les causes apparentes sont souvent un chagrin intime ou une maladie incurable. Elles ne sont pas nécessairement les plus déterminantes chez les suicidés. Les causes cachées sont définies comme « l'absence de toute raison profonde de vivre, $»^{244}$ l'espoir de la mort qui transporte le suicidaire dans une meilleure vie ou situation. Marcel Mélançon appelle ces causes, les causes médiates par opposition aux causes immédiates, car elles sont éloignées du suicide. Elles représentent la lucidité face à l'existence et au monde et donc toute la réflexion qui prépare de loin un geste comme le suicide. L'existence de Dieu peut être une cause de suicide logique. Cette lucidité, André Alter l'associe à la passion de

\footnotetext{
${ }^{243}$ Green, Journal II 196.

${ }^{244}$ Camus, Mythe 20.
} 
Caligula. Pour remédier à ce fléau et accepter l'absurde, Camus nous demande de maintenir une conscience éveillée. Selon Camus, le suicide philosophique est « un jeu qui mène de la lucidité en face de l'existence à l'évasion hors de la lumière. $~^{245}$ Dans le Mythe de Sisyphe, il le décrit comme le problème philosophique le plus sérieux, et non pas un phénomène social comme il a toujours été traité. Pour une fois, Camus présente son opinion de manière explicite, il n'utilise plus le style descriptif ou narratif. Le « je juge » définit le ton de révolte, de persuasion et d'argumentation. Pour une fois le philosophe ne met plus de distance entre lui et son récit. « Juger que la vie vaut ou ne pas la peine d'être vécue ${ }^{246}$ est la question qui préoccupe Camus. Il essaie de trouver le sens que l'homme donne à la vie et pense que la réponse à cette question lui permet de comprendre pourquoi certains ont recours au suicide. Clamence se pose les mêmes questions mais n'a pas le courage de se suicider, alors il attend sa fin.

Le suicide est un acte prémédité, qui se prépare comme une action importante ou comme dit Camus « une grande œuvre. » Il cite deux façons de se suicider : « il tire ou il plonge. » Par ces deux courtes phrases, Camus nous explique que l'idée du suicide se développe dans la tête de la victime de façon progressive mais son exécution est très brève. On peut définir le cycle de vie du suicide de la manière suivante : l'absurde pousse à la germination de l'idée, qui est d'abord suivie d'un désespoir, qui aboutit au geste fatal.

\footnotetext{
${ }^{245}$ Camus, Mythe 19.

${ }^{246}$ Camus, Mythe 17.
} 
Lorsque Caligula demande à Héron s'il pense qu'il est fou, ce dernier lui répond : «Tu sais bien que je ne pense jamais. Je suis trop intelligent pour ça. » ${ }^{247}$ Selon l'auteur, il ne faut pas trop réfléchir lorsqu' on est devant l'absurde. Il faut l'accepter et continuer de vivre ou bien trouver le bonheur dans l'absurde comme Philippe qui, à la fin du roman, renonce provisoirement au suicide et préfère partir avec son fils qui représente l'avenir.

Chez Green, le personnage romanesque se suicide ou tente de se suicider après une longue réflexion. Il lui permet souvent le passage de l'état de détresse à l'état d'apaisement. Il sert de remède contre la souffrance du corps et de l'âme. Dans Le Visionnaire et Minuit, Green décrit cette mort comme la réponse à un cri ou à une longue attente : «Et derrière toutes les idées que je me suis faite de la mort, il y a celle-ci, qui est un reste d'enfance, c'est qu'en définitive la mort est le plus beau de tous les pays lointains. ${ }^{248}$ Dans Épaves, Philippe et Henriette ont été tentés par l'idée du suicide. Lorsqu'Henriette se penche vers la fenêtre, des souvenirs d'enfance heureuse lui reviennent et se mêlent à l'idée de la mort, alors toute trace de peur et de « terreur de mourir la quittée ${ }^{249}$ et un sentiment de nostalgie et de bonheur s'installe, un retour vers les pays lointains : «Elle était heureuse [...] Ainsi, la mort l'attirait doucement vers les belles régions incertaines qui tentent les âmes sans espoir.» ${ }^{250}$ De même Philippe était

\footnotetext{
${ }^{247}$ Camus, Caligula 25.

${ }^{248}$ Green, Journal I 207.

${ }^{249}$ Green, Euvres II 177.

${ }^{250}$ Green, Euvres II 177.
} 
fasciné par la Seine, car il l'associe au suicide qui le tentait et mourir pour lui c'était simplement un pas à faire en avant.

L'idée de la mort est pour Camus l'expression ultime de l'absurde et il n'y a que deux solutions qui nous permettent d'y échapper : mourir, donc se suicider ou espérer tout en continuant à vivre. Camus veut que l'on choisisse celle qui nous permette de vivre en acceptant avec lucidité l'absurdité de la vie. Alors que pour Mélançon, le suicide physique et le suicide philosophique sont des solutions à l'absurde, Camus démontre que l'homme absurde ne se suicide pas. Il prend conscience de l'absurde mais au lieu de se suicider, il accepte l'absurde, se révolte et vit même sans espoir, sans illusion, mais aussi sans résignation. L'obsession de Philippe et Clamence ne diffère pas de celle de Camus qui toute sa vie était préoccupé par sa jeunesse qui représentait le paradis perdu. Il aurait voulu arrêter le temps. La vieillesse pour lui c'était la mort. À la différence de Camus, Green préconise le suicide comme solution facile. Étant donné que la plupart de ses protagonistes sont lâches, le suicide est donc la solution qui répond à leurs problèmes. Dans Le Voyageur sur la terre, des femmes fantasment sur la mort de leur mari. De surcroît, il est intéressant de noter que dans les romans de Green, ceux qui meurent sont les moins importants. Ils sont décrits de manière grotesque de telle sorte que le lecteur n'éprouve aucune compassion ou sentiment de pitié envers eux. Il arrive aussi de découvrir que la mort dans les œuvres de Green n'est qu'un symbole d'extermination du mal et le mort représente le mal en soi. Malgré la violence criminelle le bouleverse comme quelque chose d'incompréhensible et il écrit sur la 
violence pour mieux la concevoir. Cependant, l'auteur use de son style de génie pour atténuer la brutalité des scènes meurtrières. Léviathan, le roman le plus sanglant de Green, peut être lu sans pour autant éprouver de la sympathie pour les victimes. Comment alors peut-on imaginer qu'un homme aussi calme, pacifiste et discret que Green puisse écrire des romans aussi barbares et cruels ?

Green et Camus n’ont jamais cessé de s’intéresser à la condition humaine, à la question de la vie tout en étant conscients de son absurdité. Camus est le philosophe qui a milité le plus pour que l'homme puisse vivre en conservant sa dignité. De par sa naissance et son génie particulier, il a essayé de comprendre et de répondre aux questions sans pour autant y arriver complètement car « Toute son œuvre oscille entre la pleine terre et la pleine mer. » ${ }^{251}$ Quant à Green, après sa crise religieuse temporaire, il est passé par une période d'intérêt pour les religions orientales et a été séduit par le bouddhisme. Il s'est alors intéressé au phénomène de la réincarnation en pensant qu'il allait abolir en quelque sorte les problèmes de la condition humaine et offrir aux hommes peut-être un moyen qui leur permettrait d'échapper à l'obscurité du monde : «J'en attends beaucoup, énormément même » ${ }^{252}$ insista-t-il dans Le Journal.

\footnotetext{
251 Albert Camus et Maurice Blanchot, Hommage à Albert Camus : 1913-1960 (Paris: Gallimard, 1967) 255.

${ }^{252}$ Green, Euvres II 1487.
} 


\section{Partie III : Déchirement et châtiment}

\section{Chapitre 1 : l'eau, le cri et le rire : Les symboles du déchirement}

L'homme est le seul animal qui rit.

Aristote

Parmi les quatre éléments qui contribuent à la formation de notre univers, l'eau est le symbole le plus complexe. Elle matérialise la vie mais aussi la mort. L'eau est un thème important. Elle est l'un des éléments du naufrage. Elle correspond à l'eau du baptême comme elle correspond à l'eau dont les flots portent les épaves. Elle peut être contradictoire : calme ou violente, pure ou boueuse, dormante ou courante. Elle a réveillé des émotions bien fortes chez les poètes qui en revanche ont écrit des vers à son sujet et inventé des métaphores pour mettre en évidence les émotions cachées ainsi que les secrets de l'être face à un événement qui perturbe le calme de sa vie. L'eau est un symbole à double sens ; elle symbolise la vie et la purification comme l'eau du baptême, mais aussi par son caractère insaisissable et fuyant, la mort.

Dans les deux œuvres que nous étudions, l'eau change plusieurs fois d'apparence et chaque image, sans être une illusion factice de l'imaginaire, nous renseigne sur l'état d'âme du protagoniste : «elle [l'eau] s'alourdit, s'enténèbre, s'approfondit, elle se 
matérialise.» ${ }^{253}$ Mystérieuse, elle joue le rôle du psychanalyste qui aide son patient à découvrir tout ce qui est refoulé dans son subconscient.

Une des caractéristiques d'Épaves et de La Chute est l'intérêt et le soin que donnent les auteurs au cadre du roman. Il semble que Paris et Amsterdam soient d'autant plus importants que les protagonistes et « [tout] lecteur est au moins sensible à la présence du fleuve qui domine. ${ }^{254}$ Épaves s'ouvre sur la promenade de Philippe qui le conduit directement vers la Seine par le pont d'Iéna. Clamence évite les ponts et surtout la nuit car «c'est la conséquence d'un vœu. » ${ }^{255}$ D'après Valérie Catelain, « [les] multiples facettes de Paris présentent en quelque sorte les composantes du moi, représentant fidèlement la complexité de la richesse intérieure et les questions métaphysiques qui l'édifient. » ${ }^{256}$

Que signifie donc l'eau pour Green et Camus ? En ont-ils la même vision? Comment réagissent Philippe et Clamence au contact de l'eau ?

L'ennui et la solitude que vit quotidiennement Philippe le poussent dans les rues de Paris où, accompagné de lui-même, il apprend à se découvrir à travers « la beauté du paysage » qui « devient l'écho de l'âme. » ${ }^{257}$ Green est obsédé par la Seine : « [toute] sa vie le fleuve l'avait attiré sans qu'il pût comprendre pourquoi. » ${ }^{258}$ La dernière

\footnotetext{
253 Bachelard 30.

254 Green, Euvres II 1311.

${ }^{255}$ Camus Cuvres complètes: Théâtre 1483.

${ }^{256}$ Valérie Catelain «Paris et Épaves écriture poétique et géographie de l'âme, » Mélanges de science religieuse LVIII, 3, juillet-sept. (2001): 88.

${ }^{257}$ Catelain 88.

${ }^{258}$ Green, Euvres II 1311.
} 
promenade de Philippe avec son fils Robert s'est déroulée sur les quais de la Seine pour la simple raison que, là, Philippe « se souvenait de plus de choses que dans les rues. Sa mémoire lui parlait sans fin de ce qu'il était jadis [...] Il y avait eu dans sa vie une époque où l'homme qu'il aurait pu être l'accompagnait de jour en jour.» ${ }^{259}$ À force d'écouter le bruit de l'eau, la Seine finit par lui parler : «Ainsi lorsque Philippe se promenait le long de la Seine, il avait quelque fois l'impression fugitive qu'elle lui parlait, et de le voir souvent là elle a fini par accueillir ses secrets. ${ }^{260}$ Bien que cette eau brumeuse lui apporte un réconfort, elle l'effraie : « [elle] réveilla en lui le souvenir des crimes racontés par les journaux et d'une vieille chanson sinistre que lui racontait sa bonne, autrefois. » ${ }^{261}$ Ainsi, Bachelard dans L'Eau et les rêves affirme que «l'eau anonyme sait tous mes secrets. Le même souvenir sort de toutes les fontaines.» ${ }^{262}$ L'effet de la Seine sur Clamence lui procure « un vaste sentiment de puissance ${ }^{263}$ et «d'achèvement.» De l'autre côté des frontières, Clamence déambule dans les rues d'Amsterdam lors de promenades répétées, accompagné d'un interlocuteur étrange qu'on ne voit pas et qu'on n'entend pas. Que représente cet inconnu pour Clamence ? Serait-il aussi l'homme qu'il aurait pu être ?

\footnotetext{
${ }^{259}$ Green, Euvres II 198.

${ }^{260}$ Green, Euvres II 199.

${ }^{261}$ Green, Euvres II 29.

${ }^{262}$ Bachelard 15.

${ }^{263}$ Camus, CEuvres complètes: Théâtres 1495.
} 
Rien d'étonnant dans ces deux récits, sachant la place qu'occupe l'eau chez Green et Camus. La présence de l'eau semble rassurer Camus et lui procurer une paix sereine. Dans Carnets, il ne manque pas de la citer à maintes reprises :

Mais pourquoi ne pas donner son nom aussi à cette envie que je me sens au cœur et à ce désir tumultueux qui me prend de retrouver le cœur impatient que j'avais à vingt ans. Mais je connais le remède. Je regarde longtemps la mer. ${ }^{264}$

L'effet de l'eau sur Philippe est aussi dramatique que sur Clamence. Ses contemplations de l'eau, ce miroir pur, fait tomber les masques d'un monde parfait pour dévoiler à Philippe le monde réel dont il est le seul spectateur : «Au bord de l'eau, il sentit vivement tout ce qu'il pouvait y avoir d'accessible au fond de son propre cœur. ${ }^{265}$ Alors dans ces moments de sublimation prend-il conscience de sa force ou de sa faiblesse ?

Dans les deux œuvres, que ce soit la Seine de Paris ou les canaux d'Amsterdam, l'eau est très présente. Elle suit les deux protagonistes qui semblent avoir une attirance magique pour cette eau trouble. Dans les deux œuvres, elle représente l'endroit du crime mais sa signification change tout au long du récit.

L'eau, la mer surtout, est un élément essentiel au bonheur de Camus. Lors de ses voyages, Camus a montré son hostilité envers les pays de l'Europe de l'Est et de l'Europe du Nord, mais les pays qui bordent la Méditerranée, tels que l'Italie et la Grèce

\footnotetext{
${ }^{264}$ Amélie Charcosset, Le Sentiment d'être à sa 'place' dans les Carnets d'Albert Camus. 2008, 08 août 2012. <http://fr.scribd.com/doc/108566545/44/L\%E2\%80\%99ecriture-douloureuse-la-tentation-durenoncement>.

${ }^{265}$ Green, Euvres II 30.
} 
sont ses préférés. Ailleurs il étouffe. Dans La Chute, tout en étant athée, Camus associe l'eau au concept religieux d'abord en comparant les canaux d'Amsterdam à l'enfer de Dante : «Je trône parmi mes vilains anges, à la cime du ciel hollandais, je regarde monter vers moi, sortant des brumes et de l'eau, la multitude du jugement dernier.» ${ }^{266}$ Ensuite, il fait référence au cri qui suit Clamence là où se trouve « l'eau amère de [son] baptême. ${ }^{267}$

La Seine pour Philippe est comme la mer Méditerranée pour Camus, car elle lui permet de s'y retrouver. Il se sent différent dès lors qu'elle est proche. Elle a ce pouvoir magique d'atténuer ses remords. Cette fusion avec l'eau de la Seine lui permet de retrouver et transformer l'image qu'il a de lui-même. Il devient conscient de l'inconscient. Il la consulte à chaque fois qu'il sent ce malaise nouveau qui perturbe la sérénité d'une vie calme et tranquille. La Seine, cette eau mystérieuse lui permet de découvrir qu'il y a une rupture entre ce qu'il est réellement et ce qu'il ressent et ce qu'il croit être.

Pendant des années Philippe n'a connu qu'une image positive de lui. Bien que la Seine lui permette de découvrir un nouveau visage plus sombre, elle lui procure en quelque sorte du bonheur. Elle devient comme une confidente sachant qu'il ne peut divulguer «sa faute» ou «son crime» à personne. La Seine, elle, ne le juge pas, elle lui offre son eau qui lui transmet le reflet de ce qu'il est. Là, il se transcende et se fond avec

\footnotetext{
${ }^{266}$ Camus, Euvres complètes: Théâtre 1549.

${ }^{267}$ Camus, Euvres complètes: Théâtre 1531.
} 
son double. Il « devinait alors cette présence merveilleuse, réglant ses pensées sur les siennes avec ferveur, afin de croire que la substitution s'était accomplie, et il passa de longues années dans un contentement intérieur. ${ }^{268}$ Si le miroir de sa demeure lui rend une image figée et stable qui le tient prisonnier, le reflet de l'eau est une image qui a une vie avec laquelle il peut communiquer. Narcisse communique avec Écho qui a la même voix et le même visage que lui. Comme Narcisse, Philippe découvre sur la surface de la Seine « la révélation de son identité et de sa dualité, la révélation de ses doubles puissances viriles et féminines, la révélation surtout de sa réalité et de son idéalité. » ${ }^{269}$ Cependant ce bonheur n'est pas éternel : le déchirement interne le ramène à la réalité de la vie et « le temps amena une certaine heure où la vérité se fit pressentir [...] l'homme qu'il devait être n'existait pas. ${ }^{270}$ L'espoir d'un avenir brillant s'efface et à ce momentlà, la Seine change de visage et apparaît comme « un gouffre noir, profond comme un océan », alors Philippe « contemple cette eau lourde et silencieuse. ${ }^{271}$

Après sa chute, Clamence se retrouve à Amsterdam, une ville saturée par les eaux. C'est aussi une ville de transit grâce à son port, un endroit idéal pour la nouvelle mission de Clamence. L'effet de la mer morte, perdue dans les brumes dans l'île du Zuyderzee, pousse Clamence à faire ses confessions à son interlocuteur : « Après m’être débattu, après avoir épuisé mes grands airs insolents, découragé par l'inutilité de mes efforts, je

\footnotetext{
${ }^{268}$ Green, Euvres II 199.

${ }^{269}$ Bachelard 33.

${ }^{270}$ Green, Euvres II 199.

${ }^{271}$ Green, Euvres II 23.
} 
décidai de quitter la société des hommes. ${ }^{272}$ Clamence aimait Paris car il y avait beaucoup à faire dans la ville lumière. D'abord il y avait son travail d'avocat qui n'était point séparé de ses actes de bon citoyen charitable, puis il y avait aussi le climat favorable pour courtiser les femmes et jouir de bons moments. En somme, une vie sociale vraiment idéale. Paris, « un vrai trompe-l'œil, un superbe décor habité par quatre millions de silhouettes $»^{273}$ était un endroit où il pouvait faire ce qu'il voulait sans remords ou conscience, qu'il a appris à redouter.

Le cri, si présent dans les deux œuvres, est une composante essentielle du déchirement. Ainsi Edward Munch parlant de son œuvre maîtresse nous confie :

J'étais en train de marcher le long de la route avec deux amis - le soleil se couchait - soudain le ciel devint rouge sang - j'ai fait une pause, me sentant épuisé, et me suis appuyé contre la grille - il y avait du sang et des langues de feu au-dessus du fjord bleu-noir et de la ville - mes amis ont continué à marcher, et je suis resté là tremblant d'anxiété - et j'ai entendu un cri infini déchirer la Nature. ${ }^{274}$

Le cri, ce bruit tragique qui fait écho dans les deux œuvres, représente l'état pathologique de l'âme grégaire de Philippe et de Clamence. C'est aussi le cri d'angoisse, de souffrance, d'expiation et de désespoir, en somme, un cri d'appel au secours. «J'allais crier, appeler stupidement à l'aide », ${ }^{275}$ disait Clamence à la vue de l'épave qui flottait sur les eaux du Zuyderzee. Plusieurs interprétations ont été données au cri qu'a

\footnotetext{
${ }^{272}$ Camus, Euvres complètes: Théâtre 1526.

${ }^{273}$ Camus, Cuvres complètes: Théâtre 1478.

${ }^{274}$ Extrait du journal d'Edvard Munch qui l'associe à son tableau « Le Cri » réalisé en 1883. Tableau : Le Cri d'Edvard Munch. 4 avril 2013. < http://commentairesimages.free.fr/index.php?p=le_cri_tableau>.

275 Camus, Euvres complètes: Théâtre 1531.
} 
entendu Clamence lors de son errance sur les quais de la Seine. Par exemple, selon Todd, il correspond au cri de désespoir de la femme de Camus. Mais le cri dont Camus luimême parle dans ses Carnets correspond au «cri des hommes devant leur destin, ${ }^{276} \mathrm{car}$ selon lui « ce qui nous intéresse c'est notre destinée, oui. Mais non pas 'après', 'avant.' » 277

Rappelons aussi que le «Cri » était parmi les titres qu'on devait choisir pour La Chute pour la simple raison qu'il symbolisait la déchirure qui se produit dans la conscience de Clamence. Il est intéressant de constater que faute de choisir ce titre, Camus n'a pas cédé sur le nom de son porte-parole; Clamence est dérivé de Clamans en latin, signifiant «criant $»,{ }^{278}$ ce qui ajoute un autre sens au prénom de Clamence. Le cri de Clamence sort entre le drame et la satire, entre la vertu et la séduction et entre le rêve et le réel.

Le cri du Pied-Noir sans pays fait écho dans l'oreille du lecteur. De son exil Camus ou Clamence, on ne sait guère, veut reconstruire le monde, une tâche ardue, voire impossible. Mais si le saint Jean-Baptiste habillé de vêtements de poils de chameau a choisi le désert pour crier et prêcher la foi, la religion et l'espérance, Clamence habillé de vêtements modernes cherche à faire retentir le cri, jusque-là sourd, que nous avons tous au fond de nous. Clamence veut entraîner tout le monde avec lui. Il travaille donc sur la

\footnotetext{
${ }^{276}$ Camus, Carnets I 50.

${ }^{277}$ Camus, Carnets I 51.

${ }^{278}$ « Clamans. » Wikidictionary. 5 juin 2012. <http://en.wiktionary.org/wiki/clamans〉.
} 
«duplicité profonde de la créature. » ${ }^{279}$ Il se veut le Jean-Baptiste de notre temps, lançant le même cri que lui : «Changez de comportement car le Royaume des cieux s'est approché. ${ }^{280}$ La même phrase est prononcée par Jésus également, mais avec plus d'indulgence.

Notons qu'avant le déchirement et l'exil, Clamence avait un autre nom, mais depuis qu'il est devenu juge-pénitent, il a décidé d'adopter un nom plus approprié qui correspond mieux à sa nouvelle fonction de juge-pénitent. Le choix de Jean-Baptiste n'était pas un hasard. De tous les noms bibliques, pourquoi celui-ci ? Jean-Baptiste, ce personnage historique était connu pour être sévère envers les hommes et pessimiste en ce qui concerne la volonté des humains de changer. Clamence dans La Chute a voulu entrer dans la peau de ce personnage en secouant les lecteurs avec ses paroles provoquantes et choquantes. S'imaginant juger les hommes, il dit : « [je] vois arriver déjà le premier d'entre eux. Sur sa face égarée, à moitié cachée par une main, je lis la tristesse de la condition commune, et le désespoir de ne pouvoir y échapper. ${ }^{281}$

Le cri de la femme au bord de l'eau qui a fait trembler Philippe a laissé des séquelles ineffaçables sur lui : «Quelque chose mourait en lui depuis la nuit passée au bord de l'eau. ${ }^{282}$ Le deuxième cri qui a déchiré Philippe venait de l'intérieur. Dans une scène d'un film qu'il est allé voir, au moment où le mari trompé, qui lui ressemblait,

\footnotetext{
${ }^{279}$ Camus, Euvres complètes: Théâtre 1518.

${ }^{280}$ Bruno Holcroft, « Méditations bibliques \& Prédications d'enterrements » 15 décembre 2008. 23 novembre 2011. <http://www.protestants-niederbronn.org/Meditations/Crier-dans-le-desert_a3.html>. ${ }^{281}$ Camus, Euvres complètes: Théâtre 1549.

${ }^{282}$ Green, Euvres II 86.
} 
allait surprendre sa femme en flagrant délit avec son ami, il entendit « monter un cri du fond de son cœur et du néant de toute sa vie, une parole étrange qu'il dut réprimer sur ses lèvres : Heureux homme, il va souffrir. » ${ }^{283}$

Le cri que Clamence a entendu près du Pont Royal n'est pas forcément celui de la jeune femme qui vient de se suicider. D'abord il entend le bruit du corps qui s'abat sur l'eau puis vient le cri qui fait toujours écho à son oreille, des années plus tard lors d'un voyage où il entend le même cri. Il note : «Ce cri qui, des années auparavant, avait retenti sur la Seine, derrière moi, n'avait pas cessé, porté par le fleuve vers les eaux de la Manche, de cheminer dans le monde, à travers l'étendue illimitée de l'océan, et [qu'] il m'y avait attendu jusqu'à ce jour où je l'avais rencontré. » ${ }^{284}$ Depuis ce cri se répéta plusieurs fois. Il représente le cri de sa lâcheté, celle d'un homme qui n'a cessé de vanter son physique, ses muscles et sa force. Le cri vient de son intérieur et crie sa faiblesse mais surtout sa faute ! Dans l'ensemble de l'œuvre du moraliste, figure donc l'interrogation douloureuse et stérile sur la souffrance humaine qui représente la morale humaniste camusienne. Pour revenir au silence qui entoure Philippe, il n'est autre que le cri sourd de la misère humaine telle que la représente Green.

Comme le cri, le rire prend une place importante dans Épaves et La Chute. Pour comprendre le rôle du rire qui figure à plusieurs reprises dans chacune des œuvres que nous étudions, nous avons tenté de cerner le sujet dans l'absolu puis voir comment il

\footnotetext{
${ }^{283}$ Green, Euvres II 118.

${ }^{284}$ Camus, Cuvres complètes: Théâtre 1531.
} 
affecte les deux textes. Cependant, nous sommes surpris de découvrir que plusieurs philosophes et psychanalystes se sont penchés sur ce sujet.

Le rire a suscité un intérêt particulier chez les philosophes : de Bergson à Bakhtine en passant par Baudelaire ainsi que les psychanalystes Freud, Sibony et bien d'autres. De ce fait, on a recensé plusieurs types de rire : le rire nerveux qui semble une ruse fiable pour masquer ses angoisses, le rire fou qui dénote la libération, le rire du grotesque qui dans un sens a un côté naïf et enfin « ce rire lointain qui semble venir d'un autre monde, d'une autre réalité comme d'un rêve. ${ }^{285}$ Lors de son analyse sur le rire, Baudelaire a divisé son essai ${ }^{286}$ en deux parties :

[L'une] s'occupe des causes du rire en tant que manifestation physiologique et sociale ; l'autre traite le comique dans les arts plastiques et la littérature. Du point de vue physiologique, le rire se rapprochait des pleurs : du point de vue théologique aussi, puisqu'ils seraient tous deux des phénomènes engendrés par la chute [...] il [le rire] est un des symptômes de la faiblesse de l'homme déchu et chassé du paradis.» ${ }^{287}$

Finalement la question qu'on se pose est dans quelle catégorie peut-on classer le rire qui émerge des eaux de la Seine ? Est-ce un rire de pouvoir et de supériorité puisque Clamence régnait, ou un rire de bêtise puisqu'il se décrit comme orgueilleux, narcissique et vaniteux, ou alors est-ce le premier présage qui annonce la chute de Clamence ?

\footnotetext{
${ }^{285}$ Daniel Sibony, Les Sens du rire et de l'humour (Paris: Odile Jacob, 2010) 9.

${ }^{286}$ En 1847, Baudelaire a écrit un essai sur le rire intitulé : «De l'Essence du rire. » Il a été publié la première fois en 1855 dans Le Portefeuille. Charles Baudelaire, « «De l'Essence du rire » (Paris : Éditions Sillage, 2008).

${ }^{287}$ Rosemary Lloyd, Baudelaire et Hoffmann: affinités et influences (New York: Cambridge University Press, 1979) 178.
} 
Dans De l'Essence sur le rire, Baudelaire a repris son idée que l'homme est soumis à deux postulations : le bien et le mal et que le rire représente cette dualité de la nature humaine : «Le rire est essentiellement contradictoire, c'est-à-dire qu'il est à la fois signe d'une grandeur infinie et d'une misère infinie, misère relativement à l'Être absolu dont il possède la conception, grandeur infinie relativement aux animaux. C'est du choc perpétuel de ces deux infinis que se dégage le rire.» ${ }^{288}$

Pour analyser ce qui est dissimulé sous un rire, Baudelaire a cité comme exemple la tragédie de Melmoth, le protagoniste du roman gothique Melmoth ou l'homme errant. Cet homme, qui vend son âme au diable en échange de l'immortalité qui lui confère ce sentiment de supériorité, a fini par comprendre, malgré l'avantage qu'il a sur le reste de l'humanité, qu'il était inférieur car il n'avait plus d'âme. Le pacte qu'il a fait avec le diable est à la fois source de son bonheur et de son malheur, de sa joie et de sa tristesse, de ses pleurs et de son rire : «Et ainsi le rire de Melmoth, qui est l'expression la plus haute de l'orgueil, accomplit perpétuellement sa fonction, en déchirant et en brûlant les lèvres du rieur irrémissible. ${ }^{289}$

Le déchirement est semblable à celui de Clamence et Philippe dont la honte brûle le cœur. Ils ressemblent tous deux à Melmoth. Ils n'ont pas pu sauver la vie des deux victimes parce qu'ils tenaient trop à la vie : « J'aime la vie, voilà ma vraie faiblesse. Je

\footnotetext{
${ }^{288}$ Darriulat, Baudelaire.

${ }^{289}$ Charles Baudelaire, Curiosité esthétique (Paris: Michèle Lévy Frères Librairie, 1868) 369.
} 
l'aime tant que je n'ai aucune imagination pour ce qui n'est pas elle» ${ }^{290}$ confesse Clamence. En s'accordant une supériorité Melmoth, Philippe et Clamence n’ont fait qu'aggraver leur situation, car ils se sont isolés.

Baudelaire nous illumine sur le sujet du rire et comment il est fortement lié au caractère humain. Il écrit : «Le rire est toujours motivé par l'orgueil d'un moi spectateur qui se distingue et se juge supérieur à son semblable affligé d'une infirmité : je ris de l'animalité des autres, réconfortant ainsi en moi l'idée d'humanité, et témoignant en vérité d'une cruelle bêtise. ${ }^{291}$ Mais après le déchirement, Philippe rit de lui-même lorsqu'il découvre que ses convictions n’étaient que des illusions :

Depuis longtemps déjà, Philippe vivait avec une sorte de fantôme, quelqu'un dont sa mémoire seule pouvait lui dire quelque chose, mais que personne n'avait jamais vu. Et il ne put s'empêcher de rire tout seul en se souvenant qu'il avait cru en lui-même, et à son avenir. ${ }^{292}$

Le rire qu'entend Philippe ne date pas de cet instant. Cependant, il lui rappelle de mauvais souvenirs. Plein d'amertume, il pense au rire hystérique de sa femme lors de sa nuit de noces qui lui rappelle ses tares et ses échecs, et « pour étouffer ce rire inextinguible qui résonne éternellement aux oreilles du mari trompé, il faudrait aller plus loin, qui sait ? Frapper cette femme. ${ }^{293}$

\footnotetext{
${ }^{290}$ Camus, Euvres complètes: Théâtre 1514.

${ }^{291}$ Darriulat, Baudelaire.

${ }^{292}$ Green, Euvres II 199.

${ }^{293}$ Green, Euvres II 161.
} 
Depuis son passage sur le pont, le rire du démon ou le rire du saint s'est emparé de l'âme de Clamence. Il retrouve une certaine lucidité et découvre que sa vie était basée plus sur le sens de la bêtise, de l'égoïsme, de la vanité et du désir de domination. Alors, dit-il, « [je] me mis encore à rire. Mais c'était d'un autre rire, assez semblable à celui que j'avais entendu sur le pont des Arts. Je riais de mes discours et de mes plaidoiries. ${ }^{294}$

Dans son œuvre Curiosité esthétique, Baudelaire note que « le rire humain est intimement lié à l'accident d'une chute ancienne, d'une dégradation physique et morale. Le rire et la douleur s'expriment par les organes où réside le commandement et la science du bien et du mal : les yeux et la bouche. ${ }^{295}$ Pour le poète, le rire peut être aussi bien angélique que satanique. Il exprime à la fois l'orgueil de la supériorité et l'angoisse de la damnation.

Le rire, dont on dit parfois qu'il est diabolique, peut être familier du mal, peut avoir un sens caché ou narquois. Clamence révèle : «Je me redressai et j’allais allumer une cigarette, la cigarette de la satisfaction, quand, au même moment, un rire éclata derrière moi. » ${ }^{296}$ Et pourtant il n'y avait personne dans les environs ; il continue alors : «Je me retournai vers l'île et, de nouveau, j'entendis le rire dans mon dos, un peu plus lointain, comme s'il descendait le fleuve [...] venu de nulle part, sinon des eaux. ${ }^{297}$ Bien qu'à première vue ce rire n'ait rien de négatif ou de malicieux pour Clamence, il l'a

\footnotetext{
${ }^{294}$ Camus, Euvres complètes: Théâtre 1509.

${ }^{295}$ Baudelaire, Curiosité 363.

${ }^{296}$ Camus, Euvres complètes: Théâtre 1495

${ }^{297}$ Camus, Euvres complètes: Théâtre 1495.
} 
pourtant bouleversé, déstabilisé et surtout étouffé. Il l'a accompagné jusque chez lui et s'est mis sous sa fenêtre pour ne plus le quitter. Parfois « le rire comporte une tromperie surmontée aussitôt que perçue.» ${ }^{298}$ Selon l'écrivain psychanalyste Daniel Sibony, «le rire est une affaire de rencontre, y compris avec soi ; on y fait couple, on y est au moins double ; même le sens se dédouble. ${ }^{299}$ Ce qui nous ramène à l'idée de la rencontre du conscient et de l'inconscient.

Ce même incident, Philippe l'a vécu dans des circonstances différentes. Lors d'une de ses errances, il entend le rire des moqueurs derrière lui : « Qu'est-ce que j'ai donc ? pensa-t-il. Il ne faut pas que je m'agite. Il faut que je me retrouve, il faut demeurer calme. ${ }^{300} \mathrm{Ce}$ rire qui courait derrière Philippe l'a forcé à interrompre sa promenade et à fuir, «mais ces voix le suivaient. ${ }^{301}$ Ce rire le fait sortir d'un monde complaisant de bourgeois et le ramène à la dure réalité. À cet instant la Seine change d'habit et apparait comme un gouffre noir sous les yeux de Philippe.

Le rire qu'a entendu Clamence et qui a précédé le cri, n'est autre que les prémisses de son malaise et son déchirement. Le rire a déclenché un processus d'introspection où Clamence, au lieu de continuer à chercher la source du rire, se tourne vers son double et réalise : «De loin en loin, il me semblait l'entendre, quelque part en

\footnotetext{
${ }^{298}$ Sibony 9.

${ }^{299}$ Sibony 9.

${ }^{300}$ Green, Euvres II 23.

${ }^{301}$ Green, Euvres II 23.
} 
moi. $»^{302}$ C'est en fait ce rire de l'absurde, qui a créé en lui la phobie des ponts : «Lorsque j’y passais, » disait-il «en voiture ou en autobus, il se faisait du silence en moi. ${ }^{303}$ Le rire éveille la conscience et la mémoire de Clamence, alors ce qui est enfoui ressurgit et ses turpitudes remontent à la surface. Ce qui jadis faisait sa fierté est devenu son avilissement. Le choc est dur pour lui, il tombe malade puis il erre pendant un certain temps pour enfin retrouver un moyen mesquin de justifier ses défauts en se considérant la victime et non le bourreau. Ainsi, Camus dépeint à travers le personnage de Clamence, l'absence d'humanité et d'unité. Le monde semble dépourvu d'hommes. Clamence, faute de s'accorder avec lui-même, continue à entendre ce rire perpétuel. Il devient hélas un automate. Plus Clamence s'égare et sombre dans la débauche, moins il entend le rire. Il raconte à son compatriote lors de la traversée de la mer du Zuyderzee: « Je vivais dans une sorte de brouillard où le rire se faisait assourdi, au point que je finissais par ne plus le percevoir. ${ }^{304}$ Avec la disparition du rire il se sent beaucoup mieux et tous ses maux disparaissent. Mais cette trêve n'est que temporaire : Mais « [parfois], de loin en loin, quand la nuit est vraiment belle, j'entends un rire lointain, je doute à nouveau.» ${ }^{305}$ Cette trêve annonce surtout l'approche de la tempête. D'après Clamence un des premiers signes est $«$ je grossissais un peu ${ }^{306}$ disait-il. On croirait

\footnotetext{
${ }^{302}$ Camus, Euvres complètes: Théâtre 1497.

${ }^{303}$ Camus, Euvres complètes: Théâtre 1497.

${ }^{304}$ Camus, Euvres complètes: Théâtre 1530.

${ }^{305}$ Camus, CEuvres complètes: Théâtre 1548.

${ }^{306}$ Camus, Euvres Complètes: Théâtre 1530.
} 
entendre Philippe se soucier de son poids. Décidément ces protagonistes parlent le même langage !

D’après Bergson, on rit « lorsque à la place de l'humain, du jouable, surgit l'automate. » ${ }^{307}$ En d'autres termes, « On rit lorsque à la place du vivant humain surgit 'le mort'. » ${ }^{308}$ La mort de l'âme dont Clamence souffre le pousse au pire. Ses actes deviennent de plus en plus sataniques, le mal devient son compagnon, la perversité sa force et la dépravation sa devise. Sans morale, il se tourne vers la dérision pour vaincre le rire. Alors que Philippe, lui n'essaie pas, il n'a ni le courage ni la détermination de Clamence. Sa planche de salut est la fuite devant de pareilles circonstances. Selon Philippe Derivière, « Philippe veut renoncer à une vie manquée dans la mort. » ${ }^{309}$ Il affirme que le point commun des personnages greeniens est cette passion « qui les pousse à fuir la réalité qu'ils ont trop étreinte, vers un autre monde. ${ }^{310}$

Le rire comme le cri et l'eau sont rattachés aux protagonistes et chacun d'eux contribue à aider Philippe et Clamence à retrouver leur lucidité. L'eau, le cri et le rire s'entrelacent pour former une chaîne qui emprisonne Clamence dans un état d'âme. L'un ne peut surgir sans l'autre. Le rire sur le pont fait appel au cri venant des eaux de la Seine. Le rire éveille la conscience, le cri déchire l'âme des protagonistes et il les suit là où ils vont. Ils ne seront jamais complètement libérés de ce sortilège.

\footnotetext{
${ }^{307}$ Sibony 40.

${ }^{308}$ Sibony 40.

${ }^{309}$ Philippe Derivière, Julien Green, les chemins de l'errance (Paris: Talus d'approche, 1994) 48.

310 Derivière 48.
} 
Pendant les cinq jours, durant lesquels Clamence a présenté sa plaidoirie dans laquelle on ne peut distinguer le mensonge de la vérité, vu le doute qu'il a semé par la satire et l'ironie, on se demande s'il a atteint son but : contenir le rire et étouffer le cri ?

En quelque sorte Clamence et Philippe représentent le Caligula moderne, celui de notre temps. La parole disparaît, et après le simulacre de son suicide, la dernière scène annonce un Caligula déchu « avec un rire fou » ${ }^{311}$ où dans des cris, des hurlements, il proclame son immortalité.

${ }^{311}$ Camus, Caligula 150. 


\title{
Chapitre 2 Le miroir, reflet de la culpabilité
}

\author{
Bioy Casarès se rappela alors qu'un des hérésiarques d'Uqbar \\ avait déclaré que les miroirs et la copulation étaient abominables, \\ parce qu'ils multipliaient le nombre des hommes. ${ }^{312}$
}

\section{JL Borges}

L'un des aspects principaux d'Épaves et de La Chute est le rôle important qu'y joue le miroir. Ce dernier symbolise entre autres la découverte de soi, de la vérité. Il est censé ne rien cacher mais hélas ce n'est pas toujours le cas. Le miroir est aussi mythique que magique. Dans le conte de fées, Blanche-Neige, la belle-mère demande à son miroir qui est la plus belle, car elle sait que c'est le seul qui osera lui dire la vérité, alors que ses serviteurs vont certainement lui mentir pour éviter la mort. Philippe, jeune, beau et bourgeois ne peut s'arrêter de consulter le miroir afin de s'assurer d'un côté qu'il est toujours beau et de l'autre côté afin de vérifier que son apparence ne l'a pas trahi en divulguant le secret qui risque de le déshonorer. Quant à Clamence, il est lui-même une réflexion de miroir qui symbolise son interlocuteur. En s'autocritiquant, Clamence accuse, juge et condamne ses compatriotes de la classe bourgeoise. Si Camus semble plus discret dans l'évocation du miroir, Green en use sans discrétion. Le mot «miroir » apparaît sans cesse dans presque toutes ses œuvres et Épaves n'est pas une exception.

\footnotetext{
${ }^{312}$ Julien, Bonhomme, «Réflexion multiples. Le miroir et ses usages rituels en Afrique centrale, »Images Re-vues : histoires, anthropologies et théories de l'art avril, 2007. 23 février 2012. < http://imagesrevues.revues.org/147>. JL Borges est un écrivain argentin (1899-1986) qui, grâce à ses récits fantastiques et métaphysiques, est devenu l'une des figures de proue de la littérature sud-américaine. Julien, Bonhomme, Réflexion multiples. Le miroir et ses usages rituels en Afrique centrale.
} 
Les deux œuvres se croisent encore une fois dans le rôle commun du miroir et à travers la vanité et le narcissisme des protagonistes. Pour ces derniers, le miroir représente leur interlocuteur, leur confident et surtout leur thérapeute car il n'y a que lui qui les rassure dans leurs moments d'insécurité, de malaise et de doute. Philippe et Clamence racontent l'histoire de leur vie à « des fantômes, » qu'ils voient à travers le miroir. Le miroir sert d'outil de découverte et d'éveil de la conscience et le fait de le regarder mène les protagonistes au déchirement interne, à la scission d'eux-mêmes. Ils vont alors découvrir un autre «moi », un double qui se cache en eux et qui leur est étranger, mais qui est tantôt juge et tantôt pénitent.

Le miroir est défini comme «surface polie qui réfléchit la lumière et l'image des objets, des personnes, etc. » ${ }^{313}$ C'est donc une image fidèle mais inversée de l'objet réfléchi. L'étymologie du mot miroir vient du latin mirari, qui signifie « admirer », ainsi que « regarder avec étonnement », ou « être surpris.» En psychologie, le signe du miroir reflète la «tendance à longuement contempler sa propre image, notée chez les schizophrènes en rapport avec l'angoisse de dépersonnalisation et de perte de l'identité. » ${ }^{314}$ Dans le domaine de la psychanalyse, le miroir des rêves est le plus parfait. C'est une image davantage intérieure. Dans ce même contexte, les psychanalystes parlent également du « miroir de l'âme » : «Cette notion est accentuée par le nom donné aux

\footnotetext{
313 «Miroir. » Centre national des ressources textuelles et lexicales. <http://www.cnrtl.fr-/definition/miroir/>.

314 «Miroir. » Centre national des ressources textuelles et lexicales. <http://www.cnrtl.fr-/definition/miroir/>.
} 
grands miroirs [psyché] qui permettent de se voir intégralement de la tête aux pieds. » ${ }^{315}$ À propos du miroir, Jean Cocteau a dit : «Le miroir ferait bien de réfléchir avant de nous renvoyer notre image. ${ }^{316}$ Le miroir est apparu dans l'Antiquité et n'a cessé de se développer depuis. D’abord petit disque bombé muni d'une tige, son apparence change au Moyen Âge. Créé pour plusieurs raisons, entre autres pour se voir, certains l'utilisent plus pour s'admirer et se contempler. Dans la mythologie grecque Narcisse n'a cessé de contempler la réflexion de son image sur l'eau jusqu'à ce qu'il tombe amoureux de celleci et plonge dans l'eau où il trouve la mort. Par son pouvoir magique et mystérieux, le miroir a souvent été présent dans la littérature des contes traditionnels aux contes modernes et du romantisme au surréalisme. Si la jalousie de la belle-mère de BlancheNeige la pousse à consulter le miroir afin de s'assurer qu'elle est la plus belle, la curiosité d'Alice $^{317}$ la pousse à traverser le miroir, qui devient un outil de passage dans l'autre monde, pour vérifier qu'il y a bien du feu dans la cheminée, dans ce qu'elle appelle «la maison du miroir.»

Green est bien connu pour son utilisation récurrente du miroir dans ses œuvres. Le miroir fidèle est une utopie car il ne montre que ce que l'on veut voir. Le travail le plus important de Green est son journal qui compte dix-huit volumes mais malgré cela, il a toujours été insatisfait : «J'aurais voulu que ce journal fût plus complet, qu'il y eût

\footnotetext{
315 «Miroir, » Dictionnaire psychanalytique des images et symboles du rêve. 03 février 2012 $<$ http://www.abcdreve.fr/>.

${ }^{316}$ François Vannucci, Le Miroir aux neutrinos: Réflexions autour d'une particule fantôme (Paris: Odile Jacob, 2003) 235.

${ }^{317}$ Personnage principal du conte de Lewis Caroll, De l'autre côté du miroir et ce qu'Alice y trouva. Ce conte est la continuation de celui d'Alice au pays des merveilles.
} 
tout, mais cela n'est pas possible [...] Il faut choisir. Dans ces conditions, un journal cesse d'être le miroir fidèle qu' on voulait, il ne montre qu'un portrait partiel.» On verra par la suite que le double complètera l'être. Dans Épaves, le personnage greenien est très attiré par le miroir, à travers lequel, il découvre tantôt sa beauté et retrouve sa vanité de dandy, et tantôt la laideur et l'insécurité qui le fait sombrer dans un gouffre omniprésent, particulièrement dans les situations tragiques. De même, le miroir occupe une place prépondérante dans La Chute de Camus. Peut-on parler de la présence du miroir dans «Le Miroir»? Avant de décider d'opter pour un titre de l'œuvre de Camus, plusieurs propositions ont défilé, entre autres, «Un héros de notre temps », « Cri » titre proposé par Camus lui-même et «Le Miroir » proposé par Jean-Michel Bloch et enfin « La Chute » qui était une idée de Roger Martin du Gard. Selon Ernest Sturm :

Chacun de ces titres présentait un aspect particulier du livre. 'Le Cri' symbolisait la déchirure qui se produit dans la conscience de Clamence. 'Le Miroir' insistait sur l'intention du livre : Clamence [...] incarne les vices de sa génération, le mal de son siècle. ${ }^{318}$

Même si «Le Miroir »n'a pas été retenu comme titre de l'œuvre, le miroir, lui, est considéré comme l'autre protagoniste. Tout au long du récit, Clamence tient un miroir, prêt à le passer à celui qui est prêt à s'accuser et à se juger. Le gouffre de Clamence, c'est sa chute dans les cercles de Dante. C'est aussi le gouffre que redoute Camus et qui menace l'Europe en général et la classe bourgeoise française en particulier. Ce gouffre qui risque de mettre l'Europe en péril tout comme la guerre qui se prépare et

${ }^{318}$ Strurm 10. 
que Green appréhende. Une guerre qui s’est déjà déclenchée ailleurs et dont Camus craint les conséquences.

Philippe et Clamence sont deux hommes qui appartiennent à la même classe sociale, celle de la bourgeoisie. Ils n'ont pas souffert dans leur vie pour gagner leur pain, la chance leur a souri dès leur naissance : «Je n'ai jamais eu besoin d'apprendre à vivre $[\ldots]$ je savais déjà tout en naissant», ${ }^{319}$ dit Clamence. On pourrait en dire autant de Philippe puisque « [la] vie ne lui infligeait pas de grandes souffrances. ${ }^{320}$ Chacun d'eux représente une catégorie d'homme. L'homme inconscient et l'homme conscient, mais tous deux narcissistes coupables et impuissants. Clamence est l'homme actif, réfléchi et audacieux. Le second est passif, inerte et angoissé. Ils partagent cependant cette obsession des problèmes d'ordre moral, mais chacun à sa manière, dans un contexte d'égoïsme et d'autolâtrie. Ces deux personnages partagent quelques faiblesses telles que l'amour de la solitude, l'égoïsme et le narcissisme. Philippe vit avec sa femme et sa belle-sœur mais en réalité il est encastré dans une boîte non hermétique où il se retrouve tout seul et toute communication avec le monde extérieur est exclue. De temps en temps il se met face à face avec lui-même à travers un des miroirs qui orne la maison. Quant à Clamence, il vit seul, exilé loin de Paris, mais étrangement ni l'un ni l'autre ne semble souffrir de sa solitude. Bien au contraire, pour l'un comme pour l'autre, il n'y a que sa propre personne qui l'intéresse dans cette « solitude parfaite » qui fait que « tout homme

\footnotetext{
${ }^{319}$ Camus, Euvres complètes: Théâtre 1489.

${ }^{320}$ Green, CEuvres II 44.
} 
est roi dans un désert. » ${ }^{321}$ Ils sont des fans d'eux-mêmes, mais plus tard, le ton change et petit à petit ils se prennent en grippe. Le manque de souffrance de ces personnages est dû au manque de conscience, à l'égoïsme de chacun, et à leur insensibilité. Le seul vrai compagnon des protagonistes de ces deux œuvres est le miroir qui passe de main en main et que Clamence à la fin nous offre en disant : «Le portrait que je tends à mes contemporains devient un miroir. ${ }^{322}$ Le miroir à multiple facettes qui juge, rassure et accuse et que l'auteur d'Épaves appelle « le miroir à trois faces. » ${ }^{323}$ Plus tard et dans le même état d'esprit, Green écrit dans son journal : «Ce journal est un miroir dans lequel je me vois. Je tends le miroir au prochain non pas pour qu'il m'y voit - Comment le pourrait-il ? - mais pour qu'ils se voient eux-mêmes.» ${ }^{324}$

Philippe est obsédé par son image. Il ne cesse de se regarder dans le miroir placé au-dessus de la cheminée de son salon, car c'est dans cette pièce qu'il passe le plus clair de son temps. Il a besoin de vérifier que tout va bien et que rien ne vient altérer son image. Chaque fois que Philippe pense au drame dont il a été témoin, il cherche son miroir qui, en retour, va le rassurer : que rien n'est visible sur son visage, que cet incident n'a laissé aucune trace sur son corps sachant que ce dernier ne va jamais le trahir. Le miroir est souvent remplacé par l'eau de la Seine ou les eaux froides

\footnotetext{
${ }^{321}$ Green, Euvres II 30.

${ }^{322}$ Camus, Euvres complètes: Théâtre 1545.

${ }^{323}$ Green, Euvres II 74.

324 O'Dwyer 34.
} 
d'Amsterdam. Il est vrai que le drame ne l'a pas affecté de l'extérieur mais de l'intérieur, et il l'a abimé.

Philippe communique avec le miroir, il se confie à lui comme il le fait avec la Seine qui devient aussi sa complice. Philippe a été trop jugé, d'abord par un père autoritaire qui le trouvait mou et incompétent puis par sa femme qui le trouve stupide et impuissant et aussi par sa belle-sœur malgré l'amour qu'elle lui voue, mais dans ses moments de faiblesse, elle le met sur un piédestal. Il ne supporte plus qu'on le juge. Après le drame sur les quais de la Seine, Philippe rentre chez lui cherchant un moment de solitude afin de réfléchir sur cet événement inattendu. Après s’être débarrassé de sa belle-sœur, il n'admettait comme compagnon qu’ « une grande glace pendue au-dessus de la cheminée et s'observait sans indulgence. En de meilleurs jours, il tirait vanité de sa taille droite et de ses épaules robustes.» ${ }^{325}$ Mais à l'éveil de la conscience, le miroir ne rend plus la même image que Philippe et Clamence ont pris l'habitude de voir. Cette fois-ci, lorsque Philippe s'est regardé dans la glace, il a eu une réaction assez étrange puisqu'il a « admiré et méprisé tour à tour » ${ }^{326}$ ce qu'il venait de voir. Ce nouveau comportement symptomatique est qualifié par Heinz Kohut d' «affaiblissement, diverses régressions, et fragmentation. » ${ }^{327}$ Mais déterminé à ne pas se laisser démoraliser par cette image, il se regarde dans la glace sous un autre angle et là, il retrouve Philippe le

\footnotetext{
${ }^{325}$ Green, Euvres II 11.

${ }^{326}$ Green, Euvres II 21.

${ }^{327}$ Ziegler 38.
} 
vaniteux. Rassuré, il prononce la phase suivante : «Allons nous coucher. » ${ }^{328}$ Mais qui est ce «nous »? «Son visage anxieux interrogea le visage au fond du miroir,» ${ }^{329}$ un miroir qui lui a tenu compagnie depuis son enfance, et qui vient de lui révéler qu'il était toujours « riche, assez intelligent, beau [...] image d'une âme qu'un destin singulier avait placée à l'abri du monde. » ${ }^{330}$ Mais, selon Dominique van Hooff, le miroir révèle parfois l'idée suivante:

Alter ego énigmatique et élusif que l'on devine dans les portraits que l'on entrevoit dans les miroirs ou les reflets d'eau, serait-il alors, l'être authentique étouffé au cours des années sous les pressions et les tabous des lois familiales et sociales imposées à l'individu et que l'on retrouverait au hasard de la vie dans des états second ? ${ }^{331}$

Perturbé, agité, brisé, Philippe se cherche mais il n'arrive pas à se retrouver. «Qu'est-ce que j'ai donc ? » après de longues méditations sur le pont, il se ressaisit et trouve sa réaction un peu absurde. D'ailleurs il reprend le scénario après coup, le transforme, trouve des réponses aux questions qui l'ont tourmenté pendant trois heures et finit par se disculper. La victime n'est pas en danger et n’a pas appelé au secours, mais ce n'était qu'une pauvre mendiante qui voulait son argent. Philippe et Clamence tous deux essayent de prouver que le miroir qu'ils regardent a tort.

\footnotetext{
${ }^{328}$ Green, Euvres II 22.

${ }^{329}$ Green, Euvres II 44.

${ }^{330}$ Green, Euvres II 44.

${ }^{331}$ Dominique van Hooff, «Entre le visible et le dicible : l'art du portrait chez Julien Green. » Autour de Julien Green : au cœur de Léviathan. Société Internationale d'Études Greeniennes. Presses Universitaires de l'université de Franche Comté (France). (Paris: les Belles Lettres, 2000) 90.
} 
Clamence également remarque le changement de son image, à son retour chez lui après le rire qu'il a entendu venir des eaux de la Seine : « Mon image souriait dans la glace, mais il me sembla que mon sourire était double, ${ }^{332}$ confesse-t-il. Pour Camus, le miroir sert d'outil pour exprimer la notion de l'absurde. Dans Caligula, il montre bien le rôle du miroir dans la main de l'homme déchu : Caligula.

Dans l'autre chambre de l'appartement d'Éliane, la belle-sœur, se sentant rejetée «s'examina sévèrement dans la glace avec le désir à moitié sincère de se voir telle qu'elle était.» ${ }^{333}$ Elle regrette sa jeunesse et sa beauté : «Si j’étais plus jeune et très jolie, pensa-t-elle, cette glace ne me montrerait pas autre chose que ce que j’y découvre maintenant. » ${ }^{334}$ Mais le miroir semble jouer des tours à « la vieille fille, » selon son comportement et ses états d'âmes, il lui révèle une image différente. Par exemple, lorsqu'elle est heureuse «le miroir placé presqu'en face d'elle l'assura en effet qu'une physionomie enjouée lui ôtait dix ans, » ${ }^{335}$ alors que lorsqu'elle est triste ou qu' elle agit avec méchanceté le miroir lui montre une image « hideuse. » ${ }^{336}$ C'est la femme qu'on retrouve dans le journal de Green et qui affirme : «Je suis la femme qui voit briller près de sa trompe le revolver de l'assassin, et je suis l'assassin. » ${ }^{337}$

\footnotetext{
332 Camus, Euvres complètes: Théâtre 1495.

${ }^{333}$ Green, Euvres II 14

${ }^{334}$ Green, Euvres II 14.

${ }^{335}$ Green, Euvres II 60

${ }^{336}$ Green, Euvres II 61.

${ }^{337}$ Green, Journal I 77.
} 
Le miroir joue aussi un rôle très important pour Philippe car il revoit son enfance, son adolescence et toutes ces années passées quand son père le jugeait et le trouvait incapable : «La crainte du vieillard le tenait sans qu'il s'en rendit compte ${ }^{338}$ et continue de l'apercevoir au fond du miroir. Cependant, dès qu'il lui tourne le dos il retrouve son moi narcissique et prétentieux comme «il ne s'est jamais vu aussi beau. » ${ }^{339}$ Toute la fierté de Philippe vient de son apparence physique : «Au moins, pensa-t-il, j’ai une bonne santé et je ne suis pas difforme. ${ }^{340}$ Contraire en cela à Clamence dont la plus grande fierté, lorsqu'il parle des années avant d'arriver à Amsterdam, était non seulement son corps mais surtout sa place dans la société : «J'étais vraiment irréprochable dans ma vie professionnelle. » ${ }^{341}$ C'est un avocat accompli qui aidait les pauvres, les faibles, les orphelins et les opprimés. Malgré une résistance de la part des protagonistes, le miroir réussit à les affecter au moment où ils sont les plus vulnérables. Il divulgue la face cachée de l'autre sans leur donner le temps de plaider leur cause.

Le double comme le miroir est un motif fréquent dans la littérature et en particulier dans le genre fantastique. Il est apparu dans la littérature fantastique au XVIII $^{\mathrm{e}}$ siècle ou même avant et a pris de l'ampleur au XIX ${ }^{\mathrm{e}}$ siècle. Les thèmes du roman fantastique étaient variés mais liés aux fantômes, diables, vampires, et au double. On parle souvent de « roman noir » et le goût de l'horreur et du macabre en est une

\footnotetext{
${ }^{338}$ Green, Euvres II 48.

${ }^{339}$ Green, Euvres II 68.

${ }^{340}$ Green, Euvres II 68.

${ }^{341}$ Camus, Euvres complètes: Théâtre 1483.
} 
caractéristique. Le thème du double cependant se manifeste sous différentes formes telles que le double autoscopique comme c'est le cas dans Épaves ou le dédoublement psychologique comme dans La Chute. D'ailleurs, ce concept est récurrent dans les œuvres de Camus. Dans L'Étranger, Meursault n'arrive pas à reconnaître son reflet dans la gamelle. Meursault n'est pas le seul à se découvrir étranger à lui-même, Philippe et Clamence le sont aussi. Aussi bien Green que Camus ont dépeint des personnages à la fois anges et diables. Philippe, par exemple, oscille entre un père affectueux qui parfois caresse son fils et parfois l'étouffe en l'embrassant avec une forte étreinte. Il lui arrive même des moments de haïr cet enfant qui est sa propre chair et de vouloir s'en débarrasser.

Le concept du double a souvent une connotation négative car il fait référence à l'autre face cachée de l'être humain et qu'il révèle son côté le plus sombre. Cette scission interne génère forcément un conflit inquiétant entre les parties. Cette « inquiétante étrangeté » ${ }^{342}$ comme la qualifie Freud n'est pas rare mais apparaît sous différentes formes selon les groupes ethniques qui la définissent. Par exemple, dans la religion le thème du double n'a rien de négatif car, bien au contraire, il signifie l'immortalité de l'âme. La psychanalyse, quant à elle, en fait une tare.

Il est évident que chez Philippe comme chez Clamence, il y a deux natures différentes et étrangères coexistent. L'une visible pour le monde extérieur et la

\footnotetext{
${ }^{342}$ Sigmund Freud, «L'Inquiétude étrangeté » 11 septembre 2008. 16 mai 2012. <http://www.psychaanalyse.com/pdf/inquietante-_etrangete.pdf>
} 
deuxième, invisible et qui apparaît par déclenchement événementiel, par exemple en présence d'un danger. L'appel désespéré de la victime ou la présence du gamin, qui a voulu lui extorquer de l'argent en face de Philippe a causé une rupture et une scission pendant laquelle Philippe n'est plus arrivé à contrôler sa propre personne : «Lorsqu'il se tenait au bord de l'eau, un autre, une sorte de double avait dû parler pour lui, discuter avec ce malfaiteur. » ${ }^{343}$ Lorsqu' il revient sur ses pas vers la Seine, il réalise l'effet troublant que l'eau a sur lui : «Pour la première fois de sa vie, peut-être, des circonstances le mettaient en présence de lui-même. ${ }^{344}$

Pour Clamence, ce qui a déclenché cette rupture interne c'est le rire qu'il entendait derrière lui et le cri de la femme qui venait de se suicider. Clamence se rend compte de l'existence du double puisque il l'avoue et le généralise : «L'homme est ainsi, cher Monsieur, il a deux faces : il ne peut pas aimer sans être aimé. » ${ }^{345}$ Camus va plus loin dans le choix des mots pour faire ressortir de manière plus subtile le double de Clamence : « La face de toutes mes vertus avait ainsi un revers moins imposant. » ${ }^{346}$

La réaction de Philippe au drame qu'il a vécu le soir au bord de la Seine fut une surprise pour ce dernier. Après un bref moment il se rend compte de ce qu'il vient de faire ou plutôt ce qu'il n'a pas pu faire, alors il ne se reconnaît plus, « peut-être ne s'est-il

\footnotetext{
${ }^{343}$ Green, Euvres II 45.

${ }^{344}$ Green, Euvres II 32.

345 Camus, Euvres complètes: Théâtre 1490.

${ }^{346}$ Camus, Euvres complètes: Théâtre 1517.
} 
jamais connu avant cette minute», ${ }^{347}$ et qui est donc « ce moi étrange presque inconnu à lui-même [...] Comment donc pouvait-il espérer de n'être pas seul si lui-même à luimême demeurait étranger ? ${ }^{348}$ On découvre alors « qu'on est autre.» ${ }^{349}$ Cette notion de double et de dédoublement est bien connue chez l'auteur d'Épaves, et cela est même dû à la «double » vie qu'il mène. Attaché à des valeurs religieuses et spirituelles qui lui ont été inculquées depuis son enfance, et tenté par l'amour de la chair, Green, comme la plupart de ses protagonistes, vit un conflit interne. Un conflit que Camus précise depuis le jour où il a connu l'injustice et qui a fait de lui une âme déchirée.

Le drame de Philippe c'est qu'il se considère lui-même la victime et non pas la femme qui est peut-être morte. Cette dernière ne l'intéresse guère. Ce soir-là et comme tous les soirs, il s'agissait de lui. Le crime lui a révélé une tare qu'il croyait inexistante. Toute sa richesse, son élégance et sa beauté n'ont pas réussi à accomplir la plénitude et la perfection de sa personne : «Sa nature lui avait commandé de fuir et il avait fui. Un autre, plus ferme et plus calme, serait descendu sur le port, mais il venait justement de découvrir qu'il n'était pas l'autre. » ${ }^{350}$

Éliane, quant à elle, vit une sorte de double vie, celle de la sœur aînée bienveillante et protectrice de sa jeune sœur. Elle s'occupe d'elle comme une mère qui couve son bébé. Mais à la tombée du masque, on retrouve l'amoureuse passionnée qui

\footnotetext{
${ }^{347}$ Green, CEuvres II 6.

${ }^{348}$ Green, Euvres II 30.

${ }^{349}$ Green, CEuvres II 30.

${ }^{350}$ Green, CEuvres II 31.
} 
souffre en silence. Son double apparaît en alternance entre l'ombre et la lumière, lorsque « la lumière de l'enseigne la ramenait à elle chaque fois qu'elle inclinait la tête un peu trop bas. Les secondes d'obscurité lui paraissaient délicieuses parce qu'elle pouvait s'y cacher, et, dans le noir, la tristesse de n'être plus jeune se dissipait. » ${ }^{351}$ Elle est déchirée entre le refus d'avouer son amour qui la torture depuis onze ans et le consentement de son double qui est de défier sa sœur, la trahir et confronter Philippe en lui avouant ses sentiments. Elle n'arrive à être sincère vis-à-vis de sa propre sœur que dans l'obscurité, là où l'autre moi apparaît : « Il lui semblait que dans le noir elle ne pouvait plus tricher avec elle-même. » ${ }^{352}$ C'est dans la splendeur et la sérénité de l'ombre qu'Éliane retrouve son bien-être et son calme, mais la lumière perturbe ce calme car, chaque fois qu'elle apparaît, elle « la frappe avec la violence d'un coup de poignard. » ${ }^{353}$ Alors son double, plein de remords, s'éveille et tout le luxe qui l'entoure et qui la rendait heureuse, semble futile, laid et hideux. On trouve la même réaction chez Philippe, pour qui ce monde de somptuosité devenait « odieux. » Éliane, comme Philippe et Clamence, oscille entre deux mondes, celui de la femme prise de remords essayant de revenir en arrière après avoir jugé et corrigé ses erreurs «comme un pénitent s’enfonce des pointes dans la chair », ${ }^{354}$ et le monde de la passionnée aveuglée par la jalousie qui cherche à creuser davantage le fossé qui sépare les époux chaque fois que l'occasion lui est donnée afin de

\footnotetext{
${ }^{351}$ Green, Euvres II 14.

352 Green, Euvres II 104

${ }^{353}$ Green, Euvres II 15.

354 Green, Euvres II 51.
} 
les désunir. La conscience d'Éliane agit par intermittence. La voix qui fait écho résonne dans son oreille dans les moments de doute et d'autoscopie ; c'est la voix impérieuse et cynique de la raison et de la sensibilité « qu'elle faisait taire si souvent. » ${ }^{355}$ Cette voix lui sert de freins dans sa conquête de Philippe et la fait « sourire gaiement avec la tristesse au cœur, revenir sur un jugement sévère et défendre quelqu'un qu'elle n'aimait pas. $»^{356}$

L'oscillation entre un état de remords et un état de consolation fait perdre à Philippe petit à petit son ego au détriment d'une libération de la conscience incitée par le changement de point de vue et de perception. Philippe se détache petit à petit de luimême en donnant naissance à un autre Philippe, plus réfléchi et plus conscient de ce qui l'entoure et donc «un être devenu presque étranger à lui-même » ${ }^{357}$ mais plutôt «un complice.» Ces personnages ressemblent fortement aux personnages de Joseph Conrad car « ils souffrent de plusieurs maux exacerbés dans le lieu de l'exil qui est clos et reclus sur lui-même. » ${ }^{358}$ Roger Quilliot raconte que lors d'un entretien qu'il a eu avec Camus, ce dernier lui a confié que dans L'Étranger « le point de départ de son livre : un homme étranger à sa vie, à la vie telle qu'on la conçoit ordinairement, adapté à la nature,

\footnotetext{
${ }^{355}$ Green, Euvres II 57.

${ }^{356}$ Green, Euvres II 49.

${ }^{357}$ Green, EEuvres II 23.

${ }^{358}$ Société Conradienne Française, Époque conradienne, vol. 27 (Limoges: PULIM, 2001) 129.
} 
mais inadapté à la société.» ${ }^{359}$ Cet homme, il le choisit comme point d'arrivée dans La Chute. Le même point d'arrivée que Green nous a dévoilé dans Épaves.

Toutefois, selon Robert Ziegler, « le texte de Green présuppose que les lecteurs eux-mêmes agissent comme un miroir qui juge ces âmes blessées. » ${ }^{360}$ Cette même conclusion a été proclamée par plusieurs critiques de La Chute, qui pensent que le but de Camus est de solliciter la conscience des lecteurs et que chacun d'eux peut se rendre compte de ses actes et voir la réalité en face. Les récits d'Épaves et de La Chute s'adressent à ceux que Camus appelle les bourgeois tels que Philippe et Clamence. Le miroir de Clamence et de Philippe juge leur oisiveté, leur caractère narcissique, leur froideur et leur lâcheté. Enfin, il juge leur vie qu'ils voient passer sous leurs yeux comme les eaux de la Seine sans pouvoir en saisir les meilleurs moments. Une vie qui tombe en «chute » libre et dont il ne reste que des « épaves ». Une vie absurde puisque «l'absurdité est surtout le divorce de l'homme et du monde. » ${ }^{361}$ Comme leurs auteurs, tous ces protagonistes que la présence du double a perturbés, essaient de retrouver un équilibre dans leur vie. Trouver la juste mesure, l'équilibre entre la pulsation de vivre et la pulsation de mourir, entre la nuit et le jour, entre l'ombre et la lumière et entre l'exil et le royaume. Ils se débattent de toute leur force pour retrouver la paix qu'ils ont perdue lors de la scission interne provoquée par le miroir.

\footnotetext{
${ }^{359}$ Camus, CEuvres complètes: Théâtre 1915.

${ }^{360}$ Ziegler 35 .
} 
L'intérêt d'avoir des personnages aussi complexes est de pouvoir s'identifier à eux, à leur malaise plus particulièrement. Nos deux auteurs nous incitent à regarder assez longtemps dans le miroir afin de laisser le temps à notre vraie image d'émerger et de nous permettre de mieux nous connaître et nous guider dans la conquête de l'être. Philippe et Clamence nous ont tendu le miroir pour que nous fassions notre propre jugement, réglions nos comptes, plaidions notre cause ; ils nous offrent une deuxième chance de nous repentir.

Camus a toujours lutté contre l'idée de la culpabilité. Il a toujours rejeté l'idée du péché originel. Dans La Mort heureuse, en parlant de son protagoniste Zagreus, il note dans Carnets : «Après assassinat, reprend son appartement. N’y change rien. Met seulement une glace neuve. ${ }^{362}$ Il espérait peut-être que celle-ci n'aurait pas ce pouvoir magique de révéler sa culpabilité et d'éveiller sa conscience. Il ne veut pas être torturé.

${ }^{362}$ Camus, Carnets I 116. 


\section{Chapitre 3 : Le salut dans l'abîme}

Lorsque l'esprit impur sort de l'homme, il va par les

lieux arides, cherchant le repos, et il n'en trouve point. ${ }^{363}$

Math. XII, 43.

Les années 30 furent des années de malaise aussi bien pour Green que pour Camus. Le premier vient de s'éloigner d'une religion qu'il a adoptée depuis sa tendre enfance et qui le liait directement à sa mère au moment où il entame la rédaction d'Épaves. Le second, à travers ses premiers textes tels que Intuitions, Délires, Souhait, Les Nuits ou Stello et Retour sur moi-même, nous expose son malaise d'adolescent où il s'interroge sans trouver de réponse satisfaisante : « Je cherchais le sens de la vie, de cette vie que je ne connaissais pas. ${ }^{364}$ Le fou avec lequel Camus entreprend un dialogue dans son texte Souhait, refuse de chercher car selon lui « Refuser de savoir est un affranchissement, un définitif pas en avant et une libération de l'âme. ${ }^{365}$ Mais est-ce vrai ?

En 1932, Green note dans son journal alors qu'il travaillait sur son roman Le Visionnaire: «Je voudrais dans le personnage de Manuel, faire voir qu'il y a chez l'hypocrite des mouvements de révolte contre son hypocrisie et souvent une sincère admiration pour la vertu. » ${ }^{366}$ C'est ce manque de précision que le philosophe et critique

\footnotetext{
${ }^{363}$ Camus, Carnets II 60.

${ }^{364}$ Camus, Euvres complètes: Essais 1171.

${ }^{365}$ Camus, Euvres complètes: Essais 1171.

${ }^{366}$ Green, Journal I 120.
} 
Gabriel Marcel ${ }^{367}$ lui a reproché dans Épaves : «La découverte que fait Philippe de sa lâcheté, est admirable, 'mais le grave défaut du livre, c'est que M. Green n'est pas parvenu à développer le germe contenu dans cette révélation' » qu'il « ne traite malheureusement que par bribes. ${ }^{368}$ Pendant cette période d'incertitude, Épaves n'est pas le seul roman dont le dénouement ne répond pas aux exigences de la critique. Michèle Raclot constate que le dénouement dans Minuit est également ambigu. Rappelons aussi que cette ambiguïté vient de l'ambivalence de l'auteur lui-même.

Le drame de Philippe et de Clamence réside dans le fait qu'ils ont perdu le sens de la vie, car et que rien ne les passionne. Clamence confie à son interlocuteur : «J'étais à l'aise en tout, il est vrai, mais en même temps satisfait de rien. » ${ }^{369}$ Que cherchent-ils ces bourgeois déchus? Vont-ils enfin trouver la liberté ? Pour le moment ils souffrent de « [la] conscience intérieure du crime » car celle-ci « est plus puissante que la loi des hommes, que le châtiment des hommes. » ${ }^{370}$

Lorsqu'on nous a inculqué une certaine morale dès le jeune âge, quel que soit le chemin sinueux que l'on emprunte dans la vie, on revient toujours aux sources. Green a connu une morale religieuse par sa famille et surtout par l'éducation maternelle. Plus tard, il en fera un choix délibéré. Par ailleurs, dans Pamphlet contre les catholiques de France, Green déverse sa colère de fanatique pour le christianisme et la Bible. Il se

\footnotetext{
${ }^{367}$ Gabriel Marcel, «Les lettres, Épaves, par Julien Green. » L'Europe nouvelle, 9 avril 1932.

368 Green, Euvres II 1317.

${ }^{369}$ Camus CEuvres complètes: Théâtre 1490.

${ }^{370}$ Kissel, « Julien Green, » 121.
} 
révolte contre l'existence de l'enfer et la peur qu'elle lui procure. Il ne supporte plus l'hypocrisie de l'Église et ceux qui la dirigent. À cette époque-là, il écrit : «Vous donnez à un plaisir nécessairement limité le prix d'une chose éternelle, puisque vous paierez ce plaisir d'une éternité de regret, d'ennui et de désespoir. Il vous donnera tout ce qu'il peut, mais il ne vous laissera au cœur que l'amertume et le dégoût, et il vous fatiguera jusqu'à la mort. » ${ }^{371}$

Camus, quant à lui, bien que la religion ne soit pas son point fort et malgré les cours de catéchisme que sa grand-mère lui a fait suivre à l'église, n'a jamais été vraiment touché par le message religieux tel que le voulait l'Église catholique. Todd révèle dans la biographie de Camus que ce dernier « est élevé aux franges d'un catholicisme superficiel. » ${ }^{372}$ L'auteur de La Chute confirme : «Quand il m'arrive de prier, je prie un Christ qui m'apparaît autre que Celui que j'ai reçu. » ${ }^{373}$ Le père de Simone, sa première épouse, le qualifie de « saint Berbard. » À défaut de religion, Camus a été séduit par la morale qu'il acquit de ses maîtres et de son oncle Gustave Acault, chez qui il a vécu pendant la période de convalescence, et qui lui répétait souvent : « Les hommes intelligents sont supérieurs aux pédants, un ignorant qui a de la morale vaut plus qu'un cagot hypocrite. ${ }^{374}$ La philosophie l'a également intéressé et surtout le « Dieu des philosophes » car selon Camus ce dernier « est à bonne distance du Dieu des

\footnotetext{
${ }^{371}$ Green, Euvres I 898.

372 Todd 34.

373 Todd 42.

374 Todd 48.
} 
Évangiles. » ${ }^{375}$ Camus a toujours éprouvé un intérêt pour les problèmes métaphysiques plus que religieux, suivant les pas de son maître saint Augustin, même si ce dernier n'a pas connu le terme «métaphysique qui n’est apparu qu'au XII ${ }^{\mathrm{e}}$ siècle. Alors, lorsque Camus parle du jugement et du châtiment, il ne se réfère pas toujours au jugement dernier mais au jugement sur terre avant tout, celui de l'homme sur l'homme et le jugement de soi qui mène inéluctablement au châtiment de soi, voire parfois à l'autodestruction puisque l'homme finit par perdre l'estime de soi.

Le châtiment est défini comme étant la «punition sévère donnée à celui qui a commis une faute, pour le corriger. ${ }^{376}$ Cependant ce qui nous intéresse est l'autochâtiment, ce mal qui ronge sa victime comme un démon intérieur, qui n'est autre qu'un mal psychologique déclenché par un sentiment de culpabilité qui débouche sur une maltraitance de soi.

Pour y remédier Clamence compte sur le genièvre, boisson que l'on sert au bar Mexico-City, « la seule lueur dans ces ténèbres » ${ }^{377}$ qui protège les âmes souffrantes : «Dans l’Antiquité et au Moyen Âge, le genévrier était utilisé comme panacée, ses fumigations étaient réputées désinfectantes (notamment utilisées dans les rues pour combattre les épidémies de peste et de choléra). ${ }^{378}$ Dans l'histoire, on raconte aussi que

\footnotetext{
375 Todd 50.

${ }^{376}$ Centre national de recherche scientifique. 12 janvier 2011. http://www.cnrtl.fr/lexicographie/ch\%C3\% A2timent.

${ }^{377}$ Camus, Euvres complètes: Théâtre 1481.

378 «Genévrier ». 01 décembre 2012. http://fr.wikipedia.org/wiki/Gen\%C3\%A9vrier.
} 
cette plante servait «à la toilette des morts. ${ }^{379}$ Mais du point de vue religieux, le genévrier est vu comme « le symbole de l'épreuve ultime, de la limite à dépasser pour affronter la mort et atteindre la purification et la renaissance ${ }^{380}$ Il paraît d'ailleurs que la Vierge Marie et l'enfant Jésus se sont cachés sous le genévrier pour échapper aux soldats romains. Ainsi, nous espérons élucider l'usage de manière excessive du genièvre dans La Chute et comme par hasard dans les moments de tourmente.

En apprenant la pratique de l'estime de soi chez ses patients, le psychiatre français Christophe André constate que certains patients n’hésitent pas à se faire du mal dès qu'ils se rendent compte qu'ils ont commis une faute, quelle que soit la gravité ou la banalité de celle-ci, alors que d'autres se contentent tout simplement d'y penser sans passer à l'exécution. Toutes ces émotions ne peuvent apparaître que chez les êtres qui ont une grande sensibilité. André relate l'histoire suivante :

Je me souviens d'une jolie jeune femme qui se donnait de violentes claques, lorsqu'elle n'était pas contente d'elle, par exemple au retour d'une soirée où elle s'estimait s'être comportée comme une idiote (en parlant trop), ou comme une cruche (en ne parlant pas assez). ${ }^{381}$

Rappelons que le point essentiel qui rassemble ces deux œuvres réside dans le déchirement et le châtiment intérieur des protagonistes. Ces derniers sont à la fois victimes et témoins d'un destin qui n'est pas toujours juste, voire une condition humaine

\footnotetext{
379 « Genévrier ». 01 décembre 2012. http://fr.wikipedia.org/wiki/Gen\%C3\%A9vrier

380 « Huile essentielle de genièvre baies ». http://www.info-massage.com/huile-essentielle-de-genievre.html 01 décembre 2012

381 André Christophe, Imparfaits, libres et heureux: Pratiques de l'estime de soi (Paris: Odile Jacob, 2006) 137.
} 
tragique dont ils sont les acteurs et les spectateurs, mais « il faut se souvenir que chacun de ces spectateurs a aussi un rendez-vous avec lui-même ; qu'il le sait, et que, sans doute il s'y rendra tout à l'heure. » ${ }^{382}$ Pour se libérer des malaises que leur offre cette «nature sans grâce » et ce «monde sans Dieu, » ${ }^{383}$ et extérioriser le refoulement qui crée le conflit intérieur, un retour sur soi est inévitable. Dans Crime et châtiment, Dostoïevski consacre une partie de l'œuvre à la préparation du crime et cinq parties au châtiment de soi, de Raskolnikov. Ce tourment moral est particulièrement cruel. Commentant son œuvre, L'Homme du souterrain, Dostoïevski note :

Le tragique c'est la conscience d'être monstrueux [...] Moi seul j'ai montré la tragique du souterrain, c'est-à-dire la souffrance, l'autopunition, la prescience d'un mieux et l'impossibilité d'y parvenir, et, surtout l'ardente conviction de ces malheureux que c'est le lot de tout le monde et qu'en conséquence ce n'est pas la peine de s'y corriger ! ${ }^{384}$

Camus et Green ne réfutent pas l'idée de leur prédécesseur russe, bien au contraire ils s'engagent dans la même voie pour montrer qu'il n'est pas facile de trouver un moyen pour soulager ces âmes qui souffrent, celle de Philippe, Éliane, Henriette et Clamence. Leur drame peut en effet s'avérer désastreux car ils peuvent s'autodétruire par l'obsession du sujet qui les ronge. Hormis Clamence, chacun d'eux a fait au moins une tentative de suicide.

\footnotetext{
${ }^{382}$ Camus, Euvres complètes: Essais 10.

${ }^{383}$ Green, Euvres II 1316.

${ }^{384}$ Michel Cadot, « La double postulation de Baudelaire et sa version dostö̈evskienne ». Revue canadienne de la littérature comparée. 4.1 (1977): 63.
} 
Cependant l'effet du drame et du sentiment de culpabilité agit différemment sur chacun des acteurs. Ils essaient d'avancer et de corriger leurs fautes, de se repentir autant que possible et de régler certaines pulsions destructrices. Clamence plus lucide, se rend compte, tout comme l'auteur russe, que la faute est commune et décide d'agir : il entre dans un purgatoire. Cette différence dans la façon de mener sa vie après la faute est liée à la durée du sentiment de culpabilité et au degré de culpabilité, selon qu'il soit ponctuel, intermittent, fréquent ou permanent. Qu'il soit sincère ou pas, Clamence semble réagir.

En revanche, Philippe demeure stérile et refuse de prendre toute responsabilité et de donner le meilleur de lui. Vu le lent déroulement de l'action, l'évolution de Philippe n'est pas aussi palpable que celle de Clamence, mais tout aussi difficile à suivre. On dirait que l'auteur hésite sur le comportement de Philippe. Entre le choix de fuir ses problèmes en se suicidant ou de les ignorer et vivre avec un malaise éternel, Philippe oscille. Il essaie d'adopter des conduites de défense intérieure, de protection contre la culpabilité anxieuse, mais à force de se contrôler, il perd sa sérénité et finit par lâcher prise au point d'éprouver parfois des envies bizarres : «Un besoin de détruire le prenait, un besoin de se nuire à lui-même. » ${ }^{385}$

De même s’il existe des degrés de culpabilité, le châtiment ou la punition varie selon la gravité de la faute, et toute personne de conscience subit ce châtiment par sa propre conscience à défaut du système judiciaire. Dans Épaves et La Chute, chaque protagoniste cherche son salut peu commun, un salut qui fait mal. Par exemple, dans $L e$

${ }^{385}$ Green, Euvres II 11. 
Sous-sol de Dostoïevski, le protagoniste se punit en refusant de soigner sa maladie du foie, espérant ainsi payer sa dette :

Je suis un homme malade... Je suis un homme méchant. Je suis un homme déplaisant. Je crois que j'ai une maladie du foie. D'ailleurs je ne comprends absolument rien à ma maladie et ne sais même pas au juste où j'ai mal. Je ne me soigne pas et ne me suis jamais soigné. Si je ne me soigne pas, c'est pure méchanceté de ma part. Je sais très bien que ce ne sont pas les médecins que j'embête en refusant de me faire soigner. Je ne fais de tort qu'à moi-même ; je le comprends mieux que quiconque. Et pourtant, c'est bien par méchanceté que je ne me soigne pas. J'ai mal au foie ! Tant mieux !!! ${ }^{386}$

On retrouve cette même attitude chez nos protagonistes. Ils perdent espoir et continuent à vivre en souffrant et en attendant une libération. Cet ennemi qu'est le malaise que vivent Green et Camus semble s'être installé depuis longtemps, il les accompagne chaque jour dans leur vie. Camus confesse :

Le seul effort de ma vie, le reste m'ayant été donné, et largement (sauf la fortune qui m'indiffère) : vivre une vie d'homme normal. Je ne voulais pas être un homme des abîmes. Cet effort démesuré n'a servi de rien. Peu à peu, au lieu de réussir de mieux en mieux dans mon entreprise, je vois l'abîme s'approcher. ${ }^{387}$

Juxtaposer «l'homme normal » et «l'homme des abîmes » dans une même phrase résume la personnalité de Clamence dictée par Camus, de même que celle de Philippe par Green. Chacun d'eux veut montrer que l'on atteint cet état de normalité seulement si l'on

\footnotetext{
${ }^{386}$ Dostoïevski, Carnets du sous-sol, cité par Alexis Philonenko, La Philosophie du malheur: Chestov et les problèmes de la philosophie existentielle (Paris: Vrin, 1998) 46.

${ }^{387}$ Camus Carnets II 275.
} 
s'éloigne des abîmes, mais est-ce possible ? Selon Camus non, puisque quoi qu'il fasse «le glissement vers l'abîme » ${ }^{388}$ est incontournable.

Le comportement délirant de Clamence le pousse à s'abandonner à la mauvaise conscience obscure de l'angoisse. Toute action perverse qu'il entreprend lui permet d'accumuler plus de péchés et de se sentir encore plus mal. Il entre dans un cercle vicieux qui définit son châtiment. La culpabilité de Clamence est permanente, son créateur décide de le condamner à perpétuité, c'est-à-dire au même sort que le sien : «Je souffre de cela, comme je souffre de toute contradiction. En moi je concilie tout [...] il reste évident que je ne peux détruire les contradictions externes. Elles sont l'essence même de la vie et je suis impuissant devant elles. C'est pourquoi mon tourment est inguérissable. » 389

Clamence va plus loin que Camus, car il veut que sa punition soit pire encore ; en cachant chez lui le tableau des Juges intègres, il espère avoir une chance d'aller en prison et de payer pour ses fautes. Clamence est bien plus pessimiste que Philippe, pour lui le salut semble inaccessible. En fait, on peut s'en rapprocher le jour où l'amour de l'autre est si fort qu'on arrive à ressentir la douleur d'autrui. Alors son interlocuteur qui lui demande s'il en était capable, il répond : «Écoutez, je voudrais l'être, je le serai. Oui,

\footnotetext{
${ }^{388}$ Critique de Charpentier dans le Mercure de France : « Ses visions du paysage fluvial de Paris sont hallucinantes et traduisent admirablement le sentiment de peur, d'appel du gouffre, de glissement vers l'abîme qui est comme le thème musical d'Épaves. » Green, Euvres II 1315.

${ }^{389}$ Camus, Euvres complètes: Essais 1171.
} 
nous en serons tous capables un jour, et ce sera le salut. ${ }^{390}$ Mais comme Camus n'a plus d'espoir, le salut n'est atteint que par la mort. Il écrit : « Je me disais aussi que la mort du corps, si j'en jugeais par celle que j'avais vue, par elle-même une punition suffisante et qui absolvait tout. On y gagnait son salut [...] à la sueur de l'agonie. » ${ }^{391}$ À travers Philippe, Green exprime encore une fois sa déception en sa personne lorsqu'il n'a pas pu résister aux tentations et aux désirs du monde terrestre. Philippe n'est pas un saint et Clamence n'est pas un prophète. Cependant, tous deux ont perdu la lumière qui devait éclairer leur vie et les ramener vers ceux qui connaissent le chemin du salut : « [par] un brusque retour de son esprit, il [Philippe] se jugeait vain, inutile, mais beaucoup plus humble qu'autrefois. Et il se demanda s'il ne valait pas mieux rentrer chez lui, ôter son beau pardessus, tirer les volets, et se cacher, pour laisser la lumière à d'autres ${ }^{392}$ car lui, les ténèbres de l'abîme, il s'en accommode. Cependant pour Green, aucune repentance ne peut effacer la mort. Une idée qu'il a peut-être reçue de l'éducation puritaine de sa mère, qui lui répétait : «Si tu devais commettre une mauvaise action, j’aimerais mieux te voir mort, comprends-tu ? Mort à mes pieds. » ${ }^{393}$

L'exil est le châtiment de Clamence après le réveil de sa conscience. Cet exil se retrouve dans la confidence de Camus sur les voyages qui les prédisposent lui et son

\footnotetext{
${ }^{390}$ Camus, CEuvres complètes: Théâtre 1492.

${ }^{391}$ Camus, Euvres complètes: Théâtre 1521.

${ }^{392}$ Green, Euvres II 112.

${ }^{393}$ Green, Euvres V 689.
} 
protagoniste à une interrogation sur soi. Ainsi, lors de son voyage aux Baléares, Camus écrit :

Ce qui fait le prix du voyage, c'est la peur. C'est qu'à un certain moment, si loin de notre pays, notre langue (un journal français devient d'un prix inestimable. Et ces heures du soir dans les cafés où l'on cherche à toucher du coude d'autres hommes), [comme c'est le cas dans Mexico-City] une vague de peur nous saisit, et un désir instinctif de regagner l'abri des vieilles habitudes. C'est le plus clair apport du voyage. À ce moment-là nous sommes fébriles mais poreux. Le moindre choc nous ébranle jusqu'au fond de l'être. Qu'une cascade de lumière se rencontre, l'éternité est là. C'est pourquoi il ne faut pas dire qu'on voyage pour son plaisir. Il n'y a pas de plaisir à voyager. J'y verrais plutôt une ascèse. [...] Le plaisir nous écarte de nous-même comme le divertissement de Pascal éloigne de Dieu. Le voyage, qui est comme une plus grande et plus grave science, nous y ramène. ${ }^{394}$

Philippe et Clamence ressentent leur propre châtiment différemment. Ils se sont exilés et vivent en ermite, un châtiment qu'ils ont choisi pour payer leur crime. Leur exil est avant tout psychologique ou psychique, ce qui ne se traduit pas toujours par un déplacement physique mais par une errance de l'âme que Conrad appelle mon «exil existentiel »: «En ce sens, le héros conradien trouve son double quelques dizaines d'années plus tard dans le héros camusien, 'cet homme absurde.' » ${ }^{395}$ Nos héros s'exilent de façon différente; Philippe décide de se couper du monde extérieur et s’est fait un monde à part. Il se retrouve seul au cours de ses déambulations chargées d'angoisses, de culpabilité, et de désespoir qu'il ne confie à personne. Il a mis fin aux soirées qu'il

\footnotetext{
394 Camus, Carnets I 26.

395 Époque conradienne 129.
} 
passait chez lui avec sa belle-sœur et s'est retiré de l'entreprise que son père a construite et qu'il lui a léguée. Dans Le Mythe de Sisyphe, à propos de l'homme absurde, Camus écrit :

Dans un univers soudain privé d'illusions et de lumières, l'homme se sent un étranger. Cet exil est sans recours puisqu'il est privé des souvenirs d'une patrie perdue ou de l'espoir d'une terre promise. Ce divorce entre l'homme et sa vie, l'acteur et son décor, c'est proprement le sentiment de l'absurdité. ${ }^{396}$

Clamence suivant les conseils de son créateur, descend dans le brouillard

d'Amsterdam, passe son temps entre une chambre d'hôtel lugubre et le bar du Mexico-

City. Il procède à son propre jugement comme il explique dans son soliloque : « Ah !

Mon cher, pour qui est seul, sans Dieu et sans maître, le poids des jours est terrible. » ${ }^{397}$ Ainsi, Clamence se plie aux directives de Camus : «Il s'agit d'abord de se taire - de supprimer le public et de savoir se juger.» ${ }^{398}$ Clamence abandonne la vie mondaine de bourgeois afin de retrouver le monde « des poètes et des impuissants », ${ }^{399}$ afin d'entamer tout un travail de libération à l'égard de son égoïsme, son narcissisme, sa vanité et sa lâcheté, travail qui malheureusement n'aboutira pas.

Henriette est condamnée à vivre le reste de sa vie malheureuse par manque d'amour. Un « amour du passé qu'elle n'a plus goûté depuis son enfance, « un désir de retrouver ce pays lointain. ${ }^{400}$ Elle ne peut s'épanouir dans le milieu bourgeois que lui

\footnotetext{
${ }^{396}$ Camus, Mythe 20.

${ }^{397}$ Camus, CEuvres complètes: Théâtre 1544.

${ }^{398}$ Camus, Carnets I 107.

${ }^{399}$ Camus, Caligula 82.

${ }^{400}$ Green, Euvres II 1311.
} 
offre son mari. Elle retrouve la misère de l'enfance chez son amant. Une misère qui la rendait heureuse jadis. Dans cette relation d'adultère très particulière, Henriette ne cherche pas vraiment l'amour mais elle fait tout pour se retrouver dans la maison de son amant qui la transporte vers son paradis perdu. Éliane, quant à elle, se cantonne dans un sentiment de remords, de culpabilité, de rancune et de rêve qui ne sera jamais réalisé. Elle tente d'abord de fuir et de s'isoler dans une chambre de pension puis de se suicider.

Green, Camus, Philippe et Clamence sont en cavale, car ils se cherchent toujours. En 1950, lors d'un séjour en Haute-Savoie, Camus note dans Carnets : «Les êtres qui comme [Clamence] éternels émigrants, sont à la recherche d'une patrie finissent par la trouver, mais seulement dans la douleur. » ${ }^{401}$ Clamence est à la recherche de cette douleur qui pourrait peut-être le mener à la rédemption et au pardon. Il s'est cherché, s'est analysé pour se reconnaître et finit par s'affirmer. À Amsterdam, il se sent à sa place et ne veut pas que cela change. Il dit : «Et pourquoi changerai-je puisque j’ai trouvé le bonheur qui me convient ?... j’y ai trouvé le confort que j'ai cherché toute ma vie. » ${ }^{402}$ Et il continue : « Tout serait consommé, j’aurais achevé, ni vu ni connu, ma carrière de faux prophète qui crie dans le désert et refuse d'en sortir. » ${ }^{403}$ Clamence

\footnotetext{
${ }^{401}$ Camus, Carnets II 330. Nous avons pris l'initiative de changer la référence qui est « Les êtres qui comme M., éternels émigrants, sont à la recherche d'une patrie finissent par la trouver, mais seulement dans la douleur » en remplaçant M. par Clamence.

${ }^{402}$ Camus, Euvres complètes: Théâtre 1548.

${ }^{403}$ Camus, Euvres complètes: Théâtre 1551.
} 
annonce sa fin de la même manière que Jésus sur le crucifix voit sa mort proche :

consummatum est. ${ }^{404}$

« La chute » dans le brouillard d'Amsterdam, ville semblable à La Haye, « sans respiration possible », ${ }^{405}$ doit permettre à Clamence de revenir à lui-même. Cette ville qui est l'inverse d'Alger, dont la chaleur du soleil est remplacée par la brume et le froid, satisfait une certaine mortification nécessaire pour l'auteur. De même, la contemplation de Philippe dans les miroirs et les eaux de la Seine, cet aimant de la mort, ne révèle pas seulement son côté narcissique mais surtout un sentiment étrange et nouveau. Même lorsque le comportement de Philippe montre qu'il ne pense pas à cet incident qui a bouleversé le calme et la monotonie de sa vie, l'angoisse est là, sourde certes mais omniprésente. Dans sa solitude, ses inquiétudes et ses interrogations perpétuelles l'accompagnent.

Philippe et Clamence sont conscients que pour atteindre « le salut », ils ne doivent pas masquer la douleur qu'ils ressentent et l'expérience du mal fait partie de leur « chute» dans le néant. La douleur liée au déchirement est omniprésente dans le quotidien, de Green et de Camus. C'est le catalyseur qui pousse chacun d'eux à exceller dans sa lutte. En effet, cette douleur leur permet de ne pas oublier la réalité de la vie ou d'éviter le détournement de la culpabilité par des pensées abstraites, mais au contraire

\footnotetext{
${ }^{404}$ Didier Alexandre, L'Absolu intertextuel dans l'exégèse de Paul Claudel. 2006. 11 janvier 2013. $<$ http://narratologie.revues.org/308>

${ }^{405}$ Camus, Carnets III 114. Camus décrit la ville de La Haye lors de sa visite en Hollande en 1954, plus tard c'est ce décor qui va servir à son œuvre La Chute.
} 
« [d]'abîme en abîme, l'esprit voyage entre ces mondes. Une ivresse particulière fait chavirer nos pensées, un bonheur étrange, mes amis, quelque chose comme un long vertige sans l'horreur de la chute. ${ }^{406}$ Les mots « gouffre » et « abîme » récurrents dans Épaves accompagnent les protagonistes tout au long du récit et leur chute dans l'abîme est l'une des faces du châtiment. Ils ne restent d'eux que des épaves comme image de leur déchéance. Clamence affirme : «Les soutes, les cales, les souterrains, les grottes, les gouffres me faisaient horreur. » ${ }^{407}$

Il n'y a pas d'issue, il n'y a pas de salut. Rêvent-ils tous les deux d'une deuxième chance ? Peut-être pas. Clamence espère que la jeune fille se jette une fois encore dans l'eau pour qu'il puisse la secourir mais une partie de lui-même hésite de le faire. Le fera-t-il ? Difficile de comprendre vraiment les intentions de Clamence vu le ton sarcastique qu'il emploie. Philippe revient souvent à l'endroit du crime.

Les auteurs ont choisi une fin ironique pour montrer que malgré le déchirement vécu par les protagonistes, il n'y pas vraiment d'issue, mis à part une lueur possible d'un monde inaccessible. Clamence comme Philippe erre tourmenté en répétant :

J'ai voulu vivre pendant des années selon la morale de tous. Je me suis forcé à vivre comme tout le monde, à ressembler à tout le monde. J'ai dit ce qu'il fallait pour réunir, même quand je me sentais séparé. Et au bout de tout cela ce fut la catastrophe. Maintenant j'erre parmi des débris, je suis sans loi, écartelé, seul et acceptant de l'être, résigné à ma singularité et à mes infirmités. Et je dois reconstruire une vérité - après avoir vécu toute ma vie dans une sorte de mensonge. ${ }^{408}$

\footnotetext{
${ }^{406}$ Raclot 32.

${ }^{407}$ Camus, Cuvres complètes: Théâtre 1487.

${ }^{408}$ Camus, Carnets III 250.
} 
La tentative de suicide de Philippe et d'Éliane marque leur désespoir : « Il y a une étrange satisfaction à toucher le fond du désespoir ; l'excès du malheur procure une espèce de sécurité, havre de grâce pour l'âme naufragée qui n'ose plus croire. Telle détresse morale est l'abri le plus sûr, tel abandonnement, le repos.» ${ }^{409}$ Dans son journal, Green explique la personnalité d'Éliane et dévoile un caractère très proche de Clamence, c'est-à-dire qu'elle oscille à la fois entre le mal et le bien, un caractère presque schizophrène.

Mais avec le suicide aussi on aboutit au problème philosophique que Camus s'est posé et qui représente la fondation de son œuvre : « [juger] que la vie vaut ou ne vaut pas la peine d'être vécue. ${ }^{410}$ Éliane ne savait pas comment réagir face à l'absurdité de son destin. Toute sa révolte se résume dans ses hallucinations horribles, une fuite brève, une tentative de crime qui n' aboutit pas.

Le sort de Clamence est décidé par son créateur, car il reste à Amsterdam où il mène une vie hagarde et reste volontairement dans une prison sans issue. C'est un autre Sisyphe qui roule la pierre de la confession de la culpabilité. Son but est de pouvoir faire entendre son récit à toutes les créatures du monde, ce qui contribue à lui donner un certain pouvoir. Ce sentiment de continuité vient de Camus qui, tout au long de sa vie cherchait « la mesure », la perfection, sans être jamais satisfait. Il se proclame « le plus

\footnotetext{
${ }^{409}$ Green, Euvres I 746.

${ }^{410}$ Camus, Euvres complètes: Essai 99.
} 
démuni et le plus nécessiteux des êtres ${ }^{411} \mathrm{Il}$ a noté dans Carnets : « Si je devais mourir ce soir, je mourrais dans un sentiment affreux, qui m'était inconnu et qui pourtant me fait mal ce soir. Le sentiment que j'ai aidé et que j'aide beaucoup d'êtres - et que personne pourtant ne me vient en aide. $»^{412}$

Une autre personne semblable, dans ce contexte, à Camus est Philippe. Green également précise : «J'ai voulu faire le portrait d'un bourgeois intelligent qui se demande s'il vaut ou non la peine qu'on le sauve ? ${ }^{413}$ Une telle question dévoile l'angoisse de Green et de Camus et le châtiment qu'ils projettent sur leurs protagonistes. En reprenant une citation de Stendhal, Camus note: «Je n'aurai rien fait pour mon bonheur particulier tant que je ne serai pas accoutumé à souffrir d'être mal dans une âme. ${ }^{414}$ Alors il exile Clamence dans un endroit démuni de conformité pour qu'il y cherche le salut et y fasse pénitence. Ce que fait effectivement Clamence, mais il ne s'est pas arrêté là. À travers la parole il a poussé les compatriotes qui passent par le bar du Mexico-City à en faire autant afin qu'ils soient tous jugés, sachant que chacun va faire en sorte d'éviter le jugement et proclamer son innocence : « Car le châtiment sans jugement est supportable. Il a un nom d'ailleurs qui garantit notre innocence : le malheur. ${ }^{415}$ Clamence ou Camus dénonce

\footnotetext{
${ }^{411}$ Camus, Carnets III 45.

${ }^{412}$ Camus, Carnets III 39.

${ }^{413}$ Green, Euvres II 1306.

${ }^{414}$ Camus, Carnets II, 219.

${ }^{415}$ Camus, Euvres complètes: Théâtre 1514.
} 
même la corruption des juges puisque pour les riches « la richesse soustrait au jugement immédiat [...] ce n'est pas encore l'acquittement mais le sursis.» ${ }^{416}$

Le but de la confession de Clamence est d'être jugé ainsi que ceux qui lui ressemblent. Le sentiment de culpabilité qui le déchire n'est pas suffisant pour se purifier. Il aspire au jugement et tant qu'il n'y pas eu de jugement il n'y a pas de justice rendue et l'homme continue à commettre les mêmes fautes. Même la damnation éternelle ne peut satisfaire ni Camus ni son protagoniste.

Philippe ne peut se réconcilier avec lui-même tant qu'il continue à entendre le cri de détresse venant des profondeurs des eaux de la Seine et le bruit du remorqueur qui lui rappelle le soir où il n'a pas voulu sauver la jeune femme. Il continue alors à faire son pèlerinage sur le lieu du crime, à regarder son image reflétée par les eaux mornes du fleuve et à écouter ce cri qui le déchire encore une fois afin de goûter encore la douleur. La Seine et ses méandres traversent son cœur comme elle traverse le roman.

Avec une lueur de lumière vient l'espoir d'un monde meilleur pour l'humanité. Bien que Rieux ${ }^{417}$ ait pu combattre la peste, il restait un sentiment de crainte et d'appréhension qui l'empêchait de savourer pleinement son triomphe sur la maladie. Il savait hélas que cette trêve n'était que temporaire et que le mal ne serait jamais totalement exterminé:

\footnotetext{
${ }^{416}$ Camus, Euvres complètes: Théâtre 1517.

${ }^{417}$ Le docteur Rieux est le protagoniste qui a combattu la maladie de la peste dans le roman La Peste d'Albert Camus.
} 
[...] Les cris d'allégresse qui montaient de la ville, Rieux se souvenait que cette allégresse était toujours menacée. Car il savait ce que cette foule en joie ignorait, et qu'on peut lire dans les livres, que le bacille de la peste ne meurt ni ne disparait jamais, qu'il peut rester pendant des dizaines d'années endormi dans les meubles et le linge, qu'il attend patiemment dans les chambres, les caves, les malles, les mouchoirs et les paperasses, et que, peut-être le jour viendrait où, pour le malheur et l'enseignement des hommes, la peste réveillerait ses rats et les enverrait mourir dans une cité heureuse. ${ }^{418}$

Ce sentiment de paix que Philippe a ressenti vers la fin du roman, il savait qu'il était temporaire et le cri du remorqueur n'était qu'un avertissement qui n'annonçait que le mal, cette « roue folle qui tourne sans cesse. ${ }^{419}$ Il faut donc imaginer « Sisyphe heureux ? » L'homme, selon Camus, est considéré comme étranger à cause de cette mort ultime, car il n'y a pas de lendemain. Jean-Paul Sartre a dit : «Camus aurait tout aussi bien pu choisir, pour désigner son ouvrage le nom d'une œuvre de Georges Gissing : Né en exil. » 420

\footnotetext{
${ }^{418}$ Camus Euvres complètes: Essais 1474

${ }^{419}$ Camus, Euvres complètes: Essais 2036

${ }^{420}$ François Sobieraj, «L'Étranger ». 19 fevrier 2010. 15 mars 2012. http://meli-melosobieraj.blogspot.com/2010_02_01_archive.html.
} 


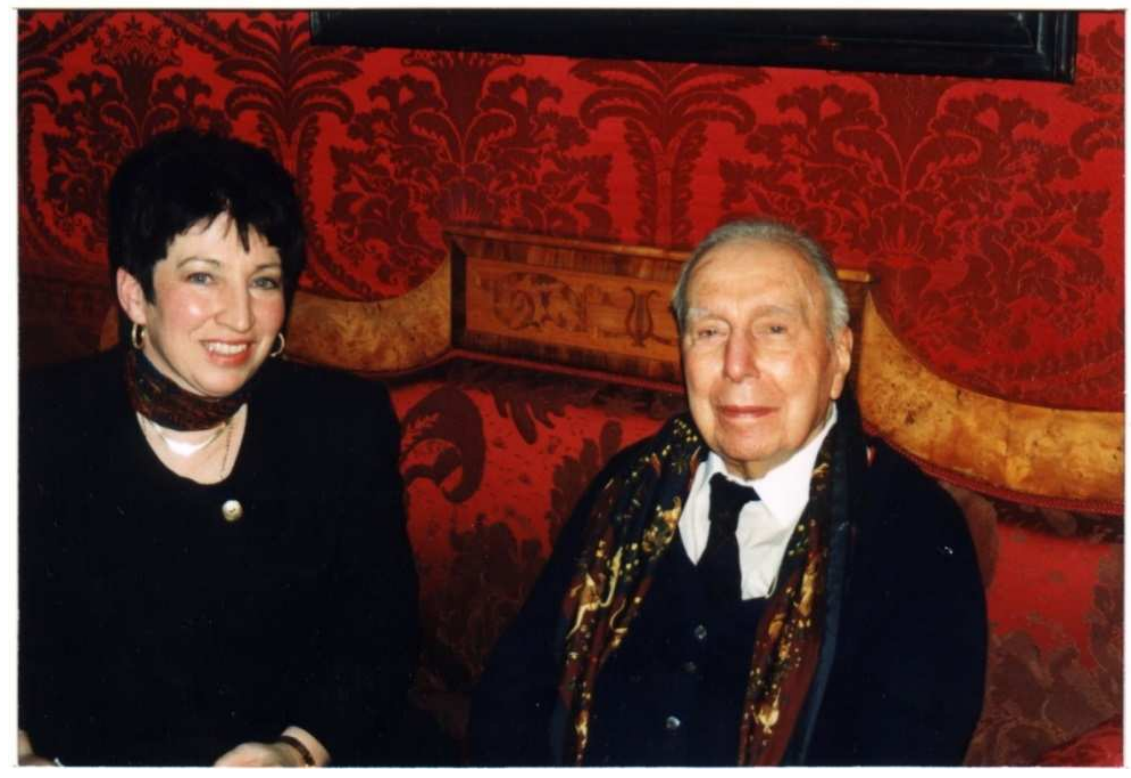

Julien Green et le professeur Dominique van Hooff ${ }^{421}$ dans l'appartement de l'écrivain, rue Vaneau à Paris en 1998 (Collection personnelle Dr. Dominique van Hooff) .

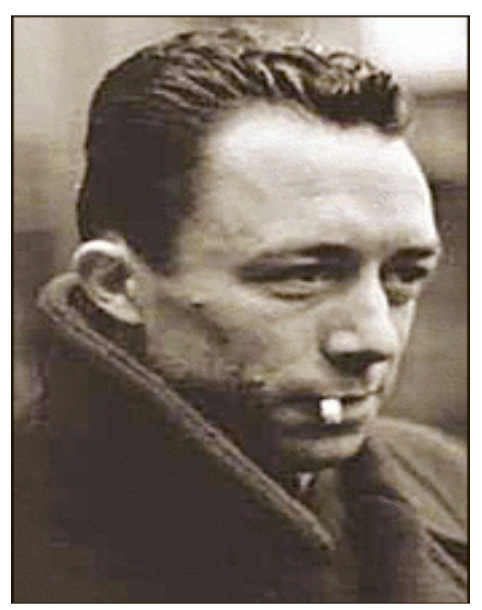

Albert Camus. $^{422}$

\footnotetext{
${ }^{421}$ Madame Dominique van Hooff est professeur au département de World Languages and Literatures à l'université de San José.

${ }^{422}$ Terms of Use: These images are public domain (PD), and that means they can be used and edited for whatever purpose you wish, personal or commercial. No attribution or linking is required. $<$ http://www.wpclipart.com/famous/philosophy/Albert_Camus.png.html>.
} 


\section{Conclusion}

Un aveugle à qui des yeux sont prêtés, un sourd qui acquiert la faculté d'entendre, un non-poète qui reçoit le don de poésie, voilà ce que c'est qu'un critique. $^{423}$

Albert Camus

Ce mémoire est le fruit d'une étude comparative entre deux œuvres de la même époque. En analysant Épaves et La Chute, nous avons tenté de démontrer comment face à l'éveil de leur conscience, deux êtres si différents pouvaient réagir au déchirement qu'ils subissaient et la souffrance qu'ils enduraient. Rappelons que la méthode que nous avons adoptée n'est exclusivement rattachée à aucune science et à aucun système. Elle ne se veut ni existentialiste, ni psychanalytique, ni philosophique, mais nous nous sommes appuyés sur la philosophie, les critiques et la psychanalyse ainsi que sur la théorie de l'autobiographie et le journal des auteurs pour comprendre ce qui se passe dans le for intérieur des protagonistes à savoir, leurs émotions, leurs désarrois et leurs pensées. Qu'est-ce qui déclenche leur douleur et leur malaise ? Comment réagissent-ils face au déchirement de soi lorsqu'ils entendent le cri, imaginent le rire et goûtent l'amertume de la culpabilité qui leur renvoie dans le miroir une image éblouissante du deuil de leurs illusions sur leur mérite. Les masques tombent! Une culpabilité qui remonte à l'origine du temps et prend source dans le péché originel, faisant ainsi de l'homme un être

\footnotetext{
${ }^{423}$ Laurent Mailhot, Albert Camus ou l'imagination du désert (Québec: Les Presses de l'université de Montréal, 1973) 8.
} 
coupable dès sa naissance. Les auteurs dépeignent des êtres dont la tête est en feu, qui ne savent vraiment pas que faire ou dans quelle direction ils doivent avancer.

De prime abord, rien ne semble justifier le rapprochement entre un écrivain chrétien et un philosophe athée, un bourgeois de Passy ${ }^{424}$ avec un pauvre de Belcourt. ${ }^{425}$ Comment peut-on comparer la sourde révolte de Green au discours retentissant de Camus ? Et pourtant le parallèle de la vie et de l'œuvre de Green et de Camus a fait ressortir de nombreuses analogies. Épaves et La Chute les conduisent vers un même esprit de justice et d'éthique. La recherche de vérité afin d'éclairer la part obscure de l'être, la méditation sur le moi aveugle de chacun d'entre nous, l'étude de l'absurde et la position humaniste sont les points communs d'un Pied-Noir et d'un exilé d'un Sud qui n'existe plus. Ils se rencontrent dans l'envers de l'un et l'endroit de l'autre. Tous deux témoignent dans leur œuvre du malaise qui condamne l'homme à ne jamais retrouver le bonheur absolu, car le malaise est toujours dissimulé dans l'autre face de leur âme, prêt à ressurgir à tout moment et la menace de la mort les guette au tournant.

À travers Philippe et Clamence, les auteurs nous dévoilent leur préoccupation majeure : comment la condition humaine peut-elle faire face à l'absurdité du monde ? Camus écrit dans Carnets : «Si le monde était clair, l'art ne serait pas - mais si le monde me paraissait avoir un sens je n'écrirais pas.» ${ }^{426}$ Green et Camus écrivent tous deux afin

\footnotetext{
${ }^{424}$ Quartier chic de Paris.

${ }^{425}$ Quartier populaire d'Alger

${ }^{426}$ Camus, Carnets II 54.
} 
d'enraciner la vie dans l'œuvre. Green note dans son Journal : «Mon plus grand péché aurait été de ne vouloir pas accepter la condition humaine. » ${ }^{427}$

Leurs protagonistes partagent la même manie des promenades nocturnes dans la brume et le brouillard à proximité de l'eau. À travers eux, les auteurs, hantés par le problème du bien et du mal, évoquent les maux de la société moderne et le déchirement de l'homme face à son destin incompréhensible. Ainsi, Green déclare à propos de son protagoniste Philippe: «Comme tout le monde, il était l'esclave du hasard. » ${ }^{428}$ Le cri que les lecteurs entendent est celui de Green et de Camus. Chacun d'eux se donne une deuxième chance. L'un aspire à extérioriser le malaise et à se libérer, l'autre cherche à juger et à être jugé. Rien ne semble apaiser leur souffrance qui s'enflamme et pourtant, ils espèrent dans l'aveu et la confession retrouver la confiance de l'autre, pour se faire pardonner ou se faire juger. On revient au point de départ.

Nous avons analysé en particulier le réveil de l'inconscient et le dédoublement dus à l'absence d'unité métaphysique, lorsque la raison et le désir déchirent l'âme. Le désir charnel qui a frappé Green dès son jeune âge a provoqué une instabilité et une angoisse schizophrénique chez le jeune chrétien, tandis que la raison qui a habité l'esprit de Camus lorsqu'il a découvert la philosophie, la misère et l'injustice. Ainsi, tous deux se retrouvent en constante lutte intérieure. En 1949, le diariste note dans son Journal : « La vérité à laquelle j'arrive après des années de lutte et de réflexion, c'est que je hais le

\footnotetext{
${ }^{427}$ Green, Euvres IV 1059.

${ }^{428}$ Green, Euvres II 24.
} 
désir sexuel. Je reconnais son importance, j'admire cette force énorme qui a produit tant d'œuvres, mais je hais le désir, cette force qui jette tant d'être sages aux pieds de tant d'imbéciles et les fait délirer comme des enfants luxurieux. Je voudrais qu'il n'en fût pas ainsi. » ${ }^{429}$ Le désir sexuel que Green réfute est son homosexualité qui, à l'époque, était considérée comme un acte scandaleux.

La Chute à travers Clamence présente un cas de discours ondoyant adoptant les incertitudes morales et existentielles de l'homme. Le pommier qui a tenté Adam et Ève est la source du bien et du mal qui a créé en l'homme le libre-arbitre, autrement dit la possibilité de juger.

Si la morale qui émane des deux œuvres semble insuffisante ou ambiguë c'est parce que ni Green ni Camus ne croit au réalisme dans l'art. Épaves et La Chute présentent deux comportements humains face au défi de l'existence : Les deux personnages ne veulent pas risquer leur vie pour en sauver une autre mais n'arrivent plus à vivre en harmonie avec eux-mêmes après la découverte de leur défaillance. On peut imaginer facilement que l'un des compatriotes que Clamence a rencontré dans le bar du Mexico-City est bel et bien Philippe puisqu'il fait partie de cette « bourgeoisie condamnée. » ${ }^{430}$ Qu'est-ce qui est resté du naufrage de leur vie et de la chute de leur âme ? Après la chute, il ne reste plus que des épaves.

\footnotetext{
${ }^{429}$ La phrase: « Je hais l'instinct sexuel » est prononcée dans Mö̈ra par Joseph Day lors de sa confrontation avec David. On retrouve plusieurs fois dans le Journal la même expression mais remaniée. Green, Euvres IV 1065.

${ }^{430}$ Green, Euvres II 1310.
} 
Bien que nous nous soyons focalisés sur les points communs des deux œuvres, notons qu'elles sont différentes sur bien des points. Militant et engagé, Camus ne manque pas de semer quelques idées politiques dans son œuvre pour exprimer l'horreur que fait subir l'homme à autrui : en passant par les quartiers juifs d'Amsterdam, il fait allusion aux crimes nazis et remonte jusqu'au trafic des esclaves. Il dénonce toute injustice faite à l'homme afin de le dominer : « Chaque homme a besoin d'esclavage comme d'air pur. Commander c'est respirer. » ${ }^{431}$ Green à travers Philippe tente de dénoncer, avec un langage plus subtil, le mal qui émane de l'être alors que ce dernier, malgré sa lutte ne peut s'en débarrasser complètement.

De plus les différences de caractère de Philippe et de Clamence sont bien palpables. Le premier, ressemblant à Green est réservé, sa voix est sourde, il parle très peu même avec ses proches. Si Green n'est pas vraiment indifférent aux méandres du monde qui l'entoure, il ne peut être considéré comme un écrivain engagé au même titre que Camus. Le second, comme son personnage, ne cesse de plaider sa cause et celle de ses semblables : «Je suis la fin et le commencement, j’annonce la loi. Bref, je suis le juge pénitent. » ${ }^{432}$ Après bien des éloges, il s'accuse et fait son propre jugement. Enfin, Clamence se met à nu devant un lecteur qui, lui, fait son analyse psychologique. Il partage avec lui sa quête sur le sens de la vie. Comme un acteur de théâtre, il joue des rôles différents, il passe de la comédie à la tragédie et du mensonge à la vérité sans que le

\footnotetext{
${ }^{431}$ Camus, Euvres complètes: Théâtre 1535.

${ }^{432}$ Camus, Euvres complètes: Théâtre 1535.
} 
lecteur puisse toujours le suivre. Quant à Philippe, la parole n'est pas son point fort. C'est le narrateur qui nous livre ses pensées et ses émotions et c'est au lecteur de faire cette analyse et d'en tirer une conclusion. Celle-ci sera subjective, vu la complexité et surtout l'ambiguïté de l'œuvre.

Dans les deux œuvres, le déchirement de l'être incapable de choisir entre deux réalités est un facteur commun certes, mais il n'est pas vécu de la même manière par Philippe et Clamence. Philippe qui semble faible, « après le drame qui aurait pu - ou aurait dû - bouleverser [sa] vie choisit de vivre comme si rien ne s'était passé. ${ }^{433} \mathrm{Y}$ arrivera-t-il ? Pas tout à fait, car après le naufrage, il n'a pas disparu complètement mais a essayé de recoller les épaves. Son fils qu'il va rejoindre dans le dernier paragraphe du roman, où le brouillard se déclenche sur le fleuve pour y laisser percer une lumière salvatrice, sera-t-il celui qui aidera Philippe à échapper au naufrage complet de son âme ? Épaves se termine, de surcrôt, par l'acceptation d'une lutte intérieure afin de conjurer la faute, voire le mal, qui est en nous et qui va de pair avec la pensée greenienne. Mais ce n'est qu'une interprétation parmi d'autres car Green crée de l'ambiguïté dans son œuvre, ce qui laisse le lecteur sur sa faim, avec un sentiment d'inassouvissement et d'interrogation quant à l'intention aussi bien du protagoniste que de son créateur. De plus, Green emploie un style poétique pour ne laisser que des pistes au lieu de dire

${ }^{433}$ Green, Euvres I 1210. 
clairement les choses telles qu'elles sont : «Toute grande œuvre est une œuvre à secret. $»^{434}$

La chute de Clamence est presque fatale. Le Clamence d'avant la chute n'existe plus, une ombre a pris sa place, un avatar qui dans son soliloque pointe du doigt le naufrage de la société et la déchéance de l'homme. Il reconnaît sa faute et il la regrette mais avec une fougue débordante, il s'en prend aux autres afin de dévoiler leurs fautes et de faire leur procès.

Ce que Green et Camus nous révèlent, ce n'est pas l'absence de conscience chez Philippe et Clamence mais la «présence » de la mauvaise conscience et comment elle accable et déchire l'homme. La faute est commise et personne n'y échappe mais la conséquence est insupportable, l'action est rare et la parole domine.

Dans la littérature, l'usage de l'eau représente typiquement le symbole du baptême. Mais dans Épaves et La Chute l'eau est aussi symbole des péchés de l'homme. Ainsi, les deux auteurs font référence à l'aspect religieux associé à l'eau mais peut-être pas de la même manière. Si Green est sincère dans ses sentiments religieux, qu'en est-il de Camus ? Se moque-t-il de la religion ou est-il sincère ? Si tel est le cas, on peut parler de paradoxe camusien face à Dieu et à la religion.

\footnotetext{
${ }^{434}$ Sandra R. Allogho Oba, L'Expression du moi dans le journal de Julien Green : 1943-1954, diss., Université François Rabelais de Tours, 2009. (Tours: SCD de l'université de Tours, 2009) 25.
} 
Nous pensons que ce travail apporte une contribution modeste dans le monde de la littérature et espérons qu'il servira de base à un travail de recherche plus important grâce aux idées extraites de l'analyse de ces deux œuvres. 


\section{Bibliographie}

Euvres citées

Alexandre, Didier. L'Absolu intertextuel dans l'exégèse de Paul Claudel. 2006. 11 janvier 2013. <http://narratologie.revues.org/308>.

Allogho-Oba, Sandra R. L'Expression du moi dans le journal de Julien Green : 19431954. Diss. Université François Rabelais de Tours, 2009. Tours: SCD de l'université de Tours, 2009. Print.

Appelbaum, Stanley. Pensées et provinciales choisies. Mineola: Dover Publication, 2004. Print.

Auroy, Carole, et Schaffner, Alain. Julien Green et alii : rencontres, parentés, influences. Dijon: Ed. Universitaire, 2011. Print.

Bachelard, Gaston. L'Eau et les rêves : Essai sur l'imagination de la matière. Paris: Librairie José Corti, 1942. Print.

Balzac, Honoré. La Peau de chagrin. Paris: BiblioBazaar, 1839. Print.

Baudelaire, Charles. Curiosité esthétique. Paris: Michèle Lévy Frères Librairie, 1868. Print.

---. Les Fleurs du mal. Paris: Librairie Larousse, 1973. Print.

---. Les Fleurs du mal. Paris: Livre de poche, 1999. Print.

---. Mon cœur mis à nu. Paris: Livre de Poche, 1972. Print.

Berat, Fanny et Langenhagen, Marie-Aude de. Baudelaire. Levallois-Perret: Studyrama, 2006. Print.

Blinoff, Marthe. « Dostoïevski et Balzac. » Comparative Literature, 3.4 (1951): 342-55. Print. 
Bonhomme, Julien. « Réflexion multiples. Le miroir et ses usages rituels en Afrique centrale, »Images Re-vues : histoires, anthropologies et théories de l'art avril, 2007. Web. 23 février 2012. < http://imagesrevues.-revues.org/147>.

Cadot, Michel. «La double postulation de Baudelaire et sa version dostoïevskienne ». Revue canadienne de la littérature comparée. 4.1(1977): 54-67. Print.

Camus, Albert. Actuelles I: Écrits politiques (Chroniques 1944-1948). Paris: Gallimard, 1950. Print.

---. Actuelles III. Chroniques algériennes 1939-1958. Paris: Gallimard, 1958. Print.

---. Caligula suivi de Le malendu. Paris: Gallimard, 1958. Print.

---. Carnets I mai 1937-février 1941. Paris: Gallimard, 1964. Print.

---. Carnets II janvier 1942-mars 1951. Paris: Gallimard, 1964. Print.

---. Carnets III mars 1951- décembre 1959. Paris: Gallimard, 1989. Print.

---. Hommage à Albert Camus : 1913-1960. Paris: Gallimard, 1967. Print.

---. Lettres à un ami allemand. Paris: Gallimard, 1972. Print.

---. Le Mythe de Sisyphe. Paris: Gallimard, 1942. Print.

---. Euvres complètes I. Bibliothèque de la Pléiade. Paris: Éditions Gallimard, 2006. Print.

---. Euvres complètes III 1949-1956. Bibliothèque de la Pléiade. Paris: Gallimard, 2008. Print.

---. Euvres complètes: Essais. Bibliothèque de la Pléiade. Paris: Gallimard, 1965. Print.

---. Euvres complètes: Théâtre, récits, nouvelles. Bibliothèque de la Pléiade. Paris: Gallimard. 1962. Print.

---. La Peste. Paris: Gallimard, 1947. Print.

Camus, Albert, et Jean Grenier. Les Correspondances, 1932-1960. Paris: Gallimard, 1981. Print. 
Camus, Albert et Maurice Blanchot. Hommage à Albert Camus : 1913-1960. Paris: Gallimard, 1967. Print.

Canérot, Marie-Françoise, et Michèle Raclot. Julien Green : non-dit et ambigüité. Paris: l'Harmattan. 2007. Print.

Catelain, Valérie. «Paris et Épaves écriture poétique et géographie de l'âme ». Mélanges de science religieuse, LVIII (2001): 87-98. Print.

«Ambivalence. » Centre national des ressources textuelles et lexicales. 18 octobre 2012. <http://www.cnrtl.fr/ definition/academie9/ambivalence/>.

«Châtiment. » Centre National de Recherche Scientifique. 12 janvier 2011. < http://www.cnrtl.fr/ lexicographie/ch\%C3\%A2timent>

« Miroir. » Centre national des ressources textuelles et lexicales. 17 septembre 2011. $<$ http://www.cnrtl.fr/-definition/miroir/>.

Charcosset, Amélie. Le Sentiment d'être à sa place dans les Carnets d'Albert Camus. 2008. 08 août 2012. <http://fr.scribd.com/doc/108566545/44/L\%E2\%80\%99ecriture-douloureuse-la-tentation-du-renoncement $>$.

Charrier, Jean-Paul. L'Inconscient et la psychanalyse. Paris: Presse Universitaire de France, 1968. Print.

Christophe, André. Imparfait, libre et heureux : pratiques de l'estime de soi. Paris: Odile Jacob, 2006. Print.

Costes, Alain. Albert Camus et la parole manquante. Paris: Payot, 1973. Print.

Coste, Martine Agathe. La Folie sur scène: Paris 1900/1968. Paris: Éditions Publibook, 2004. Print.

Cudicio, Catherine. Les Bienfaits de la simplicité. Paris: Eyrolles, 2011. Print.

Darriulat, Jacques. Baudelaire la beauté des modernes : De la damnation du Spleen à la rédemption des correspondances, 12 mars 2011. <http://www.jdarriulat.net/Auteurs-/Baudelaire/Baudbeautemod/Spleen-Corresp.html>.

Derivière, Philippe. Julien Green, les chemins de l'errance. Paris: Talus d'approche, 1994. Print. 
Dictionnaire psychanalytique des images et symboles du rêve. 03 février 2012. <http://www.abcdreve.fr/>.

Dostoïevski, Fyodor. Crime et châtiment. Paris: Gallimard, 1950. Print.

Dunaway, John M. « The Motive of Self-Discovery in Julien Green. » South Atlantic Bulletin 42.2 (1977): 85-93. Print.

« Ambivalence, psychanalyse. » Encyclopaedia Universalis. 18 octobre 2012. $<$ http://www.universalis.fr/encyclopedie/ ambivalence-psychanalyse/>.

Famery, Sarah. Etre soi sans culpabiliser. Paris: Eyrolles Pratique, 2008. Print.

Favez-Boutonier, Juliette. La Notion d'ambivalence. Étude critique, valeur séméiologique. Paris: L’Harmattan, 2004. Print.

Freud, Sigmund. «L'Inquiétude étrangeté. » 11 septembre 2008. 16 mai 2012. 〈http://www.psychaanalyse.com/pdf/inquietante-_etrangete.pdf>

Genet, Claude. «Pensées », Pascal. Paris: Hatier, 1993. Print.

«Genévrier. » 01 décembre 2012. 〈http://fr.wikipedia.org/wiki/Gen\%C3\%A9vrier.>

Gide, André. Dostö̈evski. Paris: Librairie Plon, 1923. Print.

Green, Julien. Journal I 1928-1939. Paris: Librairie Plon, 1954. Print.

---. Journal II 1940-1945. Paris: Librairie Plon, 1956. Print.

---. Euvres complètes I. Éd. Jacques Petit. Bibliothèque de la Pléiade. Paris: Gallimard, 1972. Print.

---. Euvres complètes, II. Éd. Jacques Petit. Bibliothèque de la Pléiade. Paris: Gallimard, 1973. Print.

---. Euvres complète, III. Éd. Jacques Petit. Bibliothèque de la Pléiade. Paris: Gallimard, 1973. Print.

---. Euvres complètes IV. Éd. Jacques Petit. Bibliothèque de la Pléiade. Paris: Gallimard, 1975. Print. 
---. Euvres complètes V. Éd. Jacques Petit. Bibliothèque de la Pléiade. Paris: Gallimard, 1977. Print.

---. Paris. New York: Marion Boyars, 1991. Print.

---. Partir avant le jour. Paris: Grasset, 1963. Print.

Holcroft, Bruno. « Méditations bibliques \& prédications d'enterrements. » 15 décembre 2008. 23 novembre 2011. <http://www.protestants- niederbronn.org/ Meditations/Crier-dans-le-desert_a3.html>.

Kierkegaard, Sören. «Le concept de l'angoisse - L'angoisse comme salut par la foi (chapitre V). » 24 décembre 2012. 12 janvier 2013. http://www.booston.fr/articlesoren-kierkegaard---le-concept-de-l-angoisse---l-angoisse-comme-salut-par-lafoi-chapitre-v-113765804.html>.

Kissel, Myriam. Le Cheminement de l'écriture: l'espace dans l'œuvre de J. Green. Berne: Peter Lang Édition, 2005. Print.

---. « Julien Green et Dostö̈evski : une écriture mystique. » Julien Green et alii :

Rencontres, parentés, influences. Dijon: Édition Universitaires de Dijon, 2011. Print.

Lannes, Sophie. « Julien Green, mon voisin. » 16 février 2008. 28 Juillet 2011. <http://www.arllfb.be/ebibliotheque/seancespubliques/16022008/7lannes.pdf>.

Lejeune, Philippe. Le Pacte autobiographique. Paris: Seuil, 1975. Print.

Lloyd, Rosemary. Baudelaire et Hoffmann: affinités et influences. New York: Cambridge University Press, 1979. Print.

«Les Pensées de Blaise Pascal ». 5 Juillet 2012. http://www.penseesdepascal.fr/Misere/Misere23-moderne.php

Mailhot, Laurent. Albert Camus ou l'imagination du désert. Québec: Les Presses de l'université de Montréal, 1973. Print.

Marcel, Gabriel. «Les Lettres, Épaves, par julien Green. » L'Europe nouvelle (1932). Print.

Mathew, Celine. Ambivalence and Irony in the Works of Joseph Roth. NewYork: Peter Lang, 1981. Print. 
Mattéi, Jean François. Albert Camus du refus au consentement. Paris: Presse Universitaire de France, 2011. Print.

Montoux, Alain. Le Dictionnaire des organisations. Paris: Éd. Publibook, 2012. Print.

« La Mort. » 13 mars 2010. http://fr.wikipedia.org/wiki/La_Mort_(mythologie)

Munch, Edvard. « Le Cri. » 4 avril 2013. < http://commentairesimages.free.fr/index.php ?p=le_cri_tableau>.

Nourrisson, Jean Félix. La Philosophie de saint Augustin II. Paris: Librairie Académique, 1866. Print.

O'Dwyer, Michael, et Michèle Raclot. Le journal de Julien Green: miroir d'une âme, miroir d'un siècle. Bern: Peter Lang, 2005. Print.

Petit, Jacques. Julien Green : L'Homme qui venait d'ailleurs. Paris: Institut National de l'Audiovisuel, 1969. Print.

---. Green. Paris: Desclée de Brouwer, 1972. Print.

Philonenko, Alexis. La Philosophie du malheur: Chestov et les problèmes de la philosophie existentielle. Paris: Vrin, 1998. Print.

Raclot, Michèle. «Une Approche herméneutique de Minuit: variations romantiques, oniriques et mystiques sur le thème de la chute et du salut. » Mélanges de science religieuse. 58.3 (2001): 25-38. Print.

Rose, Marilyn Gaddis. « The Journal of Julian Green. » The French Review. 39.5 (1966): 694-702. Print.

Segal, Hanna. Introduction to the Work of Melanie Klein. London: Karnac Books, 1988. Print.

Sibony, Daniel. Les Sens du rire et de l'humour. Paris: Odile Jacob, 2010. Print.

Sobieraj, François. «L'Étranger ». 19 fevrier 2010. 15 mars 2012. < http://meli-melosobieraj.blogspot.com/2010_02_01_archive.html>.

Simon, Pierre-Henri. Présence de Camus. Bruxelles: Renaissance du Livre, 1961. Print.

Société Conradienne Française. Époque conradienne. Vol. 27. Limoges : PULIM, 2001. Print. 
Sturm, Ernest. Conscience et impuissance chez Dostö̈evski et Camus. Paris: Librairie A.G. Nizet, 1967. Print.

Thody, Philip. Albert Camus. New York: St. Martin Press, 1989. Print.

Todd, Olivier. Albert Camus: Une vie. Paris: Gallimard, 1996. Print.

van Hooff, Dominique. «Entre le visible et le dicible : l'art du portrait chez Julien Green. » Autour de Julien Green : au cour de Léviathan. Éd. Société Internationale d'Études Greeniennes. Presses Universitaires de l'université de Franche Comté (France). Paris: les Belles Lettres, 2000. Print.

---. « Le Naturalisme de Julien Green dans ses premiers romans. » Julien Green Non-dit et ambiguïté. Éd. Société Internationale d'Études Greeniennes. Paris: L'Harmattan, 2007. Print.

Vannucci, François. Le Miroir aux neutrinos: Réflexions autour d'une particule fantôme. Paris: Odile Jacob, 2003. Print.

Vernescu, Flavia. Clivage et intégration du moi chez Julien Green. Illinois: Summa Publications, 1994. Print.

Vidaillet, Bénédicte, Véronique d'Estaintot et Philipppe Abecassis. La Décision. Bruxelles: De Boeck Université, 2005. Print.

Walker, David H. Éd. Actes du colloque de Keele, 25-27 mars 1993: Albert Camus, les extrêmes et l'équilibre. Amsterdam: Rodopi, 1994. Print.

«Clamans.»Wikidictionary. 5 juin 2012.< http://en.wiktionary.org/wiki/clamans>.

Wildgen, Kathlyn E. Julien Green: The Great Themes. Birmingham: Summa Publication, 1993. Print.

Ziegler, Robert. «Flattering the Analyst: Julien Green's Épaves as Judgmental Mirror.» Rocky Mountain Review of Language and Literature 45.1/2 (1991): 35-46. Print.

Euvres consultées

Amoia, Alba. Albert Camus. New York: Continuum, 1989. Print. 
Aurevilly, Barbery d'. Le XX Siècle : des auvres et des hommes. Paris: Mercure de France, 1964. Print.

Bakhtine, Mikhaïl. Esthétique et théorie du roman. Paris: Gallimard, 1978. Print.

---. Poétique de Dostoïevski. Paris: Seuil, 1970. Print.

Barthes, Roland. Le Degré zéro de l'écriture. Paris: Seuil, 1953. Print.

---. Le Plaisir du texte. Paris: Seuil, 1973. Print.

---. Roland Barthes par Roland Barthes. Paris: Seuil, 1975. Print.

---. S/Z. Paris: Minuit, 1970. Print.

Bellemin-Noël, Jean. Psychanalyse et littérature. Paris: PUF, 2002. Print.

Berat, Fanny, et Marie-Aude de Langenhagen. Baudelaire. Levallois-Perret: Studyrama, 2006. Print.

Brisville, Jean-Claude. Camus. Paris: Gallimard, 1959. Print.

Bronner, Stephen E. Camus: Portrait of a Moralist. Minnesota: University of Minnesota Press, 1999. Print.

Brunel, Pierre. La Littérature française aujourd'hui. Paris : Librairie Vuibert, 1997. Print.

Burne, S. Glenn. Julien Green. New York: Twayne. 1972. Print.

Camus, Albert. Actuelles II. Chroniques 1948-1953. Paris: Gallimard, 1953. Print.

---. Discours de Suède. Paris: Gallimard, 1958. Print.

Daco, Pierre. Les triomphes de la psychanalyse. Paris: Marabout, 1976. Print.

Dunaway, John M. The Metamorphoses of the Self: The Mystic, the Sensualist, and the Artist in the Works of Julien Green. Lexington: University Press of Kentucky, 1978. Print. 
Fitch, Brian T. The Narcissistic Text: A Reading of Camus' Fiction. Toronto: University of Toronto Press, 1982. Print.

Green, Julian. Diary 1928-1957. New York: Hartcourt, Brace \& World, 1964. Print.

Hesnard, Angelo. L'Univers morbide de la faute. Paris: Presses Universitaires de France, 1949. Print.

Kelly, Aileen. «Dostoïevski and the Divided Conscience.» Slavic Review 47.2 (1988): 239-60. Print.

Klein, Mélanie. Envie et gratitude et autres essais. Paris: Gallimard, 1957. Print.

Kulkarni, Mangesh. «The Ambiguous Fate of a Pied-Noir: Albert Camus and Colonialism. » Economic and Political Weekly 32.26 (1997): 1528-30. Print.

Lejeune, Philippe. L’Autobiographie en France. Paris: Librairie Armand Collin, 1971. Print.

Maurois, André. De Proust à Camus. Paris: Académique Perrin, 1963. Print.

Miraux, Jean- Philippe. L’Autobiographie : Écriture de soi et sincérité. Paris: Nathan, 1996. Print.

Mitterand, Henri. Dicionnaire des CEuvres du XX $X^{e}$ siècle. Paris: Les Usuels, 1995. Print.

Ozzello, Yvonne. «Julien Green: Le Langage et son double. » The French Review 61.3 (1988): 492-93. Print.

Parias, Louis-Henri. Julien Green, corps et âme. Paris: Fayard, 1994. Print.

Petit, Jacques. Julien Green : L’Homme qui venait d'ailleurs. Paris: Desclée de Brouwer, 1969. Print.

Sartre, Jean-Paul. Literature \& Existentialism. New York: Citadel Press, 1965. Print.

---. Qu'est-ce que la littérature ? Paris: Gallimard, 1948. Print.

Siguret, Pierre. «La Fortune du rire chez Baudelaire, Bergson et Bakhtine. » 2000 ans de Rire : Permanence et modernité. Comp. Mongi Madini, Colloque International GRELIS-LASELDI/CORHUM, 29-30 juin, $1^{\mathrm{er}}$ juillet. Besançon: Presses 
Universitaires Franc-Comtoises, 2002 : 103-10. PrintTadié, Jean- Yves. Le roman au XX siècle. Paris: Belfond, 1990. Print.

Tamuly, Anette. Julien Green à la recherche du réel. Sherbrooke: Naaman, 1976. Print.

Thibaudet, Albert. Histoire de la littérature française de 1789 à nos jours. Paris: Stock, 1936. Print.

Todorov, Tzvetan. Mikhaïl Bakhtine: Le principe dialogique. Paris: Seuil, 1981. Print.

---. Poétique de la prose, Paris: Seuil, 1971. Print.

Vircondelet, Alain. Albert Camus fils d'Alger. Paris: Fayard, 2010. Print.

Wildgen, Kathryn. A Thematic Concordance of Julien Green's Journal. Birmingham: Summa Publications, 1994. Print. 